\title{
Functional analysis of the MERS-coronavirus spike protein
}

\author{
Dissertation \\ zur Erlangung des mathematisch-naturwissenschaftlichen Doktorgrades \\ "Doctor rerum naturalium“ \\ der Georg-August-Universität Göttingen \\ im Promotionsprogramm Biologie \\ der Georg-August University School of Science (GAUSS) \\ vorgelegt von \\ Stefanie Gierer \\ aus Suhl
}

Göttingen, 2014 
Betreuungsausschuss

Prof. Dr. Stefan Pöhlmann, Abteilung Infektionsbiologie, Deutsches Primatenzentrum (DPZ)

Prof. Dr. med. Martin Oppermann, Abteilung Zelluläre und Molekulare Immunologie, Universitätsmedizin Göttingen

Mitglieder der Prüfungskommission

Referent: $\quad$ Prof. Dr. Stefan Pöhlmann, Abteilung Infektionsbiologie, Deutsches Primatenzentrum (DPZ)

Koreferent: Prof. Dr. med. Martin Oppermann, Abteilung Zelluläre und Molekulare Immunologie, Universitätsmedizin Göttingen

Weitere Mitglieder der Prüfungskommission:

Prof. Dr. Blanche Schwappach, Institut für Molekularbiologie, Universitätsmedizin Göttingen

Prof. Dr. Uwe Groß, Institut für Medizinische Mikrobiologie, Universitätsmedizin Göttingen

Prof. Dr. Carsten Lüder, Institut für Medizinische Mikrobiologie, Universitätsmedizin Göttingen

Prof. Dr. Lutz Walter, Abteilung Primatengenetik, Deutsches Primatenzentrum (DPZ)

Tag der mündlichen Prüfung: 26.06.2014 
For my parents. 


\section{INDEX}

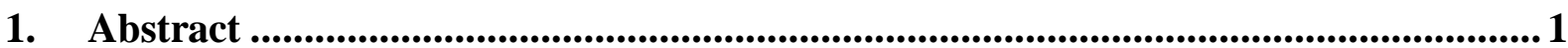

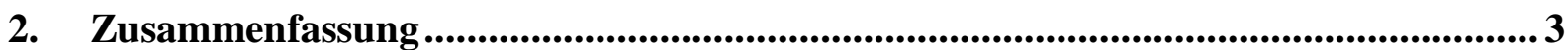

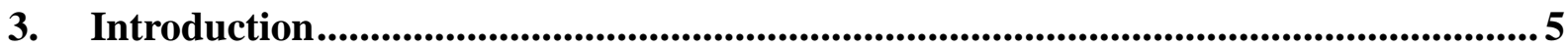

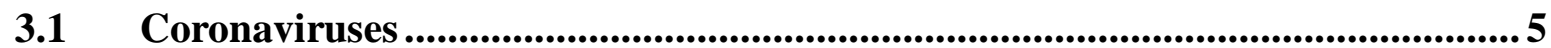

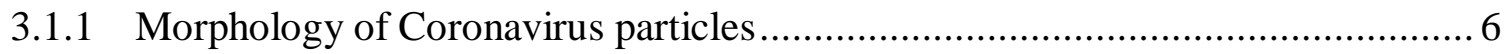

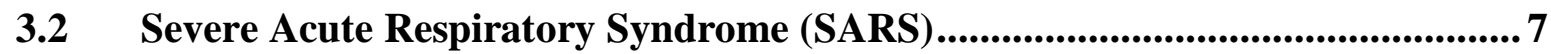

3.3 Middle East Respiratory Syndrome (MERS) .................................................9

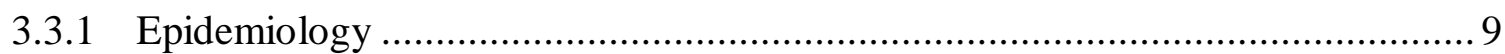

3.3.2 Natural reservoir and intermediate host of MERS-CoV .................................. 11

3.3.3 Clinical characteristics and drug therapy of MERS-CoV infection ................... 12

3.3.4 Animal models for MERS-CoV ................................................................ 13

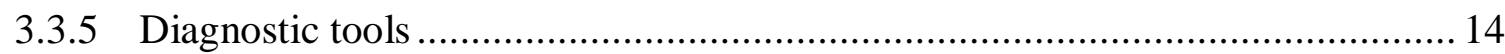

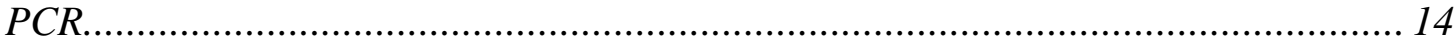

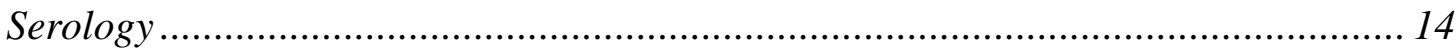

3.4 Biology of MERS Coronavirus...................................................................... 15

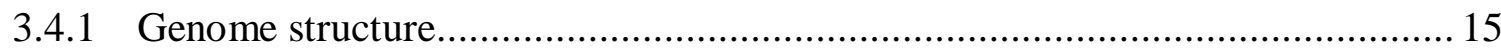

3.5 Viral Life Cycle of Coronaviruses........................................................................... 16

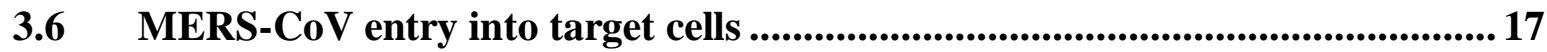

3.6.1 The MERS-CoV Spike Protein .................................................................. 17

3.6.2 Host cell receptor and tropism of MERS-CoV ............................................. 18

3.6.3 Spike-mediated membrane fusion .......................................................... 20

3.7 Host cell proteases and enzymatic processing of viral glycoproteins................. 21

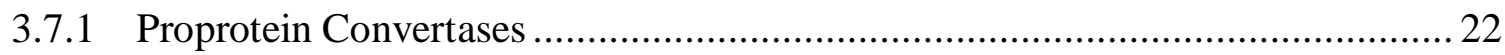

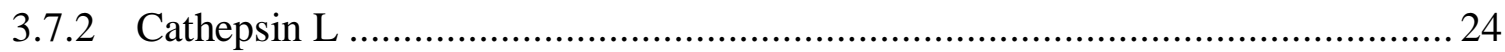


3.7.3 Type II transmembrane serine proteases (TTSPs).

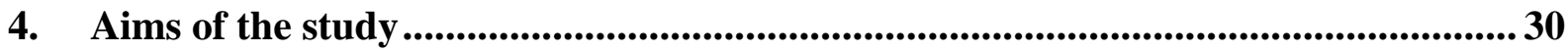

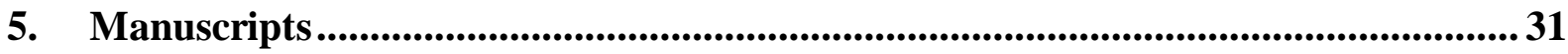

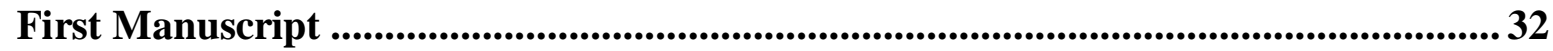

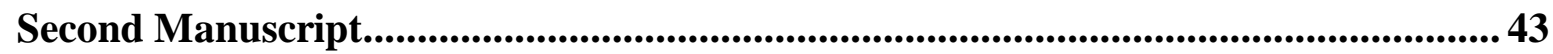

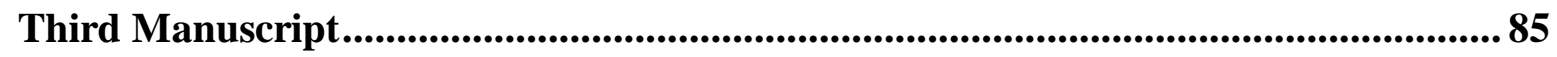

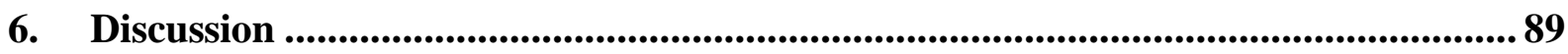

6.1 The spike protein of the emerging betacoronavirus EMC uses a novel coronavirus receptor for entry, can be activated by TMPRSS2, and is targeted by neutralizing antibodies.....................................................................................8 89

6.2 Inhibition of proprotein convertases abrogates processing of the MERScoronavirus spike protein in infected cells but does not reduce viral infectivity ......... 93

6.3 Lack of MERS coronavirus neutralizing antibodies in patients from Eastern Province, Saudi Arabia ........................................................................................... 97

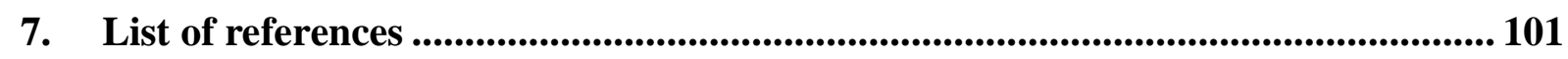

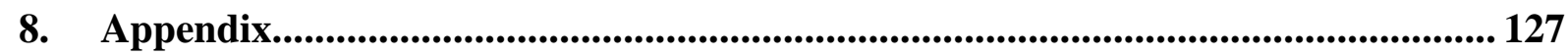

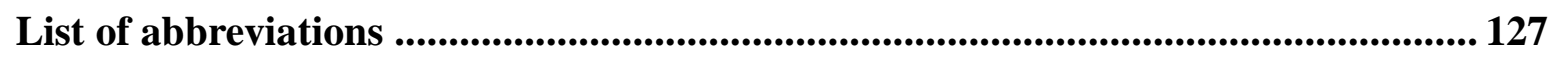

Acknowledgements..................................................................................... 130

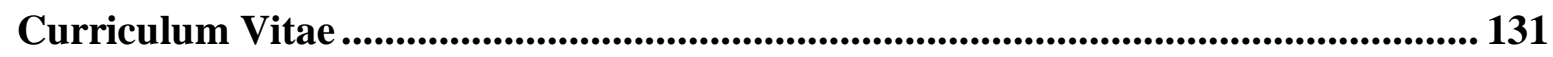

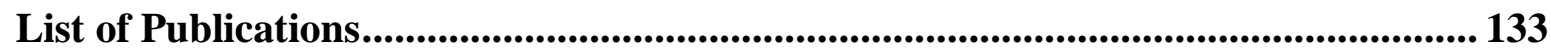




\section{Abstract}

Ten years after the outbreak of the Severe Acute Respiratory Syndrome Coronavirus, SARS$\mathrm{CoV}$, which caused the first pandemic of the $21^{\text {st }}$ century, a novel betacoronavirus, Middle East Respiratory Syndrome Coronavirus, MERS-CoV, emerged in the Arabian Peninsula. Its ongoing spread poses a significant threat to public health. The spike (S) protein of coronaviruses mediates viral entry into target cells and is a key determinant of viral tropism and pathogenesis. Understanding the parameters governing MERS-CoV spike (MERS-S)driven entry might thus yield valuable information on MERS-CoV biology and was the first goal of the present study. In order to facilitate host cell entry, coronavirus S proteins depend on activation by host cell proteases, which are potential targets for therapeutic intervention. Therefore, the second goal of the present thesis was to identify the proteases responsible for MERS-S activation. The coronavirus $S$ protein is the major target for the neutralizing antibody response and experimental systems for MERS-S can be used as diagnostic tools. The final goal of this thesis was thus to investigate the MERS-CoV seroprevalence in Saudi Arabian individuals.

A lentiviral vector system was established that allows the analysis of MERS-S-driven host cell entry. With the help of this system, MERS-S was found to mediate entry into a broad spectrum of human cell lines, including cells from lung, kidney and colon which is in concordance with the clinical picture of MERS. Host cell entry was independent of previously described coronavirus entry receptors but was promoted by the endosomal cysteine protease cathepsin L and the transmembrane serine protease TMPRSS2. In contrast, the activity of proprotein convertases was dispensable for MERS-S protein-driven entry. Finally, neutralization of S protein-mediated entry revealed that neutralizing antibodies were absent in sera from patients of the Eastern Province of Saudi Arabia taken between 2010-2011 and 2012, indicating that MERS-CoV infections were rare events before the MERS outbreak in 2012. Collectively, these results provide important insights into the processes governing MERS-CoV entry and shed light onto MERS epidemiology. Furthermore, the demonstration that the protease inhibitor camostat, which is approved for use in humans in Japan, blocks MERS-CoV entry by inhibiting TMPRSS2, might help to establish treatment options for MERS patients. 
Keywords: MERS-CoV, spike protein, neutralizing antibodies, proteolytic activation, TMPRSS2, cathepsin, proprotein convertases 


\section{Zusammenfassung}

Zehn Jahre nach dem Ausbruch des Severe Acute Respiratory Syndrome Coronavirus, SARS$\mathrm{CoV}$, ist ein neues Betacoronavirus, das Middle East Respiratory Syndrome Coronavirus, MERS-CoV, auf der arabischen Halbinsel entdeckt worden. Seine anhaltende Ausbreitung stellt eine Bedrohung für die öffentliche Gesundheit dar. Das Spike (S) Protein der Coronaviren vermittelt den viralen Eintritt in Wirtszellen und bestimmt wesentlich den viralen Tropismus und die virale Pathogenese. Das Verständnis der Determinanten des MERS-CoV Spike (MERS-S)-vermittelnden Eintritts in Zellen könnte daher wichtige Einblicke in die MERS-CoV-Biologie liefern und war somit das erste Ziel dieser Arbeit. Um den Eintritt in die Zelle zu ermöglichen, muss das Coronavirus S-Protein durch Wirtszellproteasen aktiviert werden, welche potentielle Ziele für die therapeutischen Intervention darstellen. Daher sollten im zweiten Ziel dieser Arbeit Proteasen identifiziert werden, die MERS-S aktivieren. Das SProtein ist das Hauptangriffsziel neutralisierender Antikörper und experimentelle Systeme zur S-Analyse können für die Diagnostik eingesetzt werden. Das letzte Ziel dieser Arbeit war es daher, die MERS-CoV Seroprävalenz in Saudi Arabien zu ermitteln.

Es wurde ein lentivirales Vektorensystem etabliert, welches die Analyse des MERS-Sgetriebenen Zelleintritts ermöglicht. Mit Hilfe dieses Systems konnte gezeigt werden, dass MERS-S den Eintritt in ein breites Spektrum humaner Zelllinien, wie Lungen-, Nieren- und Darmzellen vermittelt, was mit der klinischen Manifestation von MERS einhergeht. Der Wirtszelleintritt war unabhängig von bereits beschriebenen Coronavirus Eintrittsrezeptoren, wurde jedoch durch die endosomale Cysteinprotease Cathepsin $\mathrm{L}$ und die Transmembranserinprotease TMPRSS2 gefördert. Im Gegensatz dazu war die Aktivität von Proprotein Konvertasen für den S-Protein-vermittelnden Eintritt entbehrlich. Schließlich zeigten Neutralisationstests, dass Seren von Patienten aus der östlichen Provinz Saudi Arabiens, die zwischen 2010-2011 und 2012 entnommen wurden, keine MERS-Sneutralisierenden Antikörper enthielten. Dies deutet darauf hin, dass MERS-CoV-Infektionen vor dem Ausbruch 2012 nur selten vorkamen. Die gewonnen Ergebnisse tragen wesentlich zum Verständnis des MERS-CoV-Eintritts in Zellen bei und liefern wichtige Informationen zur MERS-CoV-Epidemiologie. Weiterhin könnte die Beobachtung, dass der ProteaseInhibitor Camostat, der für den Einsatz im Menschen zugelassen ist (in Japan), TMPRSS2 blockiert und damit den MERS-CoV Eintritt inhibiert, helfen, Behandlungsstrategien für MERS-Patienten zu etablieren. 
Schlagwörter: MERS-CoV, Spike Protein, neutralisierende Antikörper, proteolytische Aktivierung, TMPRSS2, Cathepsin, Proprotein Konvertasen 


\section{Introduction}

\subsection{Coronaviruses}

Coronaviruses $(\mathrm{CoVs})$ are enveloped viruses, which contain the largest linear single-stranded and positive-sense viral RNA genome known so far [Siddell et al., 1983]. Although the first coronavirus, the Infectious bronchitis virus (IBV), was discovered in 1932 [Hudson and Beaudette 1932], the virus family Coronaviridae was proposed more than 30 years later after human coronaviruses were discovered in patients suffering from the common cold [Tyrrell and Bynoe 1965, Tyrrell et al., 1975].

The family coronaviridae contains two subfamilies, Torovirinae and Coronavirinae, and within the latter, four genera have been identified based on serological and genetic analyses according to the International Committee on Taxonomy of Viruses (ICTV): Alpha-, beta-, gamma-, and deltacoronaviruses [http://ictvdb.bio-mirror.cn/Ictv/fs_coron.htm, Cavanagh et al., 1993]. A model of coronavirus evolution was established by Woo et al., tracing the gene source of alpha- and betacoronavirus back to bats and the one for gamma- and deltacoronaviruses to birds [Woo et al., 2012].

Coronaviruses mainly cause acute and self-limiting respiratory, nervous system and enteric diseases [Guy et al., 2000, Perlman and Netland 2009]. Nevertheless, infection can also result in fatal systemic diseases [Herrewegh et al., 1997]. Until the emergence of the SARS-CoV in 2003, human coronaviruses were known as the causative agent of $15-30 \%$ of the common cold [Holmes 2003]. The first human coronaviruses, HCoV-229E and HCoV-OC43, were identified in the 1960s [McIntosh et al., 1974, Holmes 2003]. They cause comparatively mild common colds, but they can also be responsible for more serious respiratory disease in infants and immunocompromised patients [Pene et al., 2003]. Subsequently, two other coronaviruses, HCoV-NL63 and CoV-HKU1, were isolated and identified to cause mild to serious lower respiratory tract infections. HCoV-NL63 was isolated from a child suffering from bronchiolitis and conjunctivitis. However, it can cause acute respiratory disease in children and immunosuppressed adults and is associated with croup [van der Hoek et al., 2004, van der Hoek et al., 2005]. CoV-HKU1 was isolated from a patient with pneumonia, and is associated with acute bronchiolitis and asthmatic exacerbation [Woo et al., 2005, Lau et al., 2006]. These four human coronaviruses are adapted to spread in the human population and circulate globally [Hendley et al., 1972]. 
In the year 2002, the "harmless" picture of coronaviruses had to be redefined, when the causative agent of the Severe Acute Respiratory Syndrome (SARS) appeared, causing lifethreatening pneumonia [Peiris et al., 2003, Zhong et al., 2003]. Ten years later, Zaki and colleagues isolated a so far unknown coronavirus from a male patient with acute pneumonia, which was later identified as a novel human coronavirus, termed Middle East Respiratory Syndrome Coronavirus (MERS-CoV) [van Boheemen et al., 2012, Zaki et al., 2012].

In contrast to HCoV-229E, HCoV-OC43, HCoV-NL63 and CoV-HKU1, SARS-CoV and MERS-CoV were recently transmitted from animals to humans and both can cause severe disease in infected patients [Ksiazek et al., 2003, Bermingham et al., 2012, Zaki et al., 2012].

\subsubsection{Morphology of Coronavirus particles}

Coronavirus virions are 60 to $220 \mathrm{~nm}$ in diameter and have a pleomorphic, although generally spherical shape (Figure 1B) [Siddell et al., 1983].

A)

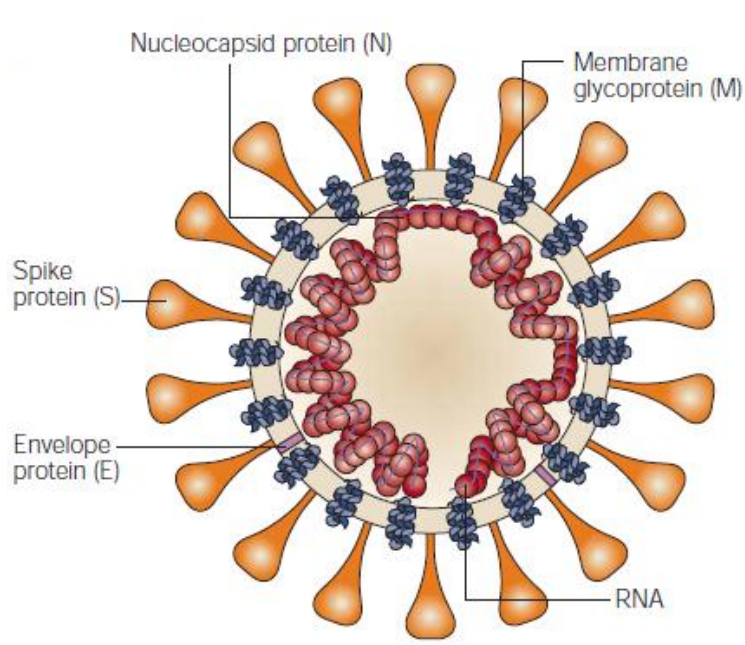

B)

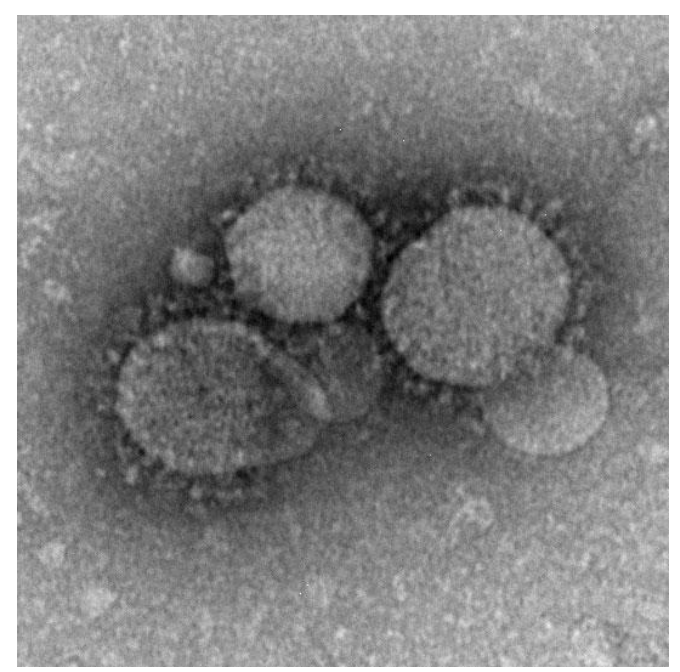

Figure 1: A) Schematic depiction of the coronavirus virion structure. The viral RNA is associated with the nucleocapsid protein $\mathrm{N}$. The lipid bilayer includes the spike protein, the membrane protein and the envelope protein (S, M, E) (Figure was taken from [Stadler et al., 2003]). B) MERS-CoV virions visualized by negative stain electron microscopy. The virions display the characteristic corona-like shape, originating from protruding spike proteins (Figure was taken from the Centers for Disease Control and Prevention (CDC) http://www.cdc.gov/Features/novel coronavirus/). 
The large positive-stranded RNA genome comprises about $30 \mathrm{~kb}$ and is associated with the $\mathrm{N}$ protein as a helical nucleocapsid, which in turn interacts with the viral membrane protein $\mathrm{M}$ [Stadler et al., 2003]. The characteristic crown-like shape of the virion is conveyed by the spike (S) protein which radiates from the viral envelope and mediates receptor binding and viral entry. The minor envelope protein $\mathrm{E}$ is necessary for particle assembly (Figure 1A) [Stadler et al., 2003].

\subsection{Severe Acute Respiratory Syndrome (SARS)}

The Severe Acute Respiratory Syndrome (SARS) was the first pandemic disease in the $21^{\text {st }}$ century. It began in Guangdong, a province in Southern China, in November 2002 where outbreaks of an atypical pneumonia were observed [Peng et al., 2003, Zhong et al., 2003]. The chain of transmission crossed Chinese boarders in February 2003 when a sick physician travelled from Guangdong province to a hotel in Hong Kong, where he transmitted the disease to 10 other guests, who then started SARS outbreaks in various Asian countries and North America. Within weeks after this event, the disease had spread to over 29 countries, infecting 8089 and killing almost 800 people (World Health Organization;http://www.who.int/csr/sars/ country/table2003_09_23/en/). On March 13, 2003 the World Health Organisation (WHO) declared a global alert and due to containment activities the spread of SARS could finally be stopped in July 2003, although in the beginning of 2004 four new, relatively mild cases of SARS were diagnosed [Zhong et al., 2003, Liang et al., 2004]. A novel coronavirus, termed SARS-CoV, was identified as the causative agent of the disease in 2003 [Drosten et al., 2003, Peiris et al., 2003, Poutanen et al., 2003]. Within weeks after the discovery of the virus, its complete genome was sequenced, revealing that SARS-CoV is not closely related to any of the previously characterized coronaviruses and forms a distinct group [Marra et al., 2003, Poon et al., 2003, Rota et al., 2003].

The major routes of human-to-human transmission of SARS-CoV were virus-carrying droplets and direct contact with infected patients. However, alternative ways of transmission like oral and conjunctival routes were also described [Peiris et al., 2003, Varia et al., 2003, Loon et al., 2004]. The incubation period ranged from 2 to 10 days, although in some patients disease developed after 16 days [Lee et al., 2003], and the initial clinical symptoms were comparable to that seen in influenza patients, including fever, myalgia, headache and 
diarrhea. However, in some patients the disease developed into an atypical pneumonia which could progress into Acute Respiratory Distress Syndrome (ARDS) [Peiris et al., 2003].

It was suspected early on that SARS-CoV was an animal virus, which had crossed the species barrier to infect humans [Marra et al., 2003]. Indeed, samples from Himalayan palm civets (Paguma larvata) and raccoon dogs (Nyctereutes procyonoides) taken in animal markets in Guandong province contained a SARS-like coronavirus with $99 \%$ nucleotide homology to the human one [Guan et al., 2003, Xu et al., 2004]. In addition, SARS-CoV specific antibodies were detected in animal traders [Guan et al., 2003]. However, due to the finding that farmed civet cats had a much lower SARS-CoV antibody prevalence compared to animals sold in markets, it was suggested that civets might have served as intermediate or amplification hosts and not as natural reservoir [Tu et al., 2004]. In the search for the natural reservoir, bats were discussed in several publications. A novel Bat-CoV was identified in the genus Miniopterus spp. and its spike protein showed $41 \%$ sequence homology to the SARS-spike protein [Poon et al., 2005]. Species from the genus Rhinolophus (horseshoe bats) demonstrated a high SARS-CoV antibody prevalence [Li et al., 2005], and specifically in Rhinolophus sinicus a SARS-CoV-like virus was identified, which was related to the human and civet one [Lau et $a l ., 2005$ ]. $84 \%$ of the bat sera contained neutralizing antibodies against bat-SARS-CoV [Lau et al., 2005]. Additional identifications of two novel bat coronaviruses from Chinese horseshoe bats that are closely related to SARS-CoV and the ability of one of them to utilize human angiotensin- converting enzyme 2 (ACE2) as an entry receptor, supports the evidence of bats to be a potential natural reservoir for the SARS-CoV [Ge et al., 2013]. 


\subsection{Middle East Respiratory Syndrome (MERS)}

\subsubsection{Epidemiology}

On June 13, 2012, a 60 year old man from Saudi Arabia was hospitalized, presenting fever, cough, expectoration and shortness of breath. Despite intensive medical treatment, the man died on day 11 after committal, due to progressive respiratory and renal failure. Chest radiography indicated ARDS with multiorgan dysfunction syndrome [Zaki et al., 2012]. Thereupon, infection of cell cultures with serum and sputum samples from the patient was found to induce a cytopathic effect (CPE), indicating virus replication [Zaki et al., 2012]. A pan-coronavirus PCR, amplifying a conserved region of the open reading frame $1 \mathrm{~b}$ of the replicase gene of coronaviruses [Drosten et al., 2003] and subsequent phylogenetic analysis revealed the presence of a novel coronavirus, named HCoV-EMC (Erasmus Medical Center), which belongs to the lineage $\mathrm{C}$ of the genus betacoronavirus, together with the bat $\mathrm{CoV}$ HKU4 and HKU5 [van Boheemen et al., 2012, Zaki et al., 2012] (Figure 2).

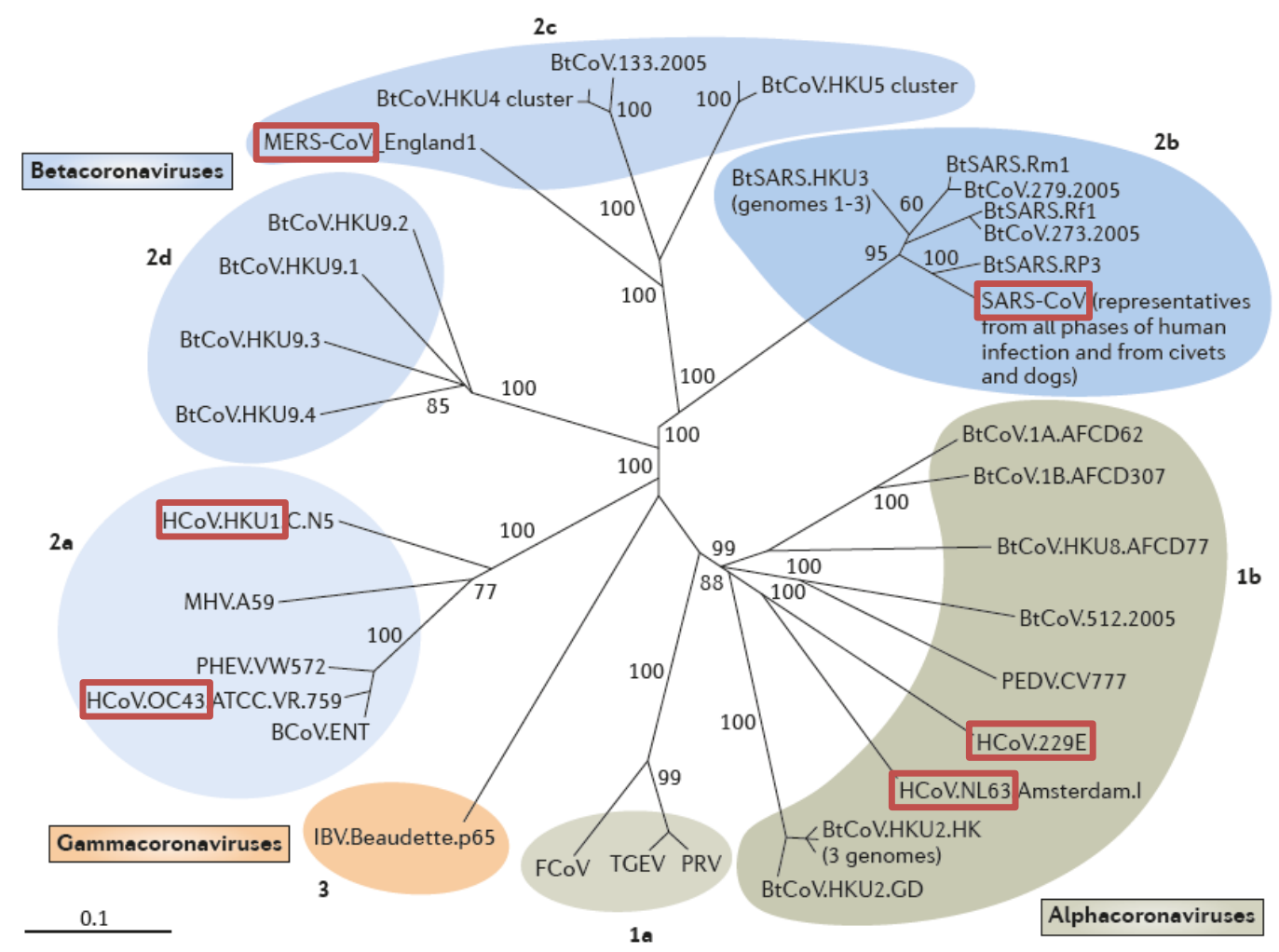

Figure 2: Phylogenetic tree of coronaviruses (adapted from [Graham et al., 2013]). Three genera of coronaviruses and their species are shown: Alphacoronaviruses (grey), betacoronaviruses (blue) and gammacoronaviruses (orange). Deltacoronaviruses are not shown. Human coronaviruses are highlighted. 
The complete genome of the novel coronavirus was determined using a combination of highthroughput techniques, including deep sequencing, cycle sequencing, rapid amplification of cDNA ends and Sanger sequencing [van Boheemen et al., 2012, Zaki et al., 2012]. HCoVEMC is the first human coronavirus within this lineage and was later renamed "Middle East Respiratory Syndrome Coronavirus" (MERS-CoV) by the Coronavirus Study Group of the International Committee on Taxonomy of Viruses [de Groot et al., 2013].

Shortly after the index case, a patient with a travel history to Saudi Arabia was transferred to a London intensive care unit, after he was hospitalized in Qatar with fever and hypoxia [Bermingham et al., 2012]. Amongst other diagnostic tests, a pan-coronavirus PCR was performed, leading to a reaction product which showed a $99.5 \%$ sequence homology to the virus isolated from the patient in Saudi Arabia. Globally, from September 2012 to date $\left(9^{\text {th }}\right.$ May 2014), 536 MERS-CoV infections resulting in 145 deaths were reported to the WHO (World Health Organization; http://www.who.int/csr/disease/coronavirus_infections/MERS_ CoV_Update_09_May_2014.pdf?ua=1). The high case fatality rate of roughly $30 \%$ is exceptional among all of the known human coronaviruses [Chan et al., 2013, Kindler et al., 2013]. Infections were identified in Saudi Arabia [Zaki et al., 2012, Memish et al., 2013], Jordan [Hijawi et al., 2013], Qatar [Bermingham et al., 2012], Oman, Kuwait, United Kingdom [Bermingham et al., 2012], Germany [Buchholz et al., 2013], France [Mailles et al., 2013], Tunisia [Gulland 2013], Italy [Puzelli et al., 2013], Greece (http://who.int/csr/don/ 2014_04_20_mers/en/), Malaysia (http://who.int/csr/don/2014_04_17_mers/en/), Philippines, in the Far East (http://who.int/csr/don/2014_04_17_mers/en/) and in the United States of America (http://who.int/csr/don/2014_05_05_mers/en/). The majority of the cases occurred in the Middle East and all other cases were at least indirectly linked to this region (Figure 3). In contrast to SARS-CoV, the MERS-CoV transmission rate seems to be rather low, thus impeding pandemic viral spread [Breban et al., 2013]. Human-to-human transmission was reported in household settings and health-care units, but the route of transmission has not been fully established [Assiri et al., 2013, Guery et al., 2013, Hijawi et al., 2013, Memish et al., 2013]. 


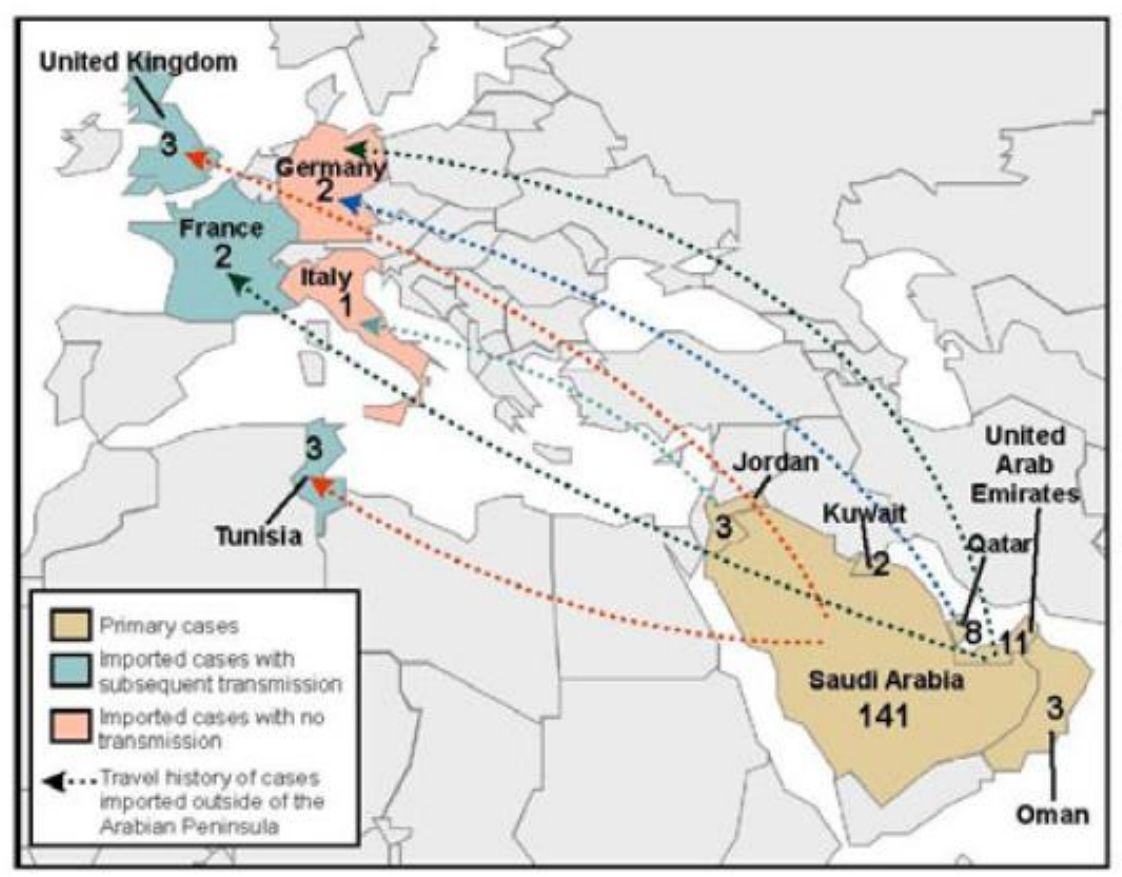

Figure 3: Geographic distribution of MERS cases. Depicted are all laboratory-confirmed MERS-CoV infections worldwide until February 1, 2014. The map is subdivided into countries in which MERS-CoV is endemic (brown), countries with imported cases with (green) and without (pink) subsequent human-to-human transmission. The travel history of the import is indicated with dotted arrows (Figure was taken from [MilnePrice et al., 2014]).

\subsubsection{Natural reservoir and intermediate host of MERS-CoV}

Phylogenetic analyses showed that MERS-CoV is closely related to bat CoV-HKU4 and CoV-HKU5, and the discovery of MERS-CoV-related viruses in Nycteris and Pipistrellus bats from Africa, Europe and America provided further evidence for bats being an animal host to MERS-CoV [Annan et al., 2013, Anthony et al., 2013, Lau et al., 2013, Memish et al., 2013]. Most notably, in Egyptian tomb bats from Saudi Arabia, a 190 nucleotide fragment with $100 \%$ identity to the MERS-CoV sequence was found [Memish et al., 2013]. In agreement with these findings, bat cell lines were found to be susceptible to MERS-CoV infection [Müller et al., 2012]. Molecular clock analysis of unlinked isolates calculated the divergence of MERS-CoV from a common ancestor in mid-2011 [Cotten et al., 2013]. However, the small size of the identified nucleotide sequences and the fact that direct contact between human and bat is rather infrequent, points towards an intermediate host, possibly 
farm animals, including camels and goats, since they are used for production of meat and milk as well as for races in the Middle East. In addition, contact between camels and MERS-CoV patients has been reported [Albarrak et al., 2012, Drosten et al., 2013, Kupferschmidt 2013] and enteric coronaviruses were previously identified in juvenile dromedary camels [Wünschmann et al., 2002]. MERS-CoV neutralizing antibodies were also found in camel sera from Jordan and the Canary islands [Reusken et al., 2013]. Thereupon, studies from Egypt, Jordan, Saudi Arabia and the United Arabian Emirates revealed neutralizing antibodies against MERS-CoV or a closely related virus in dromedary camels [Hemida et al., 2013, Perera et al., 2013, Reusken et al., 2013, Alagaili et al., 2014, Alexandersen et al., 2014, Haagmans et al., 2014, Meyer et al., 2014]. However, it has to be taken into account that camel antibodies have a different configuration compared to human antibodies and might thus bind to a broader spectrum of coronaviruses [Hamers-Casterman et al., 1993, Kupferschmidt 2013]. Besides this, the question unanswered is whether camels transmit MERS-CoV to humans or vice versa. Isolation of the MERS-CoV related virus from camels could shed light into this question. However, camel sera generally have a very high antibody titer, which might hamper virus isolation [Kupferschmidt 2013].

\subsubsection{Clinical characteristics and drug therapy of MERS-CoV infection}

The estimated incubation period of the reported MERS cases was 5.2 days (95\% CI (confidence interval) 1.9-14.7) [Assiri et al., 2013]. The median age of MERS-CoV patients was 56 years [Gulland 2013, The Who Mers-Cov Research 2013, Reuss et al., 2014] with the majority being male patients. Patients suffering from a MERS-CoV infection often present the following symptoms: Fever, myalgia, cough, shortness of breath, diarrhea and vomiting [Albarrak et al., 2012, Danielsson et al., 2012, Zaki et al., 2012, Drosten et al., 2013, Guery et al., 2013, Guberina et al., 2014]. Chest radiographies show abnormalities, as initially observed for the index patient [Zaki et al., 2012]. Most cases progressed to severe pneumonia with ARDS, requiring intensive care and ventilation. Septic shock and fatal multiorgan failure were also observed in these patients. Interestingly, the majority of severe cases was connected to underlying comorbidities, such as diabetes, cancer, hypertension, obesity and chronic diseases, while absence of serve disease was frequently observed in previously healthy patients [Assiri et al., 2013, The Who Mers-Cov Research 2013]. Noteworthy, the prevalence 
of type II diabetes and obesity in Saudi Arabia is quite high [Al-Daghri et al., 2011], which might promote disease progression.

Broad-spectrum antibiotics against bacterial superinfection and often oseltamivir as well as corticosteroids were administered to MERS patients [Albarrak et al., 2012, Zaki et al., 2012, Assiri et al., 2013, Drosten et al., 2013, Omrani et al., 2013, Guberina et al., 2014]. A study of Guberina et al. reported that treatment with corticosteroids improved the respiratory condition of a MERS patient significantly, but further investigation of this drug and its therapeutic effect is required [Guberina et al., 2014]. A combination of IFN- $\alpha 2 b$ and ribavirin could reduce viral replication in susceptible cell lines [Falzarano et al., 2013], although their administration to patients did not prevent a fatal outcome [Al-Tawfiq et al., 2014]. In accordance with the susceptibility of SARS-CoV to inhibition by IFN treatment [Cinatl et al., 2003], type I and III interferon were found to inhibit MERS-CoV replication in vitro and ex vivo [de Wilde et al., 2013, Kindler et al., 2013, Zielecki et al., 2013]. The application of high concentrations of ribavirin was effective in vitro and the reduction of the MERS-CoV replication and induced CPE was more efficient in combination with IFN- $\alpha 2 b$ [Falzarano et al., 2013]. Treatment of MERS-CoV infected Rhesus macaques with ribavirin and IFN- $\alpha 2 b$ resulted in a decrease of viral replication and an improvement of the clinical picture [Falzarano et al., 2013]. Furthermore, de Wilde and colleagues developed an assay to screen for antiviral compounds which inhibit MERS-CoV replication, and identified cyclosporin A (CsA) [de Wilde et al., 2013]. It should be noted that CsA is an immunosuppressant, and its administration to MERS patients needs to be considered.

\subsubsection{Animal models for MERS-CoV}

To test potential therapeutic strategies, the development of animal models for MERS-CoV infection is important. Replication of MERS-CoV in small animals, like mice, syrian hamsters and ferrets was not detectable [de Wit et al., 2013, Munster et al., 2013, Coleman et al., 2014, Raj et al., 2014, Yao et al., 2014], while infection studies of Rhesus macaques showed that these nonhuman primates are susceptible to MERS-CoV infection [de Wit et al., 2013, Munster et al., 2013, Yao et al., 2014]. The animals developed a mild-to moderate respiratory disease after inoculation. Virus replication was detected in the lower respiratory tract, predominantly in type I and II pneumocytes in the alveoli, which might explain the observed limited amount of virus shedding [de Wit et al., 2013, Yao et al., 2014]. A specific antibody 
response in the macaques was also detected [Yao et al., 2014]. However, the clinical picture in macaques does not completely present the clinical image of MERS in humans, since neither renal disease nor severe pneumonia were developed in macaques. The generation of a smallanimal model is still essential because this model is more widely used in research groups and more practicable than working with nonhuman primates. Zhao and colleagues were able to develop a mouse model for MERS that expresses the human host-cell receptor DPP4. These mice can be infected by MERS-CoV and develop pneumonia [Zhao et al., 2014].

\subsubsection{Diagnostic tools}

\section{PCR}

A pan-coronavirus reverse transcriptase polymerase chain reaction (RT-PCR) assay, which was designed to amplify a highly conserved region of the RNA-dependent RNA polymerase (RdRp, encoded by the ORF1b gene), is suitable to detect MERS-CoV RNA [Drosten et al., 2003, Vijgen et al., 2008, Zaki et al., 2012]. Additionally, a genome region upstream of the envelope gene (upE assay) and another part of ORF1b are amplified by related tests [Corman et al., 2012]. In addition, confirmatory real-time RT-PCR assays amplifying sequences within ORF1a and the $\mathrm{N}$ gene segment are available for MERS-CoV detection [Corman et al., 2012]. However, viral RNA could not be detected in all symptomatic patients [Corman et al., 2012].

\section{Serology}

A successful screening to complement RT-PCR findings can be the evaluation with enzymatic immunoassays (EIA) using recombinant viral proteins, enzyme-linked immunosorbent assay (ELISA) and immunofluorescence assay (IFA) [Corman et al., 2012, Reusken et al., 2013]. The latter one is based on the detection of an antibody response (by immunofluorescence microscopy) in serum samples from convalescent patients which bind to viral antigens in cells infected with MERS-CoV [Corman et al., 2012]. This assay has also been proved suitable for the detection of SARS-CoV-specific antibodies [Rabenau et al., 2005]. However, cross reactivity with other human betacoronaviruses cannot be excluded at the moment [Blanchard et al., 2011, Corman et al., 2012, Chan et al., 2013]. 
A neutralisation assay as confirmatory tests for IFA was used for example by Chan et al., where inactivated patient serum is mixed with the replication-competent virus. Target cells are then inoculated with the mixture and examined for cytopathic effects [Chan et al., 2013]. This assay is believed to be highly specific. Therefore, it was surprising, that high titers of MERS-CoV neutralizing antibodies were detected in the sera from SARS patients [Chan et al., 2013]. Crossreactivity has previously been reported only for closely related coronaviruses [He et al., 2006] and is due to sequence and structural homologies between the respective coronavirus spike proteins. Since the homology between MERS-CoV and SARS-CoV on amino acid level is low, the authors suggest that structural homologies are responsible for the crossreactivity. However, virus neutralisation assays must be carried out in biosafety level 3 laboratories. Viral vectors pseudotyped with the spike proteins of interest, mimic cellular entry of coronaviruses and can be used for the detection of neutralizing antibodies [Simmons et al., 2004, Perera et al., 2013, Zhao et al., 2013].

\subsection{Biology of MERS Coronavirus}

\subsubsection{Genome structure}

The MERS-CoV genome consists of 30119 nucleotides and comprises at least ten open reading frames (ORFs), with a high GC content of $41 \%$, which is typical for coronaviruses [van Boheemen et al., 2012]. Downstream of the 5-UTR there are two large overlapping replicase open reading frames, ORF1a and ORF1b, which require an ribosomal frame shift to produce the polyprotein pplab. The polyprotein is subsequently cleaved into 15 or 16 predicted nonstructural proteins (nsps) [van Boheemen et al., 2012]. Downstream of ORF1b, the genome encodes the structural proteins $\mathrm{S}$ (spike), E (envelope), M (membrane), and $\mathrm{N}$ (nucleocapsid) (ORF2,-6,-7, and -8a), which are translated via subgenomic mRNAs that contain a 5 'leader sequence, identical to the genomic 5 'region (Figure 4). Moreover, proteins expressed from the group-specific ORFs, ORF 3, 4a, 4b and 5 were identified. Some of them act as potent interferon antagonists, specifically the accessory proteins encoded by ORF4a, 4b, 5 as well as the structural M protein [Yang et al., 2013]. Finally, it is noteworthy that the MERS-CoV genetic structure is similar to that of the bat betacoronaviruses HKU4 and HKU5 [van Boheemen et al., 2012]. 


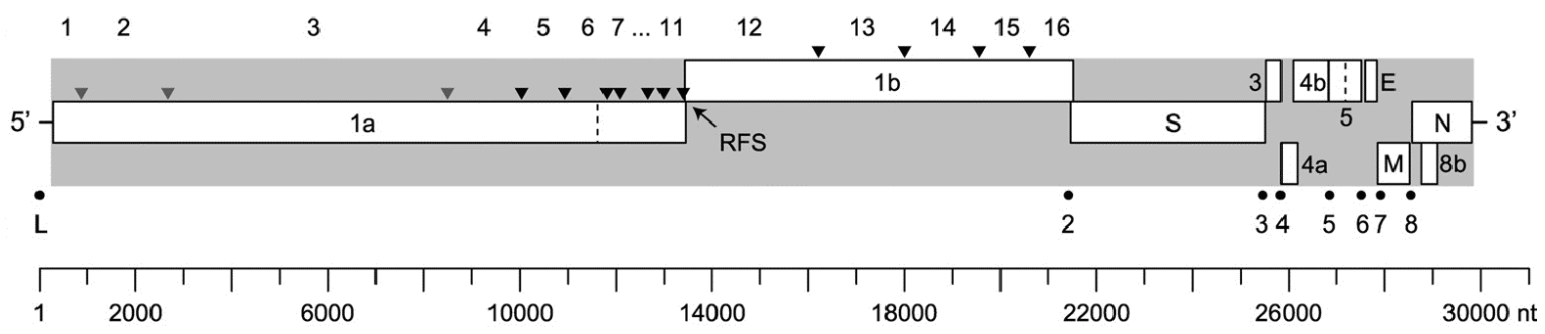

Figure 4: Genome organisation of MERS-CoV. Shown are the coding sequences and terminal untranslated regions of the genome. ORFs are depicted by rectangles. The ribosomal frameshift site (RFS) between ORF1a/ORF1b, the leader TRS (transcription-regulatory sequence) (L) and the body TRSs (numbered dots) are indicated, as well as the structural proteins S (spike), E (envelope), M (membrane), and N (nucleocapsid). Figure is derived from [van Boheemen et al., 2012].

\subsection{Viral Life Cycle of Coronaviruses}

The coronavirus infection cycle begins with the binding of the spike glycoprotein to its cellular receptor, followed by a direct entry at the cell surface or fusion with the endosomal compartment after endocytosis [Belouzard et al., 2012]. After that, the positive-stranded RNA genome is released into the cytoplasm of the host cell, followed by translation of the open reading frames ORF1a and ORF1b by ribosomal frameshifting into the polyprotein pp1ab [Stadler et al., 2003]. This protein is cleaved autoproteolytically into several replicase proteins, which form the viral replication complex, including the viral RNA-dependent RNA polymerase, which produces a negative-stranded RNA copy of the viral genome [Stadler et al., 2003]. Furthermore, a nested set of sub-genomic negative-sense RNAs is produced, serving as templates for the production of positive-stranded sub-genomic mRNAs, which are finally translated into the structural and accessory proteins [Stadler et al., 2003, Hofmann and Pohlmann 2004]. In the cytoplasm, the N protein and the genomic RNA interact and form the nucleocapsid, which acquires its envelope by budding through intracellular membranes located between the Endoplasmic Reticulum (ER) and the Golgi apparatus (ER-Golgi intermediate compartment, ERGIC). The M, E and S proteins pass the ER and are transported to the budding complex, where the helical nucleocapsid associates with the $\mathrm{M}$ protein to 
trigger assembly of the viral particle. Within the ERGIC, glycans associated with the spike protein are processed and the spike protein of some coronaviruses is cleaved [Belouzard et al., 2012, Heald-Sargent and Gallagher 2012]. The final release of the particles proceeds via exocytosis at the plasma membrane [Stadler et al., 2003].

\subsection{MERS-CoV entry into target cells}

\subsubsection{The MERS-CoV Spike Protein}

The spike protein of coronaviruses in general not only mediates virus entry into target cells, but also plays an important role for tissue tropism and virus virulence [Belouzard et al., 2012]. Synthesized in the secretory pathway of an infected cell, spike monomers are assembled into trimers and incorporated as peplomers into viral particles [Stadler et al., 2003, Heald-Sargent and Gallagher 2012]. Spike proteins are type I transmembrane proteins and can be depicted as $20 \mathrm{~nm}$-long projections on the viral membrane providing the corona-like shape seen in the electron microscope (Figure 1B) [Davies and Macnaughton 1979]. The coronavirus spike protein belongs to the class I viral fusion proteins, like other viral glycoproteins, including the influenza hemagglutinin and the human immunodeficiency virus envelope protein [Harrison 2005]. Fusion proteins from this group consist of trimers of hairpins containing a central $\alpha$-helical coiled-coiled-structure [Weissenhorn et al., 2007]. They are divided into an $\mathrm{N}$-terminal surface unit which harbours the receptor binding domain, called S1 for coronaviruses, as well as a C-terminal transmembrane unit, S2, which contains the fusion machinery.

The MERS-S protein consists of 1353 amino acids, with the S1 subunit ranging from residue 1 to 751 and the S2 subunit comprising the residues 752 to 1352 [Mou et al., 2013]. The binding of the spike protein to the cellular receptor DPP4/CD26 is mediated by the receptor binding domain (RBD), located between the residues 358-662 of the S1 subunit [Chen et al., 2013, Du et al., 2013, Mou et al., 2013]. The RBD consists of a core subdomain, which is highly similar to that of related coronaviruses and an external receptor binding motif that makes specific contacts to DPP4 and is not conserved between coronaviruses (Figure 5) [Jiang et al., 2013, Lu et al., 2013, Wang et al., 2013, Zhou et al., 2014]. The RBD elicits neutralizing antibodies, which block the binding of the spike protein to DPP4 [Du et al., 2013, Jiang et al., 2013, Mou et al., 2013], thus proposing a useful vaccine candidate. 


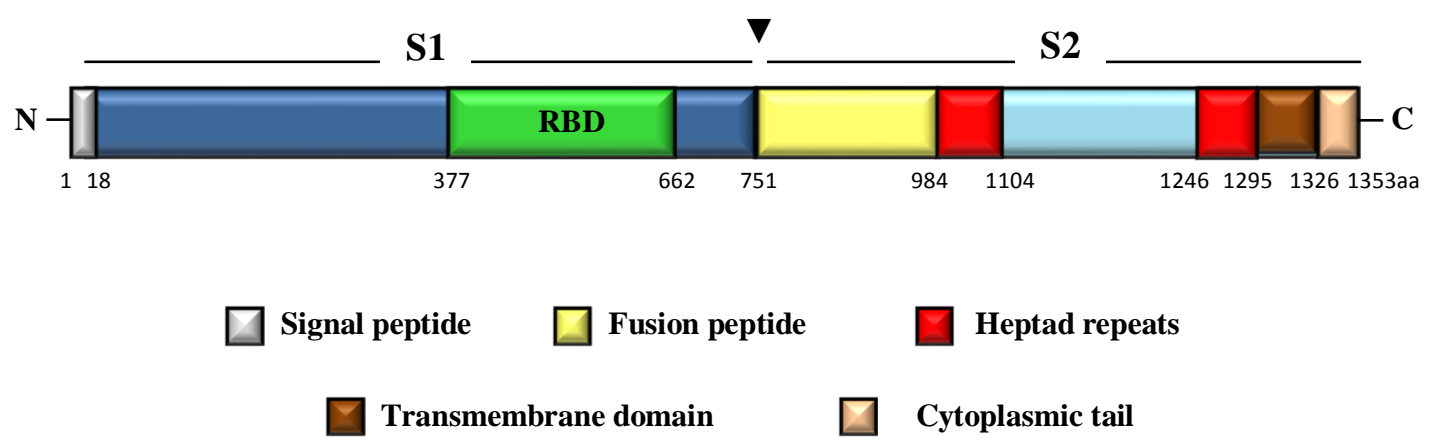

Figure 5: Shown is an image of the MERS-S protein, according to the predicted structures from Du et al. [Du et al., 2013]. The signal peptide mediates the translocation of the spike protein into the ER. The RBD within the S1 unit binds to the receptor, while the S2 subunit harbours the elements of the fusion machinery. The possible proteolytic cleavage site is indicated with a rectangle.

\subsubsection{Host cell receptor and tropism of MERS-CoV}

To facilitate host cell entry, the S1 subdomain of a coronavirus spike protein has to attach to a specific cellular receptor (Figure 6). For human coronaviruses, the following receptors have been identified: Aminopeptidase N (APN), also known as CD13, serves as a receptor for HCoV-229E [Yeager et al., 1992]. HCoV-NL63 as well as SARS-CoV employ angiotensinconverting enzyme 2 (ACE2) [Li et al., 2003, Hofmann et al., 2005]. Finally, sialic acid is engaged by HCoV-OC43 for host cell entry [Vlasak et al., 1988]. Initial efforts to identify the MERS-CoV entry receptor, these well-known coronavirus receptors could be excluded [Müller et al., 2012, Raj et al., 2013]. Employing pull-down assays and mass spectrometric analysis of RBD binding partners, Raj and colleagues were able to identify dipeptidyl peptidase 4 (DPP4, also known as CD26) as an interaction partner of the MERS-S protein [Raj et al., 2013]. Furthermore, it was shown that soluble DPP4 binds to the MERS-CoV S1 subunit, and non-susceptible cell lines gained susceptibility for S1-binding after transient expression of DPP4. Additionally, infection of susceptible cells was inhibited with a soluble form of DPP4. The same observation was made with bat DPP4, although the receptor activity of this protein was not as pronounced as that measured for human DPP4 [Raj et al., 2013]. DPP4 is the third exopeptidase identified as a coronavirus receptor. It consists of a $\alpha / \beta$ - 
hydrolase domain and an extracellular domain, including a $\beta$-propeller domain with 8 blades that contact the RBD of the spike protein (Figure 6) [Wang et al., 2013].

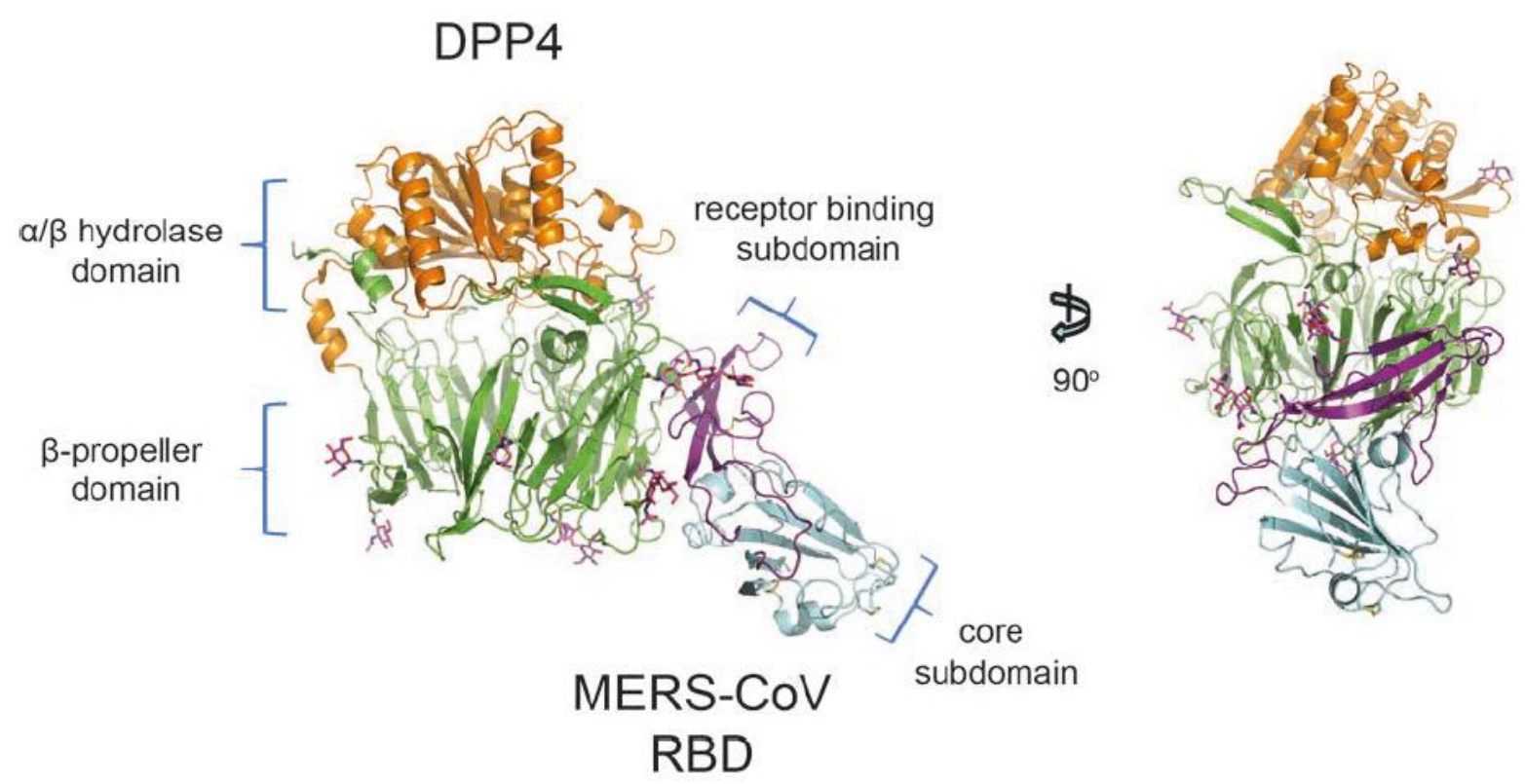

Figure 6: Chrystal structure of the complex between DPP4 and the RBD of MERS-S. The receptor contains an $\mathrm{N}$-terminal eight-bladed $\beta$-propeller domain (green) and a $\mathrm{C}$-terminal $\alpha / \beta$-hydrolase domain (orange). The RBD of the MERS-CoV consists of a core (cyan) and a receptor-binding-subdomain, that makes the contact to DPP4 (adapted from [Wang et al., 2013]).

DPP4 is a multifunctional type II transmembrane glycoprotein, which cleaves peptides and plays a role in signal transduction and glucose metabolism, cell adhesion and apoptosis, depending on its cellular localisation [Boonacker and Van Noorden 2003, Lambeir et al., 2003]. Regarding the clinical picture, DPP4 plays also a role in type 2 diabetes mellitus, which is often a comorbidity in MERS-CoV infected patients, by cleaving and thereby inactivating a hormone which stimulates insulin secretion [Augustyns et al., 1999]. DPP4 is highly conserved between different species and sequence comparisons revealed that DPP4 orthologs of human macaque, horse, rabbit and pig origin have no or little variation in the residues contacting the RBD of MERS-S [Bosch et al., 2013, Raj et al., 2013]. In contrast, the RBD contact site is not conserved in ferret DDP4 and MERS-CoV cannot use ferret DPP4 as a functional receptor for host cell entry [Bosch et al., 2013, de Wit et al., 2013]. DPP4 is expressed in the non-ciliated cells of cultured primary human bronchiolar epithelium and lung 
tissue, as well as epithelial cells of liver, intestine, kidney, prostate, on leukocytes and in a soluble form in plasma [Boonacker and Van Noorden 2003, Raj et al., 2013]. In concordance with the presence of the receptor in these cells, in vitro experiments revealed that MERS-CoV can infect cells in the human lower respiratory tract, kidney, intestine and liver [Chan et al., 2013, Zielecki et al., 2013] with predominantly non-ciliated cells being targeted in the bronchus and lung [Chan et al., 2013, Kindler et al., 2013]. The virus was also detected in patients' respiratory swabs, tracheal aspirate, sputum, urine and stool samples [Zaki et al., 2012, Drosten et al., 2013, Guery et al., 2013].

\subsubsection{Spike-mediated membrane fusion}

The binding of the viral spike protein to the cellular receptor is a prerequisite for spike protein-driven fusion between the viral and the host cell membrane [Yamada and Liu 2009]. This process can take place either at the cell surface or within the endosomal compartment after internalisation via endocytosis. To generate the fusion competent form, class I viral fusion proteins need to be proteolytically primed by host cell proteases.

There is a diversity of triggers that stimulate a viral surface glycoprotein for membrane fusion. The process can be initiated by receptor binding as it is the case for HIV gp160 and the murine leukemia virus (MLV) glycoprotein [Belouzard et al., 2012, Simmons et al., 2013]. Other viruses such as SARS-CoV, VSV and influenza virus require $\mathrm{pH}$ acidification in addition to receptor binding [White et al., 1981, Simmons et al., 2004, Yang et al., 2004]. Furthermore, activation of the spike protein can be acquired by proteolytic cleavage [Simmons et al., 2004, Watanabe et al., 2008, Taguchi and Matsuyama 2009].

The coronavirus spike protein belongs to the class I viral fusion proteins, which contain conserved functional elements in their transmembrane unit for facilitating membrane fusion: A fusion peptide and two heptad repeats (HRs) are located between the surface unit and the transmembrane domain (Figure 5) [de Groot et al., 1987]. If a primed class I membrane fusion protein is exposed to a trigger like low $\mathrm{pH}$ or receptor binding, the fusion peptide is projected towards the target cell and inserts into the cellular membrane (Figure 7). The fusion peptide is usually located at the N-terminus of the transmembrane subunit, as it is the case for HIV and likely also coronaviruses, or internally of the transmembrane protein subunit (Ebola virus glycoprotein, SARS-CoV spike) [Sainz et al., 2005, Weissenhorn et al., 2007, Belouzard et al., 2009]. Subsequently, the two HRs fold back onto each other, thereby 
forming a six-helix bundle structure (Figure 7). This conformational change relocates the Nterminal fusion peptide and thus the target cell membrane close to the transmembrane domain and thus the viral membrane, which ultimately results in membrane fusion (Figure 7) [Bosch et al., 2003, Xu et al., 2004].

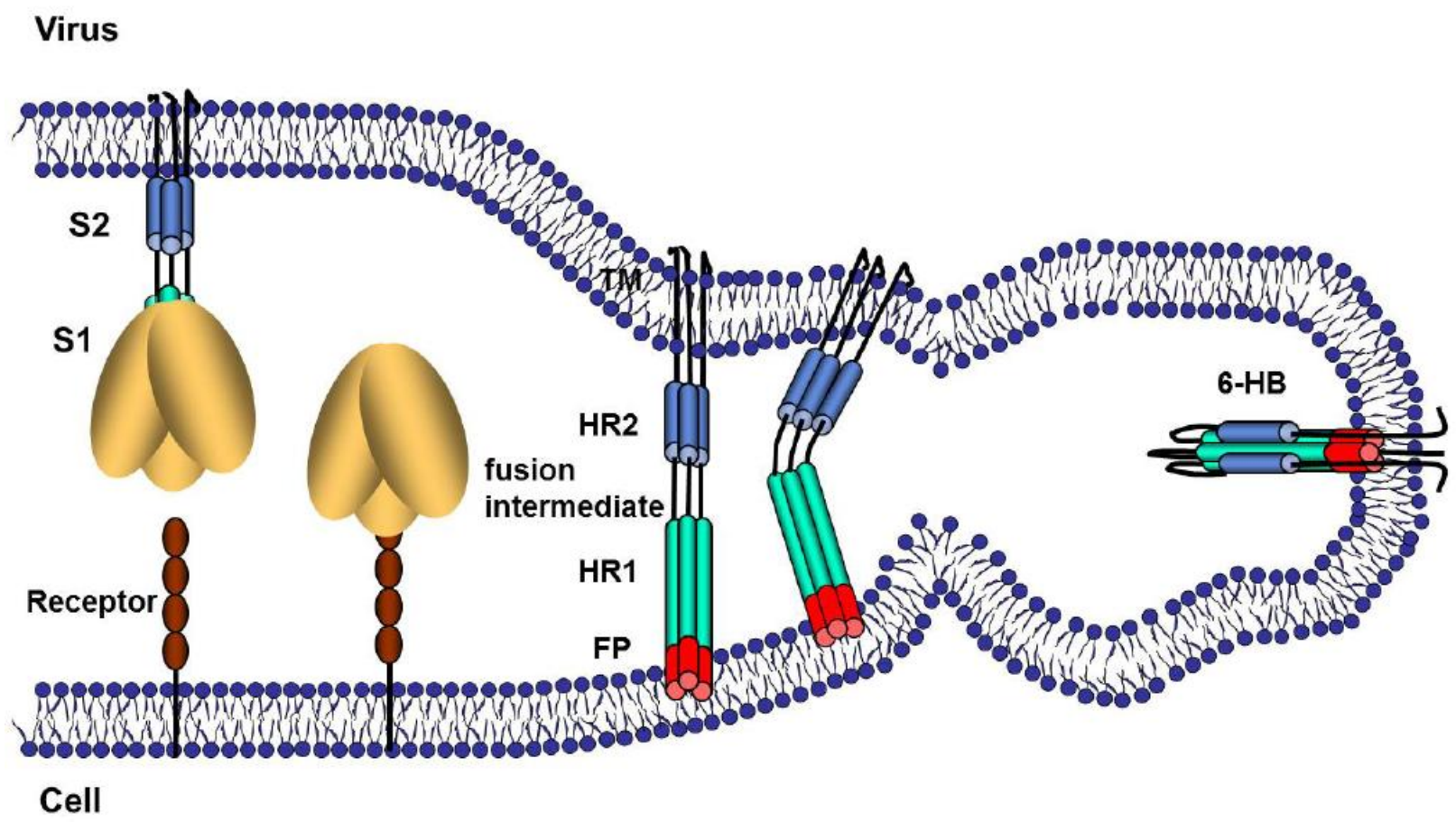

Figure 7: Glycoprotein-driven membrane fusion. The membrane fusion reaction is triggered by binding of the surface unit (S1) to a cellular receptor, $\mathrm{pH}$ reduction and/or glycoprotein proteolysis. The membrane fusion reaction is facilitated by the transmembrane unit (S2). In the course of membrane fusion, the fusion peptide (FP) inserts into the host cell membrane (fusion-intermediate stage) and the heptad repeats (HRs) in the transmembrane unit form a the six-helix bundle (6-HB) structure. As a consequence, the viral and host cell membrane are in close proximity, facilitating their fusion. Figure was taken from [Heald-Sargent and Gallagher 2012].

\subsection{Host cell proteases and enzymatic processing of viral glycoproteins}

Post-translational modification of membrane and secretory proteins by endo-and carboxypeptidases is an important requirement for their biological function, for example during viral infection [Klenk and Garten 1994, White et al., 2008]. Cleavage of viral class I 
membrane fusion proteins by host cell proteases is a prerequisite for viral infectivity and can proceed at different stages of the viral replication cycle and in different cellular locations:

The HA of the influenza virus can be primed in the Golgi apparatus by subtilisin-like proteases [Stieneke-Grober et al., 1992, Klenk and Garten 1994], by serine proteases in the endosomal compartment [Boycott et al., 1994], at the cell surface [Böttcher et al., 2006], and by soluble proteases in the extracellular compartment [Lazarowitz and Choppin 1975]. The spike protein of some coronaviruses, predominantly members of group II and III [Gallagher and Buchmeier 2001], are cleaved in the trans-Golgi compartments in infected cells by proprotein convertases [Yamada and Liu 2009] into the S1 and S2 subunit to become fusion competent [de Haan et al., 2004]. Proteolytic processing was also demonstrated for the SARS-S protein [Wu et al., 2004] but seems to be inefficient [Simmons et al., 2011]. Alternatively, proteolytic activation of the spike protein can take place in endosomal compartments [Matsuyama et al., 2005, Simmons et al., 2005, Bosch et al., 2008], which is also true for the Ebolavirus glycoprotein [Chandran et al., 2005]. However, recent findings suggest that activation in endosomes can be bypassed by expression of transmembrane serine proteases which activate $\mathrm{S}$ proteins before they are transported into the endosomal compartment [Matsuyama et al., 2010, Glowacka et al., 2011, Shulla et al., 2011]. When the experimental work documented in the present thesis begun, it was unknown which proteases activate the MERS-S protein and in which cellular compartments the activation reaction takes place.

\subsubsection{Proprotein Convertases}

Proprotein convertases (PCs) constitute a mammalian enzyme family which plays a major role in sustaining cellular homeostasis and maturation processes of viral glycoproteins [Wise et al., 1990, Pasquato et al., 2013]. PCs are calcium-dependent serine proteases that are widely expressed and comprise nine members, one of them for example furin (Figure 8). Four PC members are attached to cellular membranes, while the others are either secreted or stored in core granules [Seidah and Prat 2012]. They exhibit a characteristic domain organization: The signal peptide is followed by an N-terminal prodomain, a structurally conserved catalytic domain, and variable C-terminal domain (Figure 8) [Pasquato et al., 2013]. PCs are synthesized as zymogens and require two subsequent cleavages at the N-terminus. First, the 
signal peptide is removed in the ER, followed by cleavage of the $\mathrm{N}$-terminal prodomain in order to become functional. The autoproteolytic processing can occur in various sub-cellular locations, including the trans-Golgi network, the ER/cis Golgi, the dense core secretory granules or the cell membrane [Basak et al., 1999, Toure et al., 2000, Rousselet et al., 2011]. Most PCs recognize the motif $\mathrm{K} / \mathrm{RXnK} / \mathrm{R} \downarrow$ in target proteins. PCs cleave and prime various viral glycoproteins during maturation in the secretory pathway of infected cells. Cleavage usually occurs at the $\mathrm{N}$-terminus of the fusion peptide, thereby liberating the peptide from the surface unit and allowing it to insert into the target cell membrane.

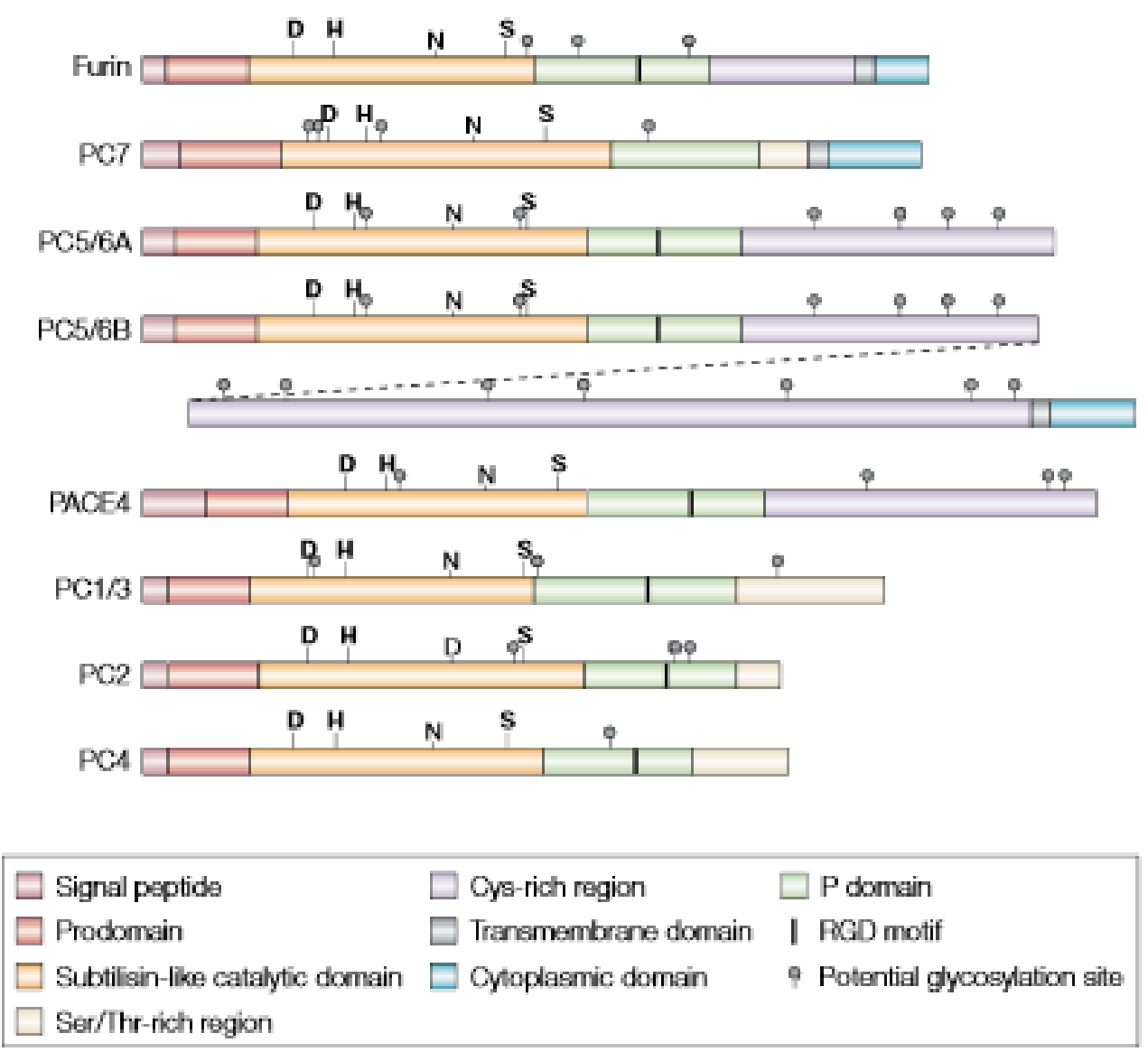

Figure 8: Domain organisation of the proprotein convertases. Domains identified in proprotein convertases are indicated. To acquire the specific activity, the zymogen is first cleaved at the signal peptide within the ER, followed by processing of the N-terminal prodomain in an organelle-specific manner. Figure was taken from [Thomas 2002]. 
Many enveloped viruses depend on processing of their viral glycoproteins by cellular PCs in order to achieve the fusion-active state. The cleavage site in the hemagglutinin proteins of avian influenza viruses is a determinant of virulence. Thus, HA proteins of low pathogenic avian influenza virus strains (LPAI) contain a single basic amino acid at the cleavage site consisting of one single arginine or lysine, which are cleaved by trypsin-like endoproteases. In contrast, the HA of highly pathogenic avian influenza viruses (HPAI) contains a multibasic cleavage site, which harbors several arginine or lysine residues and is recognized by PCs, particularly by furin [Bosch et al., 1981, Stieneke-Grober et al., 1992, Vey et al., 1992]. This diversity in cleavage sites of avian influenza viruses correlates with pathogenicity, because viral replication is restricted to the expression sites of the responsible proteases. The HIV-1 envelope glycoprotein precursor gp160 is processed by furin-like proteases into gp41 and gp120 [Hallenberger et al., 1992] and so is the glycoprotein of most Ebolaviruses, which contain a consensus furin site, but cleavage was reported to be dispensable for membrane fusion [Volchkov et al., 1998, Neumann et al., 2002, Neumann et al., 2007]. The spike proteins of certain beta-and gammacoronaviruses like MHV-A59 are also cleaved by PCs and cleavage was found to be required for cell-cell but not for virus-cell fusion [Frana et al., 1985, Spaan et al., 1988, de Haan et al., 2004]. Other MHV strains, like MHV-2, express spike proteins that are not cleaved during biogenesis in the constitutive secretory pathway of infected cells, but are processed by endosomal proteases during viral entry into target cells [Qiu et al., 2006]. One report indicates that the SARS-S protein is processed by PC in infected cells, although in an inefficient manner and that processing is required for viral spread [Bergeron et al., 2005]. Regarding the MERS-S protein, it is at present not known whether it is cleaved during maturation by proprotein convertases and whether cleavage is required for viral infectivity.

\subsubsection{Cathepsin $\mathbf{L}$}

Cathepsins belong to the lysosomal cysteine proteases and are required for the degradation of polypeptides, which had previously been taken up into lysosoms [Kominami et al., 1988, Stoka et al., 2005]. Members are cathepsin B, C, H, F, L, K, O, S, V, X and W [Turk et al., 2000, Turk et al., 2001]. Some cathepsins are expressed ubiquitously (B, H, L), while the expression of others is restricted to a specific tissue [Stoka et al., 2005]. Most cathepsins are 
monomers and have a high sequence-and folding homology. They contain a cysteine and histidine residue in the active center and require acidic $\mathrm{pH}$ to gain optimal activity [Turk et al., 2001]. Cathepsins are synthesized in the ER as precursor proteins (procathepsins) and are glycosylated [Kominami et al., 1988]. After translocation into lysosomes, they undergo an autocatalytic cleavage. Cathepsin L (CTSL) is a lysosomal endopeptidase and belongs to the papain family. It plays a major role in antigen processing, tumour invasion and metastasis, bone resorption and degradation of proteins [Kirschke et al., 1979, Kane and Gottesman 1990, Ishidoh and Kominami 1995]. CTSL also processes viral glycoproteins: Its role in viral entry and disassembly of nonenveloped reoviruses and the enveloped Ebolavirus has been well described, though the latter one depends more primarily on cathepsin B [Ebert et al., 2002, Chandran et al., 2005]. Simmons and colleagues showed that CTSL can cleave the SARS-S protein and that CTSL activity is required for spike protein-driven host cell entry (see Figure 10 in summary section) [Simmons et al., 2005]. In the light of these data, the previously documented finding that SARS-CoV entry requires low pH [Yang et al., 2004] had to be reinterpreted: The dependence on low $\mathrm{pH}$ does not reflect activation of the spike protein by protonation, as is the case for many other viral glycoproteins, but is due to CTSL requiring a low $\mathrm{pH}$ environment for its activity (Figure 10). In contrast, cellular entry of human CoVNL63, which employs the same cellular receptor for entry as SARS-CoV, was largely independent of CTSL activity [Hofmann et al., 2006, Huang et al., 2006]. The site that CTSL cleaves in the SARS-S protein was mapped to the S1-S2-boundary region where the glycoproteins of other coronaviruses are cleaved by furin. However, it is currently unclear whether inactivation of this site interferes with viral infectivity [Bosch et al., 2008]. Furthermore, HCoV-229E and certain MHV strains are activated by CTSL [Qiu et al., 2006, Kawase et al., 2009]. The role of CTSL activity in the viral entry driven by the MERS-S glycoprotein is currently not known.

\subsubsection{Type II transmembrane serine proteases (TTSPs)}

Serine proteases encompass nearly one-third of all proteolytic enzymes known so far and have an important role in a variety of biological processes, like digestion, immunity, blood coagulation and inflammation [Choi et al., 2009]. Serine proteases comprise secreted enzymes like trypsin and chymotrypsin and membrane-anchored enzymes like the type I and 
type II serine proteases (TTSPs), which are subdivided into many families. Among the membrane-anchored serine proteases, type II transmembrane serine proteases have recently been shown to process viral glycoproteins (see below) [Böttcher et al., 2006, Bugge et al., 2009, Chaipan et al., 2009, Antalis et al., 2011]. TTSPs are also involved in regulatory processes like development and homeostasis, and dysregulated TTSP expression is linked to cancer development [Antalis et al., 2011]. TTSPs are synthesized as single-chain zymogens and are autoproteolytically activated by cleavage in a conserved motif proceeding the catalytic domain [Bugge et al., 2009]. They are inserted into the plasma membrane with the transmembrane domain. The large extracellular $\mathrm{C}$-terminus plays a decisive role in protein localization, activation, inhibition and substrate specificity and consists of a stem region that has regulatory functions and a serine protease domain [Hooper et al., 2001, Szabo and Bugge 2008, Antalis et al., 2011]. The domain structure of the stem region is variable and its composition has been used to define four TTSP subfamilies: The hepsin/TMPRSS-, matriptase-, corin- and HAT/DESC-subfamily [Bugge et al., 2009, Antalis et al., 2011].

One member of the hepsin/TMPRSS subfamily is the protease TMPRSS2, which contains a group A scavenger receptor domain in the stem region, followed by a single LDLRA domain (low-density lipoprotein receptor domain class A) (Figure 9) [Paoloni-Giacobino et al., 1997, Antalis et al., 2011].

TMPRSS2
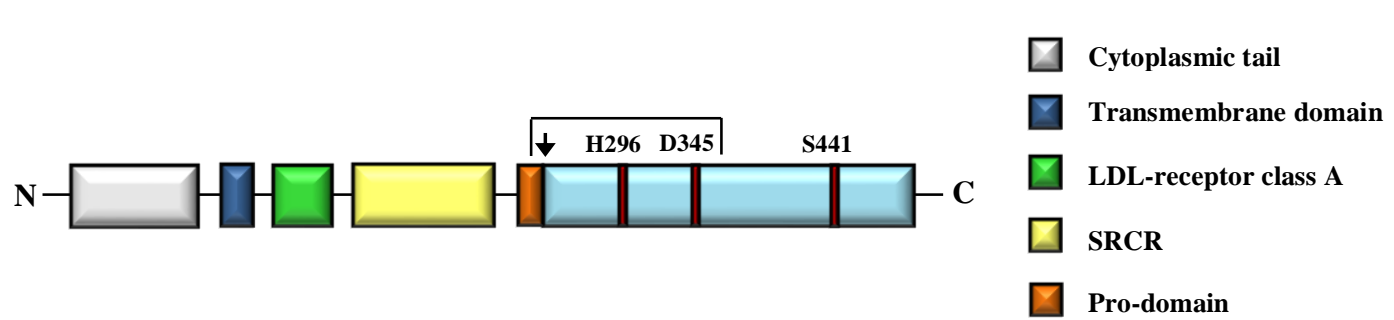

Figure 9: Domain organisation of the type II transmembrane serine protease family member TMPRSS2. The domain organisation is as follows: $\mathrm{N}$-terminal cytoplasmic tail, transmembrane domain, stem region, including LDL-receptor class A domain and scavenger receptor cysteine-rich domain (SRCR), catalytic domain. The catalytic domain consists of a catalytic triad with a serin, histidine and aspartate residue. The cleavage site between the pro-and catalytic domain is indicated by an arrow; both domains are covalently connected by a disulphide bond. 
Human TMPRSS2 is expressed to a high amount in the epithelia cells of prostate and lung, and lower levels of TMPRSS2 mRNA have been found in epithelia of breast, kidney, colon, small intestine, pancreas, ovary and stomach [Lin et al., 1999, Jacquinet et al., 2000] as well as in type II pneumocytes [Donaldson et al., 2002]. The physiological roles of TMPRSS2 are currently not known, however studies revealed that is has an impact on epithelial sodium channel current and on the development of prostate cancer [Lin et al., 1999, Lucas et al., 2008]. Moreover, a secreted form of TMPRSS2 plays a role in the regulation of sperm function [Donaldson et al., 2002, Chen et al., 2010]. A landmark study by Böttcher and colleagues showed that TMPRSS2 activates the HA proteins of all influenza virus subtypes previously pandemic in humans [Böttcher et al., 2006] and subsequent work demonstrated that also the HA of the highly pathogenic 1918 influenza virus can be activated by TMPRSS2 [Chaipan et al., 2009]. In addition, it was shown that the TTSP members TMPRSS4, HAT [Böttcher et al., 2006, Chaipan et al., 2009], MSPL, TMPRSS13 and matriptase can activate HA proteins [Okumura et al., 2010, Hamilton et al., 2012, Baron et al., 2013, Beaulieu et al., 2013]. TMPRSS2 also activates the surface protein of human metapneumovirus [Shirogane et $a l ., 2008$ ] and promotes CTSL-independent SARS-S glycoprotein-driven cell-cell and viruscell fusion by cleaving the spike protein (Figure 10) [Matsuyama et al., 2010, Glowacka et al., 2011, Shulla et al., 2011, Kawase et al., 2012]. The fact that SARS-S-mediated entry can be efficiently inhibited by an HR2 peptide in TMPRSS2 positive but not in TMPRSS2 negative cells suggests that TPMRSS2 activates SARS-S at the cell surface [Matsuyama et al., 2010]. In contrast, coexpression of TMPRSS2 and spike in the same cell does not lead to spike activation but instead results in shedding of the spike ectodomain into the extracellular space where it can function as an antibody decoy [Glowacka et al., 2011]. Besides TMPRSS2, HAT can also activate the SARS-S protein for cell-cell fusion but not for CTSL- independent virus-cell fusion [Kam et al., 2009, Bertram et al., 2011]. Finally, TMPRSS4 was shown to activate SARS-S for cell-cell fusion but no evidence for spike protein processing by TMPRSS4 was obtained [Glowacka et al., 2011] Which proteases activate the MERS-S protein was unknown when the studies, summarized in this thesis, were started. 


\section{Summary}

Class I viral membrane proteins are synthesized as inactive precursors and depend on cleavage by host cell proteases to acquire activity, and the responsible enzymes are targets for therapeutic intervention.

\section{Producer cell}

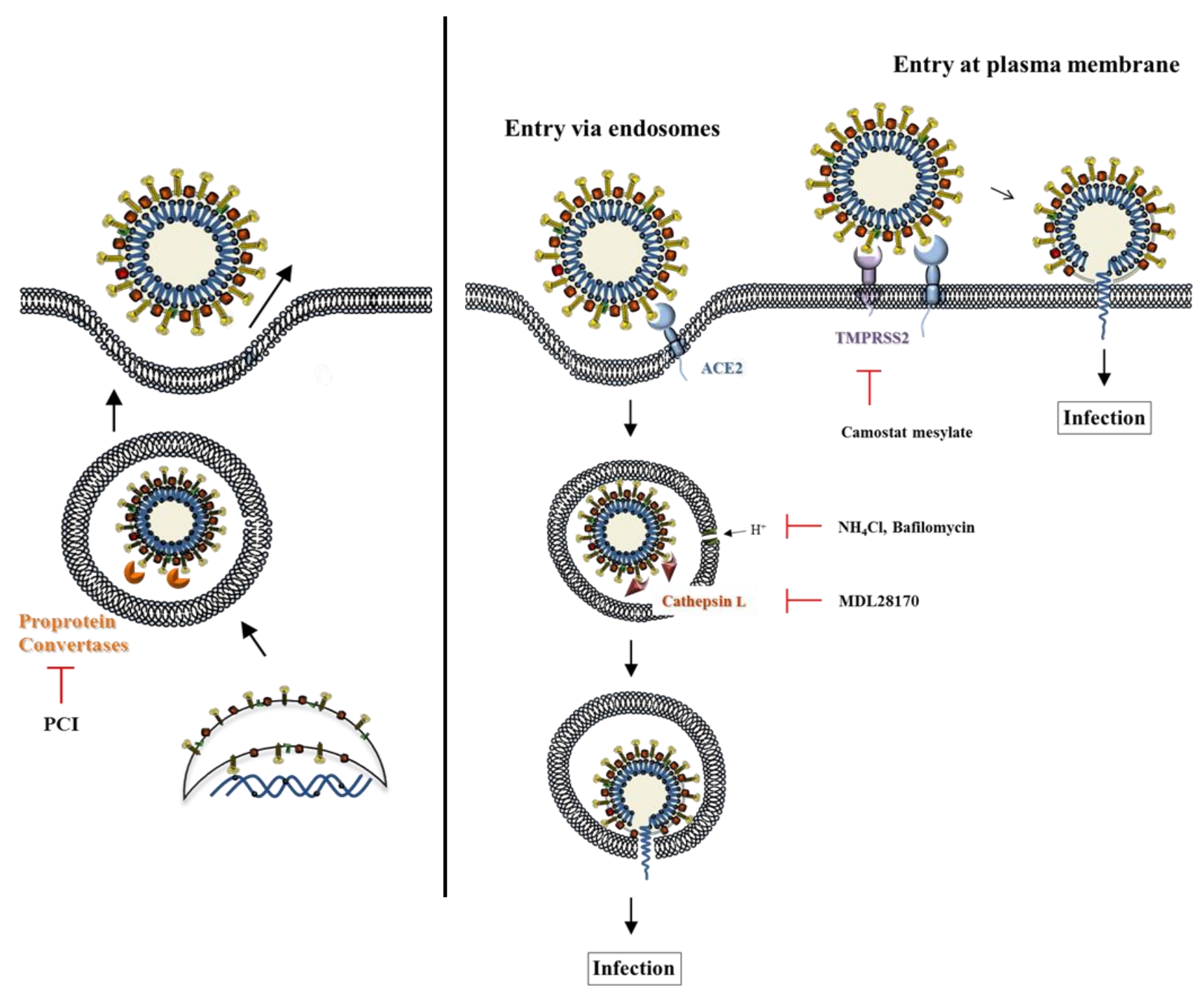

Figure 10: Enzymatic processing of SARS-S by host cell proteases. In the infected producer cell, the S protein is primed during maturation in the secretory pathway by proprotein convertases (left), which can be blocked by proprotein convertase inhibitor. The virus is then released by fusion of virion-containing vesicles with the plasma membrane. During entry process into the target cell (right), the S protein of SARS-CoV has to bind its cellular receptor, ACE2, which results in virion uptake into endosomes. Inside the endosome, the spike protein is activated by the $\mathrm{pH}$ dependent cysteine protease cathepsin $\mathrm{L}$, which can be blocked by ammonium chloride, bafilomycin A1 and MDL28170. However, the spike protein can also be activated directly at the cell surface by TMPRSS2, which can in turn be inhibited by camostat mesylate. 
It has been shown that coronavirus spike proteins can be activated by different enzymes and in different cellular locations: During biogenesis in the secretory pathway, by type II transmembrane serine proteases at or near the surface of host cells and by the cysteine protease CTSL upon uptake of virions into host cell endosomes (Figure 10). Which pathway is chosen by MERS-CoV for proteolytic activation is unknown. 


\section{Aims of the study}

The ongoing Middle East Respiratory Syndrome Coronavirus (MERS-CoV) epidemic is associated with a high case-fatality rate and poses a significant threat to public health. At present, no approved antivirals or vaccines are available to combat MERS-CoV infection and the establishment of novel antiviral strategies is an important task. The surface protein spike (S) of coronaviruses binds to host cell receptors and facilitates infectious entry of virions into target cells, and the viral and cellular components involved in the entry process are potential targets for intervention. For instance, host cell proteases, which activate $\mathrm{S}$ proteins, afford targets for antiviral approaches. Moreover, the $\mathrm{S}$ protein is the major target for neutralizing antibodies, which are a central, diagnostic marker for MERS-CoV infection and can be used to determine MERS-CoV seroprevalence of populations at risk - an important task of MERS research. Therefore, it is important to investigate how MERS-CoV S (MERS-S) facilitates host cell entry and to exploit $\mathrm{S}$ protein-based experimental systems for diagnostic purposes.

Three aims were defined for the present study: The first aim was to establish a vector system, which allows analysing MERS-S-driven entry in a convenient and safe fashion without the requirement to work with authentic MERS-CoV. This system was to be used to investigate key features of MERS-S-driven entry, in particular the cell tropism, $\mathrm{pH}$ dependence and sensitivity towards antibody-mediated neutralization.

The activation of coronavirus S proteins by host cell proteases is essential for viral infectivity. The second aim was to identify the proteases which activate MERS-S and to determine whether known proteases inhibitors can block these enzymes and thereby inhibit MERS-Sdriven entry.

The third aim was to employ the vector system to determine the MERS-CoV seroprevalence in Saudi Arabian patients before the MERS outbreak in 2012. The goal of this study was to clarify whether MERS-CoV has been circulating undetected before the first MERS cases were diagnosed in 2012, which would suggest that the virus might be able to cause mild or asymptomatic infections. 


\section{Manuscripts}

Title

The spike-protein of the emerging betacoronavirus EMC uses a novel coronavirus receptor for entry, can be activated by TMPRSS2 and is targeted by neutralizing antibodies

Journal of Virology May 2013; 87(10): 5502-5511.

Title

Inhibition of proprotein convertases abrogates processing of the MERScoronavirus spike protein in infected cells but does not reduce viral infectivity

Journal of Infectious Diseases July 2014. pii: jiu 407.

Title

Lack of MERS coronavirus neutralizing antibodies in patients from Eastern Province, Saudi Arabia

Emerging Infectious Dieseases, Dec 2013; 19(12): 2034-2036 
First Manuscript 


\title{
The Spike Protein of the Emerging Betacoronavirus EMC Uses a Novel Coronavirus Receptor for Entry, Can Be Activated by TMPRSS2, and Is Targeted by Neutralizing Antibodies
}

\author{
Stefanle Glerer," Stephanle Bertram," Franziska Kaup," Florlan Wrensch," Adeline Heurich," Annlka Krämer-Kühl," Kathrin Welsch," \\ Michael Winkler," Benjamin Meyer, ${ }^{,}$Christlan Drosten, ${ }^{b}$ Ulf Dittmer, ${ }^{c}$ Thomas von Hahn, d,e Graham Simmons, ${ }^{f}$ Helke Hofmann," \\ Stefan Pöhlmann"

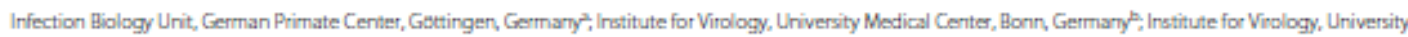 \\ Hospital Esser, University of Duisburg Esser, Essen, Germany,; Institute for Malecular Biology, Hannover Medical School, Hannover, Germany't, Department of \\ Gastroenteralogy, Hepatalogy and Endocrinalogy, Hannover Medical School, Hannover, Germany"; Blood Systems Research Institute, San Francisco, California, USA'
}

The novel human coronavirus EMC (hCoV-EMC), which recently emerged in Saudi Arabia, is highly pathogenic and could pose a significant threat to public health. The elucidation of hCoV-EMC interactions with host cells is critical to our understanding of the pathogenesis of this virus and to the identification of targets for antiviral intervention. Here we investigated the viral and cellular determinants governing hCoV-EMC entry into host cells. We found that the spike protein of hCoV-EMC (EMC-S) is incorporated into lentiviral particles and mediates transduction of human cell lines derived from different organs, including the lungs, kidneys, and colon, as well as primary human macrophages. Expression of the known coronavirus receptors ACE2, CD13, and CEACAM1 did not facilitate EMC-S-driven transduction, suggesting that hCoV-EMC uses a novel receptor for entry. Directed protease expression and inhibition analyses revealed that TMPRSS2 and endosomal cathepsins activate EMC-S for viruscell fusion and constitute potential targets for antiviral intervention. Finally, EMC-S-driven transduction was abrogated by serum from an hCoV-EMC-infected patient, indicating that EMC-S-specific neutralizing antibodies can be generated in patients. Collectively, our results indicate that hCoV-EMC uses a novel receptor for protease-activated entry into human cells and might be capable of extrapulmonary spread. In addition, they define TMPRSS2 and cathepsins B and L as potential targets for intervention and suggest that neutralizing antibodies contribute to the control of hCoV-EMC infection.

uman coronaviruses were long considered agents of mild respiratory disease, with the prototype viruses $229 \mathrm{E}$ and OC43 being responsible for up to $30 \%$ of common cold cases requiring medical attention $(1,2)$. However, the outbreak of the severe acute respiratory syndrome coronavirus (SARS-CoV) in 2002-2003 abruptly changed this view. The spread of the novel virus claimed more than 700 lives, predominantly elderly and immunocompromised individuals, and caused massive economic damage (3). SARS-CoV-related viruses were detected in bats, and it is believed that these animals served as a natural reservoir $(4,5)$ from which the virus was transmitted via intermediate hosts, such as palm civets (6), to humans. Thus, although most human coronaviruses known today (OC43, 229E, NL.63, and HKU1) circulate worldwide and cause mild respiratory disease (7), the zoonotic transmission of novel coronaviruses to humans can pose a significant threat to public health

A novel coronavirus, termed hCoV-EMC (8), recently emerged in the Middle East, and so far 13 laboratory-confirmed cases have been reported to the WHO, including 6 from Saudi Arabia, 2 from Qatar, 2 from Jordan, and 3 from the United King dom $(9,10)$. The cases from the United Kingdom cluster within one family, with the initial individual but not the subsequent ones having a history of travel to Pakistan and Saudi Arabia (10), suggesting that human-to-human transmission occurred. Disquietingly, the new virus shares several similarities with SARS-CoV. First, hCoV-EMC appears to be highly pathogenic, with 7 of the 13 identified cases having a fatal outcome, and infection induces a severe acute respiratory disease $(8,9)$. Second, the virus, like SARS-CoV, belongs to the betacoronavirus genus and might have been transmitted from bats to humans ( 8 ), as suggested by its close relatedness to the bat coronaviruses HKU4 and HKU5 and the isolation of hCoV-EMC-related viruses in bats from Ghana and Europe (11). At present, there is no evidence for efficient interindividual transmission of hCoV-EMC (9). However, a few adaptive amino acid changes might be sufficient to allow hCoV-EMC to spread rapidly within the human population, with potentially severe consequences. Therefore, it is imperative to elucidate hCoVEMC interactions with host cells and to transform this knowledge into effective antiviral strategies.

The interaction of the coronavirus spike (S) protein with host cell receptors and proteases is essential for the first step in coronavirus infection, i.e., viral invasion of host cells $(12,13)$. The binding of the S protein to host cell receptors attaches viruses to target cells and is a major determinant of the viral cell and organ tropism (14). Two receptors for human coronaviruses have been identified so far, namely, CD13 (used by hCoV-229E) (15) and ACE2 (used by SARS-CoV and hCoV-NL63) $(16,17)$. Moreover, sialic acid has been described as a receptor determinant of hCoV-OC43 (18), and the coronavirus murine hepatitis virus (MHV) was shown to

Hocolvod 17 January 2013 Accopted 27 Febeuary 2013 Published ahead of print 6 March 2013 Address correspondence to Stefan Pohlman, spoehimarniadpres $5 . \mathrm{G}$ and $5 \mathrm{~B}$ contributed $e q u a l y$ to this article. Copyright 0 2013, Aenerican Soclety for Microbiology. Al Rights Peserved. do: $10.1128 / M_{0} 0128-13$ 
engage murine but not human CEACAM1 for cellular entry (19), although it is worth noting that MHV host range mutants which employ human CEACAMI for cellular entry have been reported $(20,21)$. The $\mathrm{S}$ proteins are synthesized as inactive precursors and transform into an active state upon proteolytic cleavage $(12,13)$. The activity of the pH-dependent endosomal cysteine proteases cathepsin B and, particularly, cathepsin L was found to be required for entry of SARS-CoV (22) and hCoV-229E (23) into certain host cells, and evidence for S-protein proteolysis by cathepsins was provided (22). However, recent work indicates that the type II transmembrane serine proteases (TTSPs) TMPRSS2 and HAT can cleave the SARS-CoVS protein (SARS-S) and that SARS-S processing by TMPRSS2 allows for cathepsin $\mathrm{B} / \mathrm{L}$-independent virus-cell fusion (24-28). Which receptors and proteases are used by hCoV-EMC for attachment and activation is unknown at present.

Here we investigated the viral and cellular determinants of hCoV-EMC entry into host cells. We show that the hCoV-EMC S protein (EMC-S) mediated transduction of a broad range of human target cells when the protein was incorporated into lentivira particles. EMC-S did not engage known coronavirus receptors for cellular entry and was activated by TMPRSS2 and endosomal cathepsins. Finally, transduction was inhibited by serum from an hCoV-EMC-infected patient, indicating that S-protein-specific neutralizing antibodies are generated in the context of hCoVEMC infection.

\section{MATERIALS AND METHODS}

Cell culture. Most of the adherent cell lines were maintained in Dulbecco's modified Eagle's medium (DMEM: Gibco, Invitrogen) supplemented with 5 to $10 \%$ fetal calf serum (FCS; Bsochrom) and $1 \%$ penictllin-streptomyctn sulfate (Cytogen). 293T cells genetically engineered to stably express human ACE2 (hACE2; 293T-ACE2 cells) (29) or hCD13 (293TCD13 cells) (S. Bertram et al., submitted for publication) were maintatned in DMEM supplemented with $100 \mu \mathrm{g} / \mathrm{ml}$ Zeocln (Invitrogen). Cacocells were cultured in DMEM-GlutaMAX medium (Invitrogen) supplemented wtth 10\% FCS. The promonocytic cell line THP-1 was grown in RMPI 1640 medtum (G1bco) supplemented with 10\% FCS and antibtotics and differentlated into a macrophage-like culture by induction with phorbol myristate acetate (PMA) (20 ng/ml: Stgma) for $48 \mathrm{~h}$. For generation of primary human monocytes, pertpheral blood mononuclear cells were putfied by Ficoll gradient centrifugation and cultured in monocyte adherence medtum (RPMI 1640 medium with $7.5 \%$ human fibrin-depleted plasma) for $24 \mathrm{~h}$. Thereafter, adherent cells were resuspended in monocyte differentiation medtum (X-Vivo 10 medium (Lonza) supplemented with $1 \%$ human fibrin-depleted plasma and $1 \%$ pentallin-streptomydin sulfate), seeded into 96-well plates at a denstly of $7.5 \times 10^{4} \mathrm{cells} / \mathrm{well}$, and allowed to differenthate into monocyte-derived macrophages for at least $?$ days before usage for transduction experiments. Microscopic inspection of cells used for transduction revealed a clear macrophage-like morphology. All cells were grown in a humtdified atmosphere at $37^{\circ} \mathrm{C}$ and $5 \% \mathrm{CO}_{2}$

Plasmids and antibodies. Expresston plasmids for SARS-S, 229E-S, Zaire ebolavirus glycoprotein (EBOV-GP), vestcular stomatttis virus glycoprotein (VSV-G), and murine leukemia virus envelope protein (MLV Env) have been described previously $(30,31)$. Plasmids encoding the transmembrane proteases TMPRSS2, TMPRSS4, TMPRSS3, TMPRSS6, and HAT were published earlier $(24,32-34)$. An expresslon plasmid encoding EMC-S (EMC-S FL.AG) with a C-terminal FL.AG tag was generated by reverse transcription, using RNAs from $\mathrm{CoV}$-EMC-infected cell cultures and the oligonucleotides $2 \mathrm{C}$-nhCoV-S-BamHI-F (TAOGGATCOC CCACCATGATACACTCAGTGTTTCTACTGATGT) and $2 \mathrm{c}$-nhCoV SflagC-Sall-R (AGCGTCGACTTACTTGTCATCGTCATCCTTGTAAT CGCCTCCGTGAACATGAACCTTATGCGGC), followed by ligation of the PCR fragment into plasmid pOG1. The resulting plasmid was used as a template for amplification of the EMC-S open reading frame without a tag, using oligonucleotides p5-BetaCoV Kpn (GATCGGTACCACCATC ATACACTCAGTGTTTCTACTG) and p3-BetaCoV_Xho (GATCCTCC AGTTAGTGAACATGAACCTTATGCGGCTCTAGG). The PCR amplicon was then tnserted into the plasmid pCAGGS by using the Kpnl and Xhol restriction sittes. The resulting plasmid expresses EMC-S with a sequence identical to that deposited under GenBank accesston number AFS88936. To generate EMC-S with a V5 tag, the C-terminal sequence of EMC-S was amplified ustng oligonucleotides BetaCoV seq 2567 (CTCA ATCATCTCCTATCATACCAGG) and p3-BetaCoV_Xho_V5 (GATCCT CGAGTTACGTAGAATCGAGACCGAGGAGAGGGTTAGGGATAGC CTTACCGTGAACATGAACCTTATGCGGCTCTAGG), followed by replacement of the corresponding sequence withtn the pCAGGS-EMC-S plasmid by use of Sphl and Xhol. The integrity of all PCR-ampltied nucleotide sequences was verified by automated sequence analysts. For generation of lentiviral virus-like particles (VL.Ps), plasmid p967M651gag. opt, encoding human immunodefictency virus type 1 Gag (p55), was employed (35). A V5-reactive monoclonal antibody was obtained from Invitrogen: HIV Gag proteins were detected using the hybridoma 183. H12-5C cell culture supernatant (NIH AIDS Reagent Program). Secondary antibodies were purchased from Dlanova. An hCoV-EMC-reactive serum was tsolated from a blood sample obtatned from an hCoV-EMC infected pattent treated in a hospital in Fissen, Germany.

Production and analysts of VLPs. VLPs were generated as described prevously (25). Brtefly, plasmtd p96ZM 651 gag-opt was coexpressed with etther an empty plasmid as a control or plasmids encoding the S proteins of SARS-CoV and hCoV-EMC, followed by concentration of superna. tants by ultrafiltratton using Vivaspin centrifugal concentrators (Sartorlus) and purificatton of VLPS by centrifugation of supernatants through a $20 \%$ sucrose cushson at $13,000 \times g$ for 2 to $3 \mathrm{~h}$ at $4^{\circ} \mathrm{C}$. Concentrated VLPs were treated with $\operatorname{trypsin}(100 \mu \mathrm{g} / \mathrm{ml})$ for $10 \mathrm{mtn}$ at room temper. ature, followed by the additton of the same concentratton of soybean trypsin inhtbitor (Sigma). The samples were then analyzed by Western blotting, employing a monodlonal antibody directed against the V 5 tag.

Production and analysis of lenttviral pseudotypes. Lentiviral psendotypes were generated and harvested from the calture supernatants of transfected $293 \mathrm{~T}$ cells as described previously $(31,36)$. The supernatants were harvested, passed through $0.45-\mu \mathrm{m}$-pore-stze filters, and stored at $-80^{\circ} \mathrm{C}$. Before usage in experiments, pseudotypes were normalized for equal infectivity by transduction of Caco-2 cells with serially diluted su. pernatants followed by determination of luctferase activity in cell lysate according to the manufacturer's instructions (Promega). Normalization of the viral p24 capsid protein content was performed using a commerctally avallable HIV-1 p24 enzyme-linked immunosorbent assay (EL.ISA) (HIV-1 p24 antigen capture assay; Advanced BsoSctence Laboratorles).

Neutralization assay. The neutralizing activity of serum obtatned from an hCoV-EMC-tnfected patlent treated in Essen, Germany, was measured by pretncubatton of lentiviral pseudotypes with defined serum dilutions in triplicate for $30 \mathrm{~min}$ at $37^{\circ} \mathrm{C}$ in a total volume of $50 \mathrm{\mu l}$. Thereafter, the mixture was added to $10^{4}$ Caco- 2 cells in 96 wells for $8 \mathrm{~h}$, followed by complete exchange of the culture medtum. After $72 \mathrm{~h}$, the reduction in transduction efficiency was measured by quantifying luctferase activittes in cell lysates.

Inhlbitton studles. The inhibttors MDL28170 (Calbsochem), camostat mesylate (Tocris), leupeptin, and ammonfum chlorlde (Sigma) were dfluted in solvent as recommended by the manufacturers and used at the indicated concentrattons. Within the experiments, the volume of solvent was kept constant, and solvent without inhibitor was used as a control. Target cells were pretreated with the inhibitors for $60 \mathrm{~min}$ at $37^{\circ} \mathrm{C}$ and transduced with infectivity-normalized pseudotypes in the presence of tnhibttor. The inhtbitor-containing medium was replaced by fresh cal ture medium without inhtbitor at $8 \mathrm{~h}$ postransduction, and transduction efficlency was measured after $72 \mathrm{~h}$. 
A)

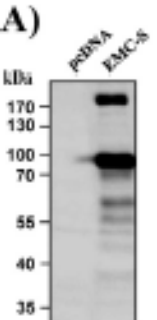

2937

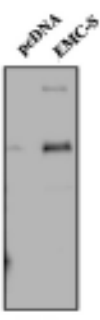

Hela

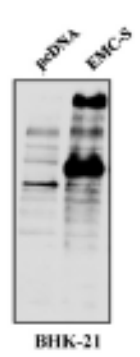

B)

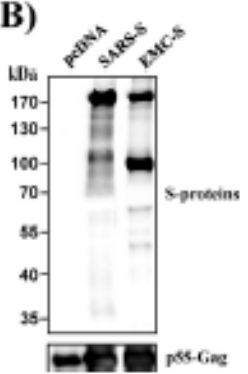

FIG 1 EMC-S is expressed in transfected cells and incorporated into lentiviral particles. (A) Plasmids encoding EMC-S with a C-terminal tag were trans. fected into 293T, Hela, and BHK-2l cells, as indicated. The transfected cells were lysed, and the lysates were analyzed by Western blatting using tag-specific monoclonal antibodies. Cells transfected with empty plasmid (pcDNA) served as a negative control. (B) SARS-S or EMC-S with a C-terminal V5 tag was coexpressed with HIV-1 Gag protein in $293 \mathrm{~T}$ cells. Cells expressing Gag-Pol alone were used as a control ( $\mathrm{pcDNA}$ ). At $48 \mathrm{~h}$ posttransfection, virus-like particles were harvested, concentrated via ultrafiltration and high-speed centrifugation hrough a sucrose cushion, and analyad by Western blotcentrifugetio $v 5$ hocifict ling using a V5-specific antibody and a p55-Gag-reactive antibody as loading control. The results are representative of at least three independent experiments.

\section{RESULTS}

The human coronavirus EMC spike protein is expressed in transfected 293T cells and incorporated into retroviral particles. Retroviral particles pseudotyped with S proteins (pseudotypes) have been used successfully to characterize the host cell entry of coronaviruses, including SARS-CoV (37-39). Therefore, we asked if pseudotyping can be employed to study the cellular entry driven by EMC-S. Efficient expression of viral envelope proteins in transfected cells is a prerequisite for pseudotyping. Western blot analysis of $293 \mathrm{~T}$, HeLa, and BHK-21 cells transfected to express EMC-S with a C-terminal antigenic tag revealed two prominent bands, of 170 and $100 \mathrm{kDa}$, and a minor band, of 60 $\mathrm{kDa}$, which were not detected in control cells transfected with empty plasmid, indicating that the $\mathrm{S}$ protein was expressed efficiently (Fig. 1A). The detection of two bands is consistent with cleavage of the $\mathrm{S}$ protein $(170 \mathrm{kDa}$ ) into an $\mathrm{N}$-terminal (not detected) and a C-terminal ( $100 \mathrm{kDa}$ ) subunit by host cell proteases. In order to determine whether efficient EMC-S expression allows for virion incorporation, we coexpressed HIV-1 Gag and EMC-S in $293 \mathrm{~T}$ cells and analyzed the S-protein incorporation into particles released from these cells. SARS-S was included as a positive control, since we and others previously showed that SARS-S is incorporated into retroviral particles (37-39). Western blot analysis of pseudoparticles released from transfected 293 T cells indeed revealed efficient particle incorporation of SARS-S, and the S protein was largely uncleaved, in agreement with published data (3739) (Fig. 1B). A signal of similar intensity was measured for EMC-S, and again, two prominent bands, of 170 and $100 \mathrm{kDa}$, were detected (Fig. 1B), indicating that EMC-S and SARS-S are incorporated into retroviral particles with similar efficiencies and that the former but not the latter $\mathrm{S}$ protein is efficiently processed by host cell proteases.

The human coronavirus EMC spike protein mediates entry into cell lines derived from different human tissues. We next investigated if retroviral particles pseudotyped with EMC-S were able to transduce human cells. Pseudotypes bearing the G protein of VSV were used as a positive control, since VSV-G facilitates transduction of an extremely broad range of cell types. Bald particles bearing no glycoprotein were used as negative controls (pCAGGS). A vector encoding luciferase was used for pseudotyping, and transduction efficiency was determined by quantifying luciferase activities in the lysates of transduced cells. Pseudotypes bearing VSV-G were able to robustly transduce all cell types tested, while signals measured upon transduction with particles bearing no glycoprotein were within the background range (Fig. 2A), as expected. EMC-S facilitated transduction of Caco-2 (colon), HOS (osteosarcoma), Huh-7 (liver), and MRC5 (lung) cells, while RPE (retina), U373 (glioblastoma), EA-hy (endothelium), and A549 (lung) cells were not susceptible to EMC-S-mediated transduction (Fig. 2A, left panel). Transduction of 293 and 293T (kidney) cells was also observed (Fig. $2 \mathrm{~A}$, right panel), although some batches of these cells were nonsusceptible, potentially due to batch-or culture-dependent differences in the expression of the so far unknown hCoV-EMC receptor. Finally, THP-1 monocytic cells were nonsusceptible to EMC-S-driven transduction but acquired susceptibility upon PMA-induced differentiation into macrophages (Fig. 2B, left panel), suggesting that expression of the EMC-S receptor might be induced upon differentiation of monocytes into macrophages. Indeed, primary human monocyte-derived macrophages could be transduced efficiently by EMC-S-bearing pseudotypes (Fig. 2B, right panel), in agreement with robust receptor expression. In sum, EMC-S mediates transduction of a broad range of target cells, indicating that the viral receptor is expressed in different cell types and organs.

The spike protein of the human coronavirus EMC does not use known coronavirus receptors for host cell entry. The following proteinaceous receptors for coronavirus have been identified so far: CD13 (used by hCoV-229E and others [15]), murine CEACAM-1 (used by MHV [19]), and ACE2 (used by SARS-CoV and hCoV-NL.63 $[16,17])$. We investigated if EMC-S was able to employ one of these receptors for host cell entry. For this purpose, the respective receptors were transiently expressed in $293 \mathrm{~T}$ cells and the cells subsequently transduced with pseudotypes bearing the S proteins of hCoV-229E (229E-S), MHV (MHV-S), and SARS-CoV. ACE1 was also included in this experiment due to its sequence similarity with ACE2. Expression of the respective coronavirus receptors did not modulate host cell entry driven by VSV-G (Fig. 3). In contrast, ACE2 but not ACE1 expression augmented transduction driven by SARS-S, while expression of CD13 and murine but not human CEACAM-1 facilitated entry driven by $229 \mathrm{E}-\mathrm{S}$ and MHV-S, respectively (Fig. 3), in keeping with published results $(15,19)$. Notably, expression of none of the receptors tested augmented transduction driven by EMC-S (Fig. 3), indicating that hCoV-EMC uses a different host cell factor for cellular entry.

Low $\mathrm{pH}$ and cathepsin activity are required for transduction mediated by the human coronavirus EMC spike protein. The cellular entry of enveloped viruses requires envelope proteindriven fusion of the viral membrane with a host cell membrane. The membrane fusion reaction is energetically unfavorable and can proceed only once the envelope protein receives a trigger, either receptor engagement, low $\mathrm{pH}$, or both $(40,41)$. In addition, many viral glycoproteins require activation by host cell proteases, including the $\mathrm{pH}$-dependent endosomal cysteine proteases 
A)

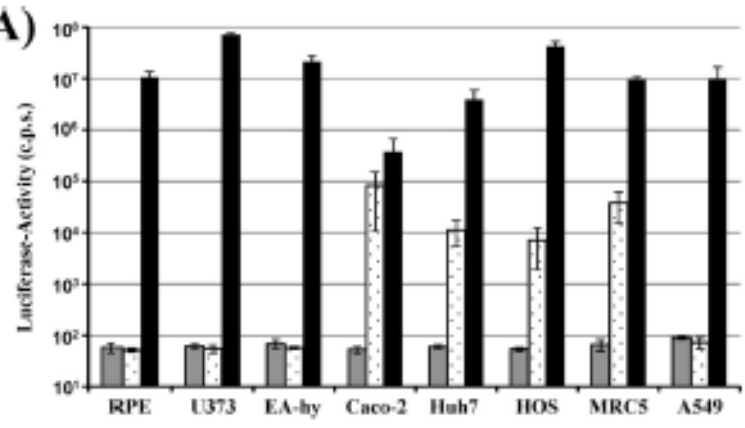

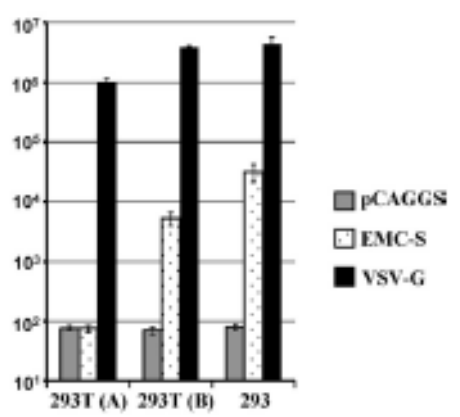

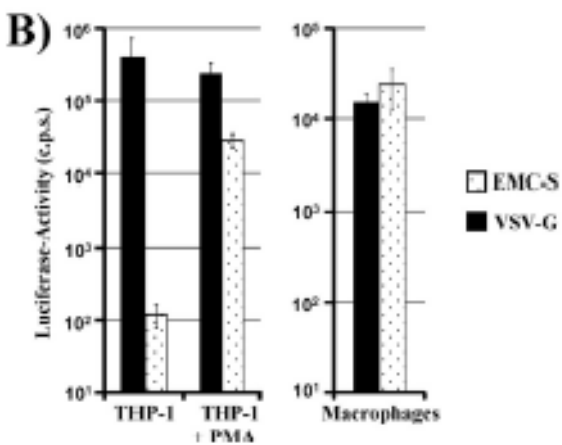

FIG 2 Lentiviral pseudotypes bearing EMC-S transduce a broad spectrum of human cells. Lentiviral pseudotypes carrying the glycoprotein of VSV or EMC as well as pseudotypes bearing no glycoprotein (pCACGS) were normalized for equal p24 capsid protein content and used for transduction of the indicated human cell lines (A) or unstimulated and PMA-stimulated THP-I cells and primary human monocyte-derived macrophages (B). Cells were incubated with pseudatypes for $8 \mathrm{~h}$, followed by replacement of the infection medium with fresh culture medium. After $72 \mathrm{~h}$, cell lysates were prepared and analyzed for luciferase activity. The results shown are representative of three (A) or two (B) experiments performed in triplicate, using two independent pseadotype preparations. Error bars indicate standard deviations (SD).

cathepsins B and $\mathrm{L}_{\text {, }}$ which activate the Ebola virus glycoprotein (EBOV-GP) (42) and SARS-S (22). Entry of viruses which depend on low pH can be inhibited by lysosomotropic agents such as ammonium chloride, and these agents also block entry of viruses which require cathepsin $\mathrm{B} / \mathrm{L}$ activity for entry (22). In contrast, protease inhibitors such as MDL.28170 specifically block activation of viruses which require cathepsin $\mathrm{B} / \mathrm{L}$ activity for entry but do not inhibit viruses which are activated by low $\mathrm{pH}$ alone (22).

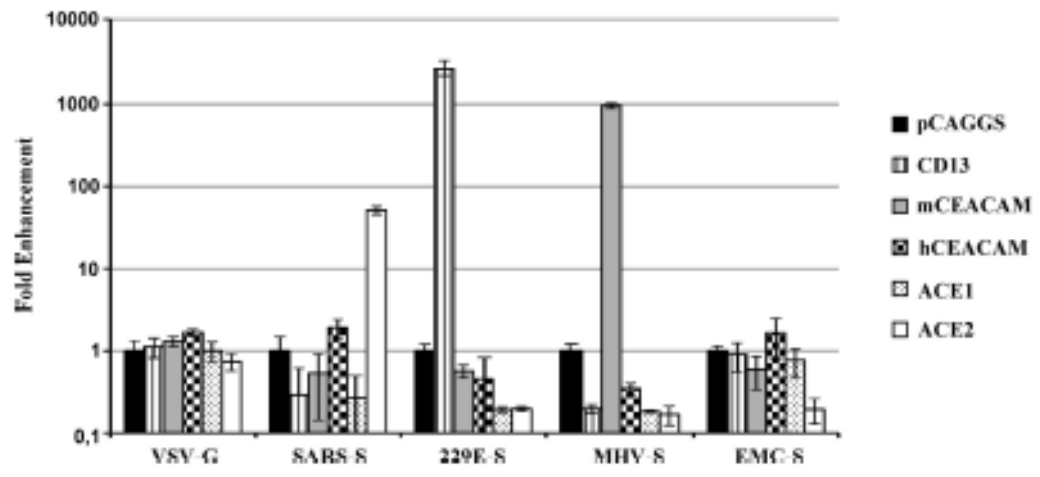

FIG 3 EMC-S does not employ previously described coronavirus receptors for entry into tanget cells. 293T cells were transiently transfected with empty plasmid (pCACCS) or plasmids expresing the indiated coronavirus receptors. The cells were then transduced with infectivity-normalized preudatypes bearing VSV-G, SARS-S, 229E-S, MHV-S, or EMC-S. Luciferase activities in cell lysates were determined at $72 \mathrm{~h}$ postinfection. Similar results were obtained in an independent experiment. Transduction of cells transfected with receptor-encoding plasmids is shown as fold enhancement relative to transduction of cells transfected with empty plasmid, which was set as 1 . 


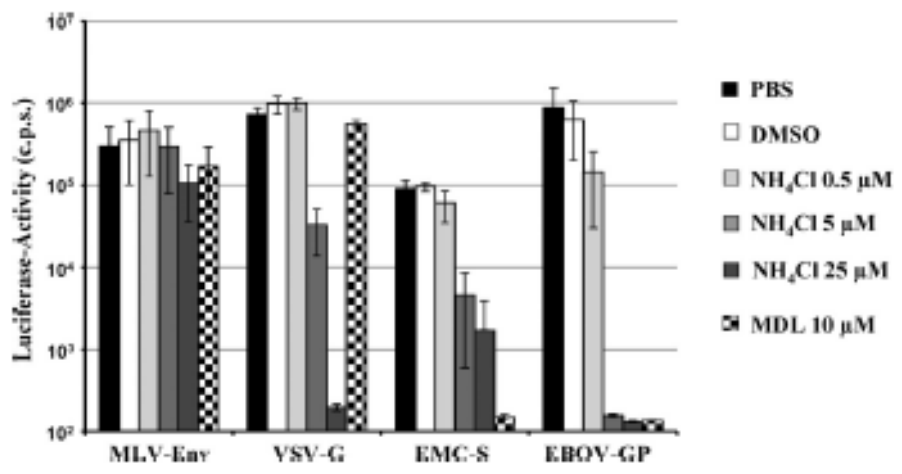

FIG 4 EMC-S-driven cellular entry depends on the activity of cathepsin B and/or L. MRCS target cells were preincubated with the indicated concentrations of ammonium chloride, MDL28170, dimethyl sulfoxide (DMSO), or phosphate-buffered saline (PBS) for 60 min, followed by inoculation with infectivitynormalized pseudatypes bearing the glycoprotein of VSV, MLV, hCoV. EMC, or EBOV. Luciferase activity in cell lysates was measured at 72 h postinfoxtion. The results of a represtave set as $100 \%$. Error bars indicate SD. Sermilar results were obtained in another experiment using different pseudotype preparations.

We employed ammonium chloride and MDL 28170 to determine which host cell factors trigger EMC-S for virus-cell fusion. The murine leukemia virus envelope protein (MLV-Env) is triggered by receptor engagement for membrane fusion $(43,44)$, and transduction mediated by MLV-Env was not blocked by any of the agents tested (Fig. 4), as expected. In contrast, VSV-G requires low $\mathrm{pH}$ as a trigger for membrane fusion (45), and VSV-G-driven transduction was inhibited by ammonium chloride but not by MDL28170 (Fig. 4), in keeping with published results (22). Transduction by EBOV-GP depends on cathepsin B/L activity (42) and was thus inhibited by both ammonium chloride and MDL.28170 (Fig. 4), again in accordance with published data $(22,42)$. Finally, transduction mediated by EMC-S was also blocked by ammonium chloride and MDL28170 (Fig. 4), indicating that EMC-S, like EBOV-GP and SARS-S, depends on cathepsin B/L activity for host cell entry.

TMPRSS2 activates the spike protein of human coronavirus EMC for cathepsin B/L-independent host cell entry. We and others have previously shown that the TTSP TMPRSS2 cleaves SARS-S and that cleavage activates SARS-S for cathepsin B/L-independent host cell entry (25-27). We therefore analyzed if TMPRSS2 can also activate EMC-S for virus-cell fusion. For this purpose, we first asked if TMPRSS2 and other members of the TTSP family cleave EMC-S with a C-terminal antigenic tag when coexpressed in transfected 293T cells. The effect of trypsin on EMC-S was analyzed in parallel. Western blot analysis of cells transfected to express EMC-S in the absence of a protease revealed prominent bands of 170 and $100 \mathrm{kDa}$ and a minor band of approximately $60 \mathrm{kDa}$ (Fig. 5A), in agreement with our previous findings (Fig. 1A). Trypsin treatment produced an additional cleavage fragment of $40 \mathrm{kDa}$, indicating that a trypsin-sensitive site is located within the S2 portion of EMC-S. Coexpression of TMPRSS2 produced prominent EMC-S cleavage fragments of 90 and $58 \mathrm{kDa}$, with additional fragments of 15,35 , and $40 \mathrm{kDa}$ (Fig. $1 \mathrm{~A}$ and $5 \mathrm{~A}$ ). Expression of HAT also resulted in EMC-S proteolysis, but the cleavage fragments differed from those produced by TMPRSS2. Finally, coexpression of TMPRSS3, TMPRSS4, and TMPRSS6 did not result in EMC-S cleavage, despite robust expression of these proteases in the transfected cells, as determined by Western blotting of epitope-tagged proteins (data not shown), indicating that these proteases do not recognize EMC-S as a substrate. Thus, EMC-S is processed by a so far unknown protease expressed in host cells and can additionally be cleaved by trypsin, TMPRSS2, or HAT. Western blot analysis of EMC-S bearing VLPS generated in the presence of trypsin, TMPRSS2, and HAT revealed that EMC-S cleavage products were incorporated into the viral membrane (Fig. 5B). Thus, the EMC-S fragments of 170 and 100 $\mathrm{kDa}$ detected in control VL.Ps were partially replaced by prominent fragments of 40 and $90 \mathrm{kDa}$ in VL.Ps generated in cells coexpressing HAT and TMPRSS2, respectively (Fig. 5B). Similarly, a predominant fragment of $40 \mathrm{kDa}$ was detected in trypsin-treated VLPS.

In order to assess if cleavage results in EMC-S activation, we performed inhibition analyses with MDL.28170, an inhibitor of cathepsin B/L (22), and camostat mesylate (camostat), a serine protease inhibitor active against TMPRSS2 (28). VSV-G-dependent transduction of $293 \mathrm{~T}$ cells transfected with empty plasmid or a TMPRSS2 expression plasmid was not inhibited by MDL28170, camostat, or a combination of both inhibitors (Fig. 5C), as expected. Similarly, camostat treatment of target cells transfected with empty plasmid had little effect on EMC-S-mediated transduction, although a slight reduction in transduction efficiency was observed. In contrast, incubation of empty plasmid-transfected target cells with MDL.28170 alone markedly reduced transduction efficiency, and inhibition was not increased by simultaneous treatment with camostat (Fig. 5C). Notably, inhibition by MDL 28170 was fully rescued by expression of TMPRSS2, but entry remained sensitive to inhibition by camostat (Fig. 5C), indicating that TMPRSS2 can activate EMC-S for cathepsin B/L-independent entry. The activation of EMC-S by TMPRSS2 in transfected cells raised the question of which activation pathway dominates in target cells that are naturally susceptible to EMC-S-mediated transduction. We selected Caco-2 cells to address this question, since these cells express endogenous TMPRSS2 (32) and are susceptible to EMC-S-driven transduction (Fig. 2A). None of the inhibitors tested reduced VSV-G-mediated transduction of Caco-2 cells, although a modest reduction was observed when a combination of MDL28170 and camostat was tested (Fig. 5D). Incubation of 
A)

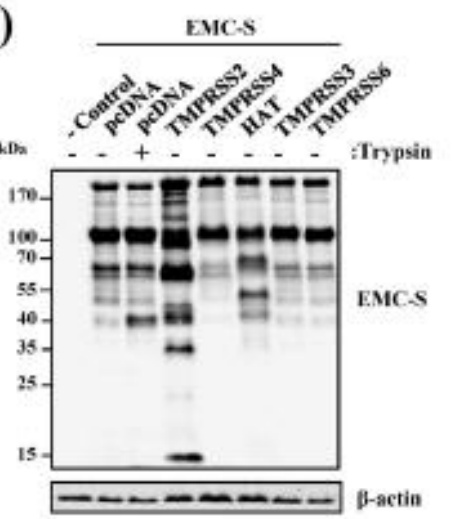

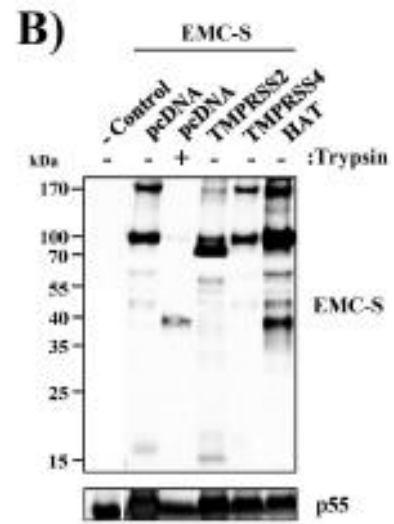

C)
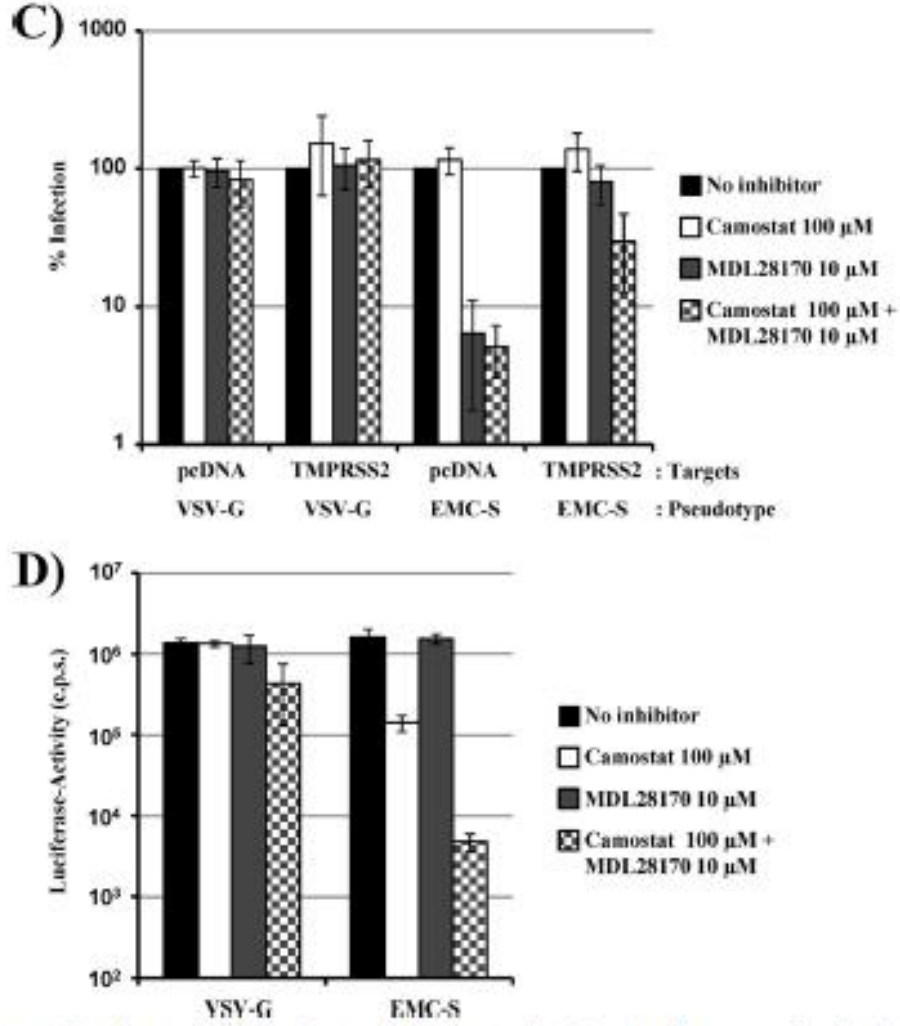

FIG 5 TMPRSS2 activates EMC-S for cathepsin B/L-independent entry into target cells. (A) 293T cells were transfected with empty plasmid (-cantrol) or cotransfected with plasmids encoding EMC-S and the indicated proteses. Forty-eight hours after transfection, cells were either left untreated or treated with trypsin, and lysates were analyzed by Western blotting using a V5 antibody or a $\beta$-actin antibody as a loading controL. The results are representative of three independent experiments with different plasmid preparations. (B) Incorporation of cleaved EMC-S forms into lentiviral particles was assessed by coexpression of EMC-S (with a C-terminal V5 tap) with the indicated proteases and HIV-1 Gag. Virus-like particles were concentrated from the culture supernatants and analyzed by Western blotting using a V5 antihody, with a p55-Cag antibody used as a loading control. The experiment shown is representative of three independent experiments. (C) $293 \mathrm{~T}$ cells were transiently transfected with empty plasmid (pcDNA) or a plasmid encoding TMPRSS2 and used as target cells for transduction by lentiviral vectors bearing EMC.S or VSV.G (as a control). Prior to infection, target cells were incuhated with the indicated protease inhilhitors. Luciferase activities in cell lysates were measured at $72 \mathrm{~h}$ postinfection. The average of three experiments (two for VSV-G-mediated transduction of TMPRSS2. expressing cells) performed in triplicate is shown. Transduction of untreated cells was set as $100 \%$. Error bars indicate standard errors of the means (SEM). (D) Caco-2 cells, which express endogenous TMPKSS2, were incubated with DMSO or the indicated protesse inhibitors, followed by transduction with lentiviral pseudotypes bearing EMC-S or VSV-G (as a control). At 72 h postinfection, luciferase activities in cell lysates were measured. The results of a representative experiment performed in triplicate are shown; error bars indicate SD. Comparable results were observed in two independent experiments. 


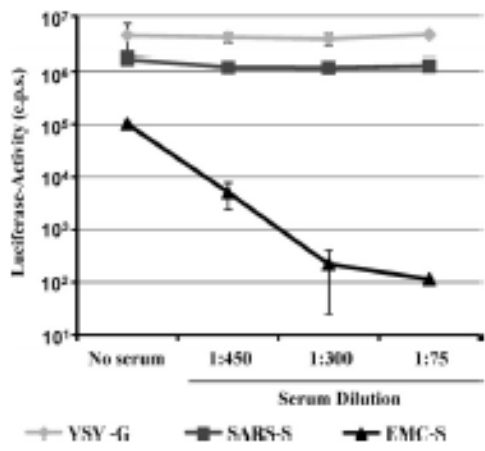

FIG 6 Host cell entry driven by EMCS is neutralized by serum from an hCoV-EMC-infected putient. Pseudotypes bearing the glycoproteins of VSV, SARS COV, and hCoV-EMC, normalined for equal infectivity, were preinceSARSCON, and hCoVEC, no dized for equal infectivity, were preincuin room temperature. Thereafter, the mintures were added to $293 \mathrm{~T}$-ACE2 2 cells for $8 \mathrm{~h}$, followed by replacement of the infection medium by fresh culture medium. Luciferase activities were determined after $72 \mathrm{~h}$ postinfection. The results shown are representative of three independent experiments. Error bars indicate SD.

Caco-2 cells with camostat reduced EMC-S-mediated transduction about 10-fold, while MDL28170 treatment had no effect, indicating that TMPRSS2-dependent activation prevails over cathepsin B/L-mediated activation in Caco-2 cells (Fig. 5D). However, a combination of camostat and MDL.28170 was required to reduce transduction efficiency to background levels (Fig. 5D), indicating that both TMPRSS2 and cathepsin B/L can activate EMC-S for entry into naturally susceptible cells.

The serum from a human coronavirus EMC-infected patient contains neutralizing antibodies. The generation of neutralizing antibodies might be important for the control of hCoV-EMC infection, and an efficient method for the detection of such antibodies could be highly useful for diagnostic efforts. Therefore, we tested if EMC-S-mediated transduction could be blocked by serum obtained from an hCoV-EMC-infected patient who survived the disease. The patient serum did not diminish VSV-G-or SARSS-mediated transduction of 293T-ACE2 cells but reduced EMCS-mediated transduction up to 1,000 -fold, in a concentrationdependent manner (Fig. 6). Thus, neutralizing antibodies are generated in infected, surviving patients and can be detected in a highly efficient and quantitative fashion in the pseudotype transduction system.

\section{DISCUSSION}

The constantly increasing exploitation of natural resources, personal mobility, and climate change facilitate the zoonotic transmission of novel viruses to humans (46), with potentially dramatic consequences, as exemplified by the SARS pandemic. The outbreak of hCoV-EMC in Saudi Arabia raises concerns that a SARS-like pandemic might be about to unfold (47). Assessment of the pandemic potential and the development of specific antiviral measures require an understanding of hCoV-EMC interactions with host cells. Employing lentiviral pseudoparticles, we investigated the viral and cellular factors contributing to hCoV-EMC entry into host cells. We showed that a broad panel of human cell lines is susceptible to EMC-S-driven transduction, suggesting that the viral receptor is broadly expressed. The nature of the receptor remains to be explored, since none of the known coronavirus receptors augmented EMC-S-dependent transduction. Inhibitors of cathepsins B and L and TMPRSS2 blocked EMC-S-dependent virus-cell fusion, indicating that EMC-S can use redundant proteolytic pathways to ensure its activation. Finally, serum from an hCoV-EMC-infected patient inhibited EMC-S- but not VSV-Gor SARS-S-driven transduction, indicating that S-protein-specific neutralizing antibodies are generated in patients and might contribute to control of hCoV-EMC infection. Our results reveal important insights into the molecular processes underlying hCoVEMC entry into host cells and define targets for intervention.

The incorporation of foreign glycoproteins into lentiviral particles, termed pseudotyping, offers an efficient means of studying host cell entry of highly pathogenic viruses without the need for a high level of biocontainment. Pseudotyping has been used successfully in the past to study the host cell entry of coronaviruses, including SARS-CoV $(37,39)$, and proved to be a suitable tool to analyze the entry of hCoV-EMC. Thus, EMC-S was efficiently incorporated into lentiviral particles, and pseudotypes bearing EMC-S were able to readily transduce a panel of human cell lines, including cells derived from the colon, liver, kidney, and lung. Whether these cell lines are also susceptible to infection by authentic hCoV-EMC and adequately mimic infection of primary cells remains to be determined. The susceptibility of lung-derived cell lines to EMC-S-mediated transduction was expected, since the virus causes severe respiratory disease and was isolated from sputum (8). The susceptibility of intestine- and kidney-derived cell lines is notable because these organs are also targeted by SARS$\mathrm{CoV}(48,49)$. The invasion of the intestines by SARS-CoV might account for the diarrhea frequently observed in SARS cases (50), while viral spread to the kidney might promote renal failure (51), a symptom occasionally associated with SARS-CoV infection. Five of the nine hCoV-EMC-infected patients documented up to December 2012 developed renal failure (9), and it is thus conceivable that hCoV-EMC, like SARS-CoV, is capable of extrapulmonary spread, which might account for certain aspects of the disease presentation.

The observation that SARS-CoV and hCoV-EMC both infect certain kidney- and colon-derived cell lines $(8,17,52,53)$ indicates that these viruses might use the same receptor for host cell entry, i.e., ACE2. Alternatively, hCoV-EMC might have adapted to use one of the other previously identified coronavirus receptor proteins, i.e, CD13 (15) or CEACAM-1 (19). However, directed expression of these receptors did not augment EMC-S-driven transduction of target cells, while transduction mediated by control S proteins was enhanced, demonstrating that EMC-S did not adapt to use any of the known coronavirus receptors. This conclusion is in keeping with results reported by Muller and colleagues, who recently demonstrated that hCoV-EMC does not use ACE2 for entry (53). Which cellular receptor is bound by EMC-S and whether binding is mediated by a receptor binding site proposed on the basis of bioinformatic analysis (54) remain to be determined. As was done for the identification of the SARS-CoV receptor ACE2 (17), coimmunoprecipitation followed by mass spectrometric identification of binding partners might be a suitable way to identify the elusive hCoV-EMC receptor. The observation that THP-1 cells acquire susceptibility to EMC-S-driven transduction upon differentiation into macrophages, most likely because of upregulation of receptor expression, might aid in these endeavors. 
The coronavirus S proteins characterized so far are class I membrane fusion proteins. A characteristic of class I membrane fusion proteins is their need for proteolytic activation (40). 'Thus, the proteins are synthesized as inactive precursors which transit into an active state only upon proteolysis. $A$ seminal study showed that SARS-S, like EBOV-GP, is activated by the pH-dependent endosomal cysteine proteases cathepsins B and L during uptake of virions into target cells (22). Inhibitors of cathepsins B and L, such as MDL 28170 , are available, and their development as therapeutics for coronavirus and filovirus infection has been proposed (22, 55). However, recent studies demonstrated that the type II transmembrane serine proteases TMPRSS2 and HAT, which were initially shown to activate influenza viruses (56), also activate SARS-S and that activation by TMPRSS2 renders SARS-S-mediated entry cathepsin B/L independent (24-28). TMPRSS2 and HAT are coexpressed with ACE2 in human respiratory epithelium (57), and TMPRSS2 was shown to contribute to SARS-S activation in cultured human airway-derived cells (28), indicating that TMPRSS2-mediated SARS-S activation might be operative in vivo.

In contrast to SARS-S, EMC-S is efficiently cleaved in transfected cells, and likely also in infected cells. The nature of the responsible proteolytic activity and the biological relevance of cleavage are unknown at present. Although EMC-S is cleaved in transfected cells and processed $\mathrm{S}$ protein is incorporated into virions, further processing by host cell proteases during viral entry is required for EMC-S activation. A similar observation has been documented for EBOV-GP, which is processed by furin in infected cells (58) but requires cathepsin activity in target cells in order to facilitate infectious entry (42). EMC-S can be activated by cathepsin $B / L$, as demonstrated by inhibition of EMC-S-dependent transduction by the cathepsin B/L inhibitor MDI.28170. In addition, EMC-S can be processed and activated by TMPRSS2 for cathepsin $\mathrm{B} / \mathrm{L}$-independent entry. Thus, EMC-S, like SARS-S, is activated by endosomal cathepsins and type II transmembrane serine proteases in cell culture, suggesting that the activities of both proteases must be blocked in patients in order to efficiently suppress viral replication.

Coronavirus $S$ proteins are major targets for neutralizing antibodies $(37,39,59,60)$, and the observation that serum from an hCoV-EMC-infected patient specifically neutralized EMC-S but not VSV-G or SARS-S is in keeping with this notion. Notably, work published during the revision of the present article demonstrated that the patient serum we used also neutralizes authentic hCoV-EMC (61), indicating that the pseudoparticle system adequately mirrors neutralization of authentic hCoV-EMC. Whether the neutralizing antibodies contributed to control of hCoV-EMC infection or were produced largely after the viral spread subsided is at present unknown. Regardless of the role of neutralizing antibodies, the easy detection of neutralizing activity present in human serum by the vector systems used here suggests that this tool might prove useful in determining the frequency of hCoV-EMC infection in patients and the potential cross-reactivity of serum with other coronavirus S proteins. Our initial analysis demonstrates that antibodies generated in hCoV-EMC-infected patients do not cross-neutralize SARS-S. Whether the same is true for the more closely related S proteins of HKU4 and HKU5 remains to be investigated.

In sum, the present study provides important insights into hCoV-EMC cell tropism and should contribute to our under- standing of the pathogenesis of this virus. In addition, it demonstrates that hCoV-EMC uses a novel receptor for cellular entry, and it defines host cell enzymes important for activation of EMC-S, which might constitute targets for intervention. Finally, the study identifies pseudotypes as a valuable tool for the detection of neutralizing antibodies directed against EMC-S, a finding that has important implications for diagnostic approaches and efforts to characterize the humoral immune response in hCoV-EMCinfected patients.

\section{ACKNOWLEDGMENTS}

We thank A. Krueger and N. Meyer for technical assistance and all members of our group for helpful discussions.

This work was supported by BMBE, SARS Verbund (grant 01KI1005C to S.G., A.H., C.D., and S.P.), the Letbniz Graduate School ElDIS (F.W.), SFB 900 (K.W.), the Letbniz Foundation, and grant R01Al074986 from the National Institute of Allergy and Infectious Diseases (G.S.).

\section{REFERENCES}

1. Bradburne AF, Bynoe ML, Tyrrell DA. 1967. Effects of a "new" hurman respiratory virus in volunteers. Br. Med. J. 3:767-769.

2. Holmes KV. 2001. Coronaviruses, p 1187-1203. In Knipe DM, Howley PM, Griffin DE, Lamb RA, Martin MA, Roizman B, Straus SE (ed), Fields virology, 4th ed. Lippincott Williams \& Wilkins, Philadelphiz, PA.

3. Peiris JS, Guan Y, Yuen KY. 2004. Severe acute respiratory syndrome. Nat. Med. 10:588_s97.

4. Lau SK, Woo PC, Li KS, Huang Y, Tsoi HW, Wong BH, Wong SS, leung SY, Chan KH, Yuen KY. 2005. Severe acute respiratory syndrame coronavirus-like virus in Chinese horseshoe bats. Proc. Natl. Acad. Sci. coronavirus-like virus in Chin

5. Li W, Shi Z, Yu M, Ren W, Smith C, Epstein JH, Wang H, Crameri G, Hu Z, Zhang H, Zhang J, McFachern J, Field H, Daszak P, Faton BT, Zhang S, Wang L.F. 2005. Bats are natural reservoirs of SARS-like coronaviruses. Science 310:676-679.

6. Guan $\mathrm{Y}$, Zheng BJ, He YQ, Liu XI, Zhuang ZX, Cheung Cl, Lao SW, Li PH, Zhang L, Guan Y], Butt KM, Wong KL, Chan KW, Lim W, Shortridge KF, Yuen KY, Peiris IS, Poon L. 2003. Isolation and characterization of viruses related to the SARS coronavirus from animals in acterization of viruses related to the SARS

7. Pyrc K, Berkhout B, van der Hoek L. 2007. The novel human coronaviruses NL63 and HKUI. J. ViroL. 81:3051-3057.

8. Zaki AM, van Boheemen S, Bestebroer TM, Osterhaus AD, Fouchier RA. 2012. Isolation of a novel coronavirus from $a$ man with pneumonia in Saudi Arabiz. N. Engl. J. Med. 367:1814-1820.

9. World Heal th Organization. 2012. Background and summary of novel coronavirus infection-as of 21 Decernber. World Health Organization, Geneva,
Switzerland. hatp://www.who.int/cor/divease/coronavirus_infections/update 20121221/en/index.html.

10. World Health Organization. 21 February2013. Novel coronavirus infection—update. World Health Organization, Geneva, Switzerland. http: //www.who.int/csr/don/2013_02_21/en/index.html.

11. Annan A, Baldwin HJ, Corman V, Klose SM, Owusu M, Nkrumah EE, Badu EK, Anti P, Asbenyega O, Meyer B, Oppong S, Sarkodie YA, Kalko EXV, lina PHC, Godlevska EV, Reusken C, Seebens A, Gloza Rausc F, Vallo P, Tschapka M, Drosten C, Drexler I. 2013. Hurza betacoronavirus 2c EMC/2012-related viruses in bats, Chana and Europe. Emerg. Infect. Dis. 19:456-459.

12. Belouzard S, Millet JK, Licitra BN, Whittaker GR. 2012. Mechanisms of coronavirus cell entry mediated by the viral spike protein. Viruses 4:10111033.

13. Heald-Sargent T, Gallagher T. 2012. Ready, set, fuse! The coronavirus spike protein and acquisition of fusion competence. Viruses 4:557-580.

14. Kuo I, Godeke GJ, Raamsman MJ, Masters PS, Rottier PJ. 2000. Retargeting of coronavirus by substitution of the spike glycoprotein ectoResargeting of coronavirus by substitution of the spike glycoprotein ecto-

15. Yeager CI, Ashmun RA, Williams RK, Cardellichio CB, Shapiro L.H, Look AT, Holmes KV. 1992. Human aminopeptidase $\mathrm{N}$ is a receptor for hurnan coronavirus 229E. Nature 357:420-422.

16. Hofmann H, Pyrc K, van der Hoek L, Geier M, Berkhout B, Pohlmann 
S. 2005. Human coronavirus NL.63 employs the severe acute respiratory syndrome coronavirus receptor for cellular entry. Proc. Natl. Acad. Sci. U. S. A. 102:7988-7993.

17. Li W, Moore MJ, Vasilieva N, Sui J, Wong SK, Berne MA, Somasundaran $M$, Sullivan $\mathrm{JL}_{\text {, Luzuriaga }} \mathrm{K}$, Greenough $\mathrm{TC}_{\text {, }}$ Choe $\mathrm{H}_{\text {, }}$ Farzan M. 2003. Angiotensin-converting enzyme 2 is a functional receptor for the SARS coronavirus. Nature 426:450-454.

18. Vlasak R, Luytjes W, Spaan W, Palese P. 1988. Human and bovine coronaviruses recognize sialic acid-containing receptors similar to those of influenza C viruses. Proc. Natl. Acad. Sci. U. S. A. 85:45264529 .

19. Walliams RK, Jing GS, Holmes KV. 1991. Receptor for mouse hepatitis virus is a member of the carcinoembryonic antigen family of glycoproteins. Proc. Natl. Acad. Sci. U. S. A. 88:5533-5536.

20. Baric RS, Sullivan E, Hensley L, Yount B, Chen W. 1999. Persistent infection promotes cross-species transmissibility of mouse hepatitis virus. J. Virol. 73:638-649.

21. McRoy WC, Baric RS. 2008. Amino acid substitutions in the $\$ 2$ subunit of mouse hepatitis virus variant V51 encode determinants of host range expansion. J. Virol. 82:1414-1424.

22. Simmons G, Gosalia DN, Rennekamp AJ, Reeves JD, Diamond SI, Bates P. 2005. Inhibitors of cathepsin L prevent severe acute respiratory syndrome coronavirus entry. Proc. Natl. Acad. Sci. U. S. A. 102:11876syndrom 11881 .

23. Kawase M, Shirato K, Matsuyama S, Taguchi F. 2009. Proteasemediated entry via the endosome of human coronavirus 229E. J. Virol. 83:712-721.

24. Bertram S, Glowacka I, Muller MA, Lavender H, Gnirss K, Nehlmeier I, Niemeyer D, He Y, Simmons G, Drosten C, Soilleux EJ, Jahn O, Steffen I, Pohlmann S. 2011. Cleavage and activation of the severe acute respiratory syndrome coronavirus spike protein by human airway trypsinlike protease. J. Virol. 85:13363-13372.

25. Glowadka I, Bertram S, Muller MA, Allen P, Soilleux E, Pfefferle S, Steffen I, Tsegaye TS, He Y, Gnirss K, Niemeyer D, Schneider H, Drosten C, Pohlmann S. 2011. Evidence that TMPRSS2 activates the severe acute respiratory syndrome coronavirus spike protein for mem. brane fusion and reduces viral control by the humoral immune response. J. Virol. 85:4122-4134.

26. Matsuyama $S$, Nagata $N$, Shirato $K$, Kawase $M$, Takeda M, Taguchi F. 2010 . Efficient activation of the severe acute respiratory syndrome coronavirus spike protein by the transmembrane protease TMPRSS2. J. Virol. 84:12658-12664.

27. Shulla A, Heald-Sargent T, Subramanya G, Zhwo J, Perlman S, Gallagher T. 2011. A transmembrane serine protesse is linked to the severe acute respiratory syndrome coronavirus receptor and activates virus entry. J. Virol. 85-873-882

28. Kawase M, Shirato K, van der Hoek L. Taguchi F, Matsuyama S. 2012. Simultaneous treatment of human bronchial epithelial cells with serine and cysteine protease inhibitors prevents severe acute respiratory syndrome coronavirus entry. J. Virol. 8606537-6545.

29. Glowadka I, Bertram S, Herzog P, Pfefferle S, Steffen I, Muench MO, Simmons G, Hofmann H, Kuri T, Weber F, Eichler J, Drosten C, Pohlmann S. 2010. Differential downregulation of ACE2 by the spike proteins of severe acute respiratory syndrome coronavirus and human proteins of severe acute respiratory syndrom
coronavirus NL63. J. Virol. 84:1198-1205.

30. Hofmann H, Simmons G, Rennekamp AJ, Chaipan C, Gramberg T, Heck E, Geier M, Wegele A, Marzi A, Bates P, Pohlmann S. 2006. Highly conserved regions within the spike proteins of human coronaviruses $229 \mathrm{E}$ and N1.63 determine recognition of their respective cellular receptors. J. Virol. 80-8639-8652.

31. Simmons G, Reeves JD, Grogan CC, Vandenberghe LH, Baribaud F, Whitbeck JC, Burke E, Buchmeier MJ, Soilleux EJ, Riley JL, Doms RW, Bates P, Pohlmann S. 2003. DC-SICN and DC-SIGNR bind Ebola glyBates P, Pohlmann S. 2003. DC-SICN and DC-SIGNR bind Ebola gly-
coproteins and enhance infection of macrophages and endothelial cells. Virology 305:115-123.

32. Bertram S, Glowacka I, Blazejewska P, Soilleux E, Allen P, Danisch S, Steffen I, Choi SY, Park Y, Schneider H, Schughart K, Pohlmann S. 2010. TMPRSS2 and TMPRSS4 facilitate trypsin-independent spread of influenza virus in Caco-2 cells. J. Virol. 84:10016-10025.

33. Jung H, Lee KP, Park SI, Park JH, Jang YS, Choi SY, Jung JG, Jo K, Park DY, Yoon JH, Park JH, Lim DS, Hong GR, Choi C, Park YK, Lee JW, Hong HJ, Kim S, Park YW. 2005. TMPRSS4 promotes invasion, migra- tion and metastasis of human tumor cells by facilitating an epithelialmesenchymal transition. Oncogene 27:2635-2647.

34. Shirogane $Y$, Takeda $M$, Iwasaki $M$, Ishiguro $N$, Takeuchi $H$, Nakatsu Y, Tahara M, Kikuta H, Yanagi Y. 2008. Efficient multiplication of human metapneumovirus in Vero cells expressing the transmembrane serine protezse TMPRSS2. J. ViroL 82:8942-8946.

35. Gao F, Li Y, Decker JM, Peyerl FW, Bibollet-Ruche F, Rodenburg CM, Chen Y, Shaw DR, Allen S, Musonda R, Shaw GM, Zajac AJ، Letvin N, Hahn BH. 2003. Codon usage optimization of HIV type 1 subtype $\mathrm{C}_{\text {gag. }}$ pol, env, and nef genes: in vitro expression and immune responses in DNA-vaccinated mice. AIDS Res. Hum. Retroviruses 19: $817-823$.

36. Evans MJ, von Hahn T, Tscherne DM, Syder AJ, Panis M, Wolk B, Hatziioannou T, McKeating JA, Bieniasz PD, Rice CM. 2007. Claudin-1 is a hepatitis $\mathrm{C}$ virus co-receptar required for a late step in entry. Nature 446:801-805.

37. Hofmann $\mathrm{H}$, Hattermann K, Marri A, Gramberg T, Geier M, Krumbiegel M, Kuate S, Uberla K, Niedrig M, Pohlmann S. 2004. S protein of severe acute respiratory syndrome-associated coronavirus mediates entry into hepatoma cell lines and is targeted by neutralizing antibodies in infected patients. J. Virol. 78-6134-6142.

38. Moore MJ, Dorfman T, Li W, Wong SK, Li Y, Kuhn JH, Coderre J, Vasilieva N, Han Z, Greenough TC, Farzan M, Choe H. 2004. Retroviruses pseudotyped with the severe acute respiratory syndrome coronavirus spike protein efficiently infect cells expressing angiotensinconverting enxyme 2. J. Virol. 78:10628-10635.

39. Simmons G, Reeves ID, Rennekamp AJ, Amberg SM, Piefer AJ, Bates P. 2004. Characterization of severe acute respiratory syndrome-associated 2004. Characterization of severe acute respiratory syndrome-associated
coronavirus (SARS-CoV) spike glycoprotein-mediated viral entry. Proc. Natl. Acad. Sci. U. S. A. 101:42 $40-4245$.

40. Kielian M, Rey FA. 2006. Virus membrane-fusion proteins: more than one way to make a huirpin. Nat. Rev. MicrobioL. 4:67-76.

41. White JM, Delos SE, Brecher M, Schornberg K. 2008. Structures and mechanisms of viral membrane fusion proteins multiple variations on a common theme. Crit. Rev. Biochem. Mol. Biol. 43:189-219.

42 Chandran K. S ullivan NI, Fellhor U, Whelan SP, Cunningham JM. 2005. Chandran K, Sullivan NJ, Felbor U, Whelan SP, Cunningham JM. 2005. .
Endosomal proteolysis of the Ebola virus glycoprotein is necessary for infection. Science 308: 1643-1645.

43. MoClure MO, Marsh M, Weiss RA. 1988. Human immunodeficiency virus infection of CD4-bearing cells occurs by a pH-independent mechanism. EMBO J. 7:513-518.

44. MoClure MO, Sommerfelt MA, Marsh M, Weiss RA. 1990. The pH independence of mammalian retrovirus infection. J. Gen. Virol. 71:767773 .

45. Superti F, Seganti L, Ruggeri FM, Tinari A, Donelli G, Orsi N. 1987. Entry pathway of vesicular stomatitis virus into different host cells. J. Gen. Virol. 68:387-399.

46. Karesh WB, Dobson A, Loyd-Smith JO, Lubroth J, Dixon MA, Bennett M, Aldrich S, Harrington T, Formenty P, Loh EH, Machalaba CC, Thomas MJ, Heymann DL 2012. Ecology of xoonoses: natural and unnatural histories. lancet 380:1936-1945.

47. Chan JF, Li KS, To KK, Cheng VC, Chen H, Yuen KY. 2012. Is the discovery of the novd human betacoronavirus $2 c$ EMC/2012 (HCOV-EMC) the beginning of another SARS-like pandemic? J. Infect. $650477-489$.

48. Farcas GA, Poutanen SM, Mazzulli T, Willey BM, Butany J, Asa SL, Faure P, Akhavan P, Low DE, Kain KC. 2005. Fatal severe acute respiratory syndrome is associated with multiorgan involvement by coronavirus. J. Infect. Dis. 191:193-197.

49. Gu J, Gong E, Zhang B, Zheng J, Gao Z, Zhong Y, Zou W, Zhan J. Wang S, Xie Z, Zhuang H, Wu B, Zhong H, Shao H, Fang W, Gao D, Pei F, Li X, He Z, Xa D, Shi X, Anderson VM, Leong AS. 2005. Multiple organ infection and the pathogenesis of SARS. I. Exp. Med. 202:415-424.

50. Kwan AC, Chau TN, Tong WL, Tsang OT, Tso EY, Chiu MC, Yu WC, Lai TS. 2005. Severe acute respinatory syndrome-related diarrhez. J. Gastroenterol. Hepatol. 20:606-610.

51. Huang JW, Chen KY, Tsai HB, Wu VC, Yang YF, Wu MS, Chu TS, Wu KD. 2005. Acute renal failure in patients with severe acute respiratory syndrome. J. Formos. Med. Assoc. 104:891-896.

52. Cinatl J, Jr, Hoever G, Morgenstern B, Preiser W, Vogel JU, Hofmann WK, Bauer G, Michaelis M, Rabenau HB, Doerr HW. 2004. Infection of cultured intestinal epithelial cells with severe acute respiratory syndrome coronavirus. Cell. MoL Life Sci. 61:2100-2112. 
53. Moller MA, Raj VS, Muth D, Meyer B, Kallies S, Smits SL, Wollny R, Bestebroer TM, Specht S, Suliman T, Zimmermann K, Binger T, Eckerle I, Tschapka M, Zaki AM, Osterhaus AD, Fouchier RA, Haagmans BL, Drosten C. 2012. Human coronavirus EMC does not require the SARS-coronavirus receptor and maintains broad replicative capability in mammalian cell lines. mBio 3:e0515-12 doi:10.1128 imBio.00515-12.

54. liang S, Lu L, Du L, Debnath AK. 22 December 2012. A predicted receptor-binding and critical neutralizing domain in $\mathrm{S}$ protein of the novel human coronavirus HCoV-EMC. J. Infect. doi:10.1016/j.jinf novel human
.2012 .12 .003 .

55. Zhou Y, Simmons G. 2012. Development of novel entry inhibitors targeting emerging viruses. Expert Rev. Anti Infect. Ther. 10:1129. 1138 .

56. Bottcher E, Matrosovich T, Beyerle M, Klenk HD, Garten W, Matrosovich M. 2006. Proteolytic activation of influenza viruses by serine proteases TMPRSS2 and HAT from human airway epithelium. J. ViroL 80 : 9896-9.988.

57. Bertram S, Heurich A, Lavender H, Gierer S, Danisch S, Perin P, Lacas JM, Nelson PS, Pohlmann S, Soilleux EJ. 2012. Influenza and SARS. coronavirus activating proteases TMPRSS2 and HAT are expressed at multiple sites in human respiratory and gastrointestinal tracts. PLoS One 7:e35876. doi:10.1371/journal.pone.0035876.

58. Volchkov VE, Feldmann H, Volchkova VA, Klenk HD. 1998. Processing of the Fbola virus glycoprotein by the proprotein convertase furin. Proc. Natl. Acad. Sci. U.S. A. 95:5762-5767.

59. Godet M, Grosclaude J, Delmas B, Laude H. 1994. Major receptorbinding and neutralization determinants are located within the same domain of the transmissible gastroenteritis virus (coronavirus) spike protein. J. Virol. 68:8008-8016.

60. Reguera J, Santiago C, Mudgal G, Ordono D, Enjuanes L, Casasnovas JM. 2012. Structural bases of coronavirus attachment to host aminopeptidase $\mathrm{N}$ and its inhibition by neutralizing antibodies. PLoS Pathog. 8:e1002859. doi:10.1371/journal.ppat.1002859.

61. Buchholz U, Maller M, Nitsche A, Sanewski A, Wevering N, BauerBalci T, Bonin F, Drosten C, Schweiger B, Wolff T, Muth D, Meyer B, Suda S, Krause G, Schade L, Hass W. 2013. Contact investigation B, Suda S, Krause G, Schade L, Hass W. 2013. Contact investigation of a case of human novel coronavirus infection treated in a German //www.eurosurveillance.org/ViewArticle.aspx?Articleld-20406. 
Second Manuscript 
Inhibition of proprotein convertases abrogates processing of the MERScoronavirus spike protein in infected cells but does not reduce viral infectivity

Stefanie Gierer, ${ }^{1}$ Marcel A. Müller, ${ }^{2}$ Adeline Heurich, ${ }^{1}$ Daniel Ritz, ${ }^{2}$ Benjamin Springstein, ${ }^{1}$

Christina B. Karsten, ${ }^{1}$ Alexander Schendzielorz, ${ }^{1}$ Kerstin Gnir $B,{ }^{1}$ Christian Drosten, ${ }^{2}$

Stefan Pöhlmann, ${ }^{1, *}$

German Primate Center, Göttingen, Germany'; Institute of Virology, University of Bonn Medical Centre, Bonn, Germany ${ }^{2}$

${ }^{*}$ Corresponding author. Please direct correspondence to: Infection Biology Unit, German Primate Center, Kellnerweg 4, 37077 Göttingen, Germany. Phone: +49 5513851 150, Fax: +49 5513851

184, E-mail: spoehlmann@dpz.eu

Running title: Role of proprotein convertases in MERS-coronavirus infection

Key words: MERS, protease, TMPRSS2, trypsin, pro-protein convertase 
Middle East respiratory syndrome coronavirus (MERS-CoV) infection is associated with a high-case fatality rate and the potential pandemic spread of the virus is a public health concern. The spike protein of MERS-CoV (MERS-S) facilitates viral entry into host cells, which depends on activation of MERS-S by cellular proteases. Proteolytic activation of MERS-S during viral uptake into target cells has been demonstrated. However, it is unclear whether MERS-S is also cleaved during $S$ protein synthesis in infected cells and whether cleavage is required for MERS-CoV infectivity. Here, we show that MERS-S is processed by proprotein convertases in MERS-S transfected and MERS-CoV infected cells and that several RXXR motifs located at the border between the surface and transmembrane subunit of MERS-S are required for efficient proteolysis. However, blockade of proprotein convertases did not impact MERS-S-dependent transduction of target cells expressing high amounts of the viral receptor, DPP4, and did not modulate MERS-CoV infectivity. These results show that MERS-S is a substrate for proprotein convertases and demonstrate that processing by these enzymes is dispensable for $\mathrm{S}$ protein activation. Efforts to inhibit MERS-CoV infection by targeting host cell proteases should therefore focus on enzymes which process MERS-S during viral uptake into target cells. 


\section{SIGNIFICANCE}

The spread of the emerging Middle East respiratory syndrome coronavirus (MERS-CoV) caused 80 deaths so far and the identification of novel antiviral strategies is an important task. The viral infectivity depends on proteolytic activation of the spike protein by host cell proteases and the responsible enzymes constitute potential targets for intervention. We and others could previously show that the spike protein can be cleaved and activated during viral entry. In the present study we demonstrate that the spike protein is also cleaved during biosynthesis in infected cells and we identify proprotein convertases as the responsible enzymes. However, processing of the spike protein by these proteases was found to be dispensable for viral infectivity. These results provide valuable insights into MERS-CoV interactions with host cells and suggest that, unlike for other viral infections, proprotein convertase activity is not a suitable target for antiviral strategies. 


\section{INTRODUCTION}

The emergence and subsequent pandemic spread of the severe acute respiratory syndrome coronavirus in 2002/2003 caused almost 800 deaths and wrecked enormous economic havoc ( 1 , 2). The virus was transmitted from bats, potentially via intermediate hosts, to humans demonstrating that the zoonotic transmission of novel coronaviruses from animal reservoirs to humans can pose a significant threat to public health $(3,4)$. A similar outbreak scenario unfolded in 2012 when a novel coronavirus, initially named coronavirus EMC and now termed Middle East respiratory syndrome coronavirus (MERS-CoV) (5), was detected in a patient from Jordan hospitalized with a severe and ultimately fatal pneumonia (6). Subsequently, the virus spread within the Middle East and, due to travel activity, occasionally to Europe (7-10). The outbreak so far entailed 189 laboratory confirmed infections and 82 deaths (as of March 12, 2014) (11) and adaptation of the virus to more efficient human-to-human spread is a public health concern (12). Therefore, it is imperative to identify and explore novel targets for antiviral therapy.

The viral surface protein spike (S), a type I transmembrane protein synthesized in the constitutive secretory pathway of infected cells, mediates coronavirus entry into target cells (13, 14). For this, the MERS-CoV spike protein (MERS-S) binds to its receptor dipeptidylpeptidase (DPP4, CD26) on the surface of target cells $(15,16)$ and drives fusion of the viral envelope with a target cell membrane, which allows delivery of viral proteins and RNA into the host cell cytoplasm, the site of viral replication. However, MERS-S and other coronavirus $\mathrm{S}$ proteins are synthesized as inactive precursors in infected cells and only acquire the ability to drive membrane fusion upon processing into the surface unit (S1) and the transmembrane unit (S2) by host cell proteases $(17,18)$. The activity of the responsible proteases is essential for viral infectivity, which makes these enzymes potential targets for antiviral intervention. In fact, all viral glycoproteins with a domain organization comparable to that of MERS-S, which are collectively termed class I 
membrane fusion proteins, depend on proteolytic cleavage to unfold their fusogenic potential (19). Specifically, cleavage can prime viral glycoproteins for a subsequent trigger of the membrane fusion reaction, like low $\mathrm{pH}$, as is the case for the influenza virus hemagglutinin (20). Alternatively, cleavage can directly activate glycoproteins for the membrane fusion reaction, as is suspected for MERS-S and other coronavirus S proteins (18).

It has been demonstrated that the cysteine protease cathepsin $L(17,21)$, the type II transmembrane serine protease TMPRSS2 $(17,21,22)$ and a so far unidentified enzyme (21) can activate MERS-S during viral uptake into target cells. Cathepsin $\mathrm{L}$ and TMPRSS2 are also hijacked by other coronaviruses for viral activation (23-27) and TMPRSS2 has recently been shown to be essential for activation of H1N1 influenza viruses in mice (28). However, priming of viral glycoproteins, including priming of the $\mathrm{S}$ protein of certain strains of the coronavirus infectious bronchitis virus (IBV) (29), may also proceed in the constitutive secretory pathway of infected cells and is often accomplished by furin and other proprotein convertases (30-33). Whether MERS-S is also cleaved during the passage of the secretory pathway and whether these cleavage events contribute to $S$ protein activation is at present unknown.

Here, we show that proprotein convertases process MERS-S in transfected and infected cells and we demonstrate that the integrity of several RXXR motifs located at the border of the $\mathrm{S} 1$ and $\mathrm{S} 2$ subunit is required for $\mathrm{S}$ protein processing. Similarly, treatment of MERS-CoV infected cells with a proprotein convertase inhibitor abrogated $\mathrm{S}$ protein cleavage but did not alter viral infectivity, indicating that $\mathrm{S}$ protein processing in infected cells is dispensable for MERS-S activation. 


\section{MATERIAL AND METHODS}

Plasmids. Expression plasmids encoding MERS-S (17), vesicular stomatitis virus glycoprotein (VSV-G) (34), Zaire ebolavirus glycoprotein (EBOV-GP) (34), Lassa virus glycoprotein (LASVGPC) (34), DPP4 (16) and TMPRSS2 (24) have been described previously. Plasmids pGAL4VP16 (35), pGAL5-luc (35), pNL4-3-Luc-R'E- (36), p96ZM651gag-opt (37) as well as plasmids encoding MERS-S (17) and EBOV-GP (38) with C-terminal V5 tag have also been described, A construct expressing LASV-GPC with a C-terminal V5 tag was generated by PCR-based mutagenesis using the primers $5^{\circ}$-GCGCCCGGGGGATGGGACAAATAGTGACATTC- 3 and

\section{5 '-CGCGCTAGCCCTCACGTAGAATCGAGACCGAGGAGAGGGTTAGGGATAGGCT}

TACCTCTCTTCCATTTCACAGG-3'and inserted into plasmid pCAGGS via the Nhel and SmaI restriction sites. Mutagenesis of MERS-S was performed by overlap extension polymerase chain reaction (PCR), resulting in MERS-S potential cleavage site mutants (PCM) 1 (626-AXXA-629), PCM2 (691-AXXA-694), PCM3 (748-AXXA-751) and PCM4 (884-AXXA-887) containing a V5 tag. For the generation of these mutants the following oligonucleotides were used as inner primers: 5'-GCACAGCTGTAGGTGTTGCACAGCAGGCCTTTGTTTATGATGCG-3' and $5^{\prime}$-GGTACGCATCATAAACAAAGGCCTGCTGTGCAACACCTACAGCTGTGC-3 ${ }^{\circ}$ (mutant PCM1), 5'-CCATGTCTCAATACTCCGCTTCTACGGCATCAATGC-3' and 5'-CGCCGTT TAAGCATTGATGCCGTAGAAGCGGAGTATTGAGACATGG-3’ (mutant PCM2), 5 '-CCTA GTACTCTCACACCTGCCAGTGTGGCCTCTGTTCCAGG-3' and 5'-GCCAAGCGCATT TCACCTGGAACAGAGGCCACACTGGCAGGTGTGAGAGTACTAGG-3' (mutant PCM3) and $5^{\prime}$-CCTGTTTCTATATCTACTGGCAGTGCTAGTGCAGCTAGTGC- 3 ' and 5 -GCAAAT CCTCAATAGCACTAGCTGCACTAGCACTGCCAGTAGATATAGAAACAGG-3' (mutant PCM4), Oligonucleotides 5'-GATCGGTACCACCACCATGATACACT-3' and 5'-GCTG 


\section{GACCTTGCTGCATGCAATCATCGTAACCTTGCATATAACCAGG-3' served as outer} primers. The PCR products were cloned into pCAGGS via KpnI and SphI restriction sites. The integrity of all PCR amplified sequences was confirmed by automated sequence analysis.

Cell culture. 293T cells were propagated in Dulbecco's modified Eagle's medium (DMEM; Life Technologies) supplemented with 10\% fetal bovine serum (FBS, PAN-Biotech), penicillin and streptomycin, Caco-2 cells were cultured in DMEM-GlutaMAX medium (Invitrogen) supplemented with $10 \%$ FBS, penicillin and streptomycin. Vero B4 cells were cultured in DMEM supplemented with $5 \% \mathrm{FBS}, 1 \% \mathrm{~L}$-glutamine, $1 \%$ sodium pyruvate, $1 \%$ nonessential amino acids (all from Life Technologies) and antibiotics as stated above. All cell lines were grown in humidified atmosphere at $37^{\circ} \mathrm{C}$ and $5 \% \mathrm{CO}_{2}$

Analysis of MERS-S expression and cleavage. For the detection of the expression of MERS-S wt and MERS-S mutants in transfected cells, 293T cells were calcium phosphate transfected with the respective plasmids encoding $\mathrm{S}$ proteins with C-terminal V5 antigenic tag. For analysis of MERS-S processing by TMPRSS2, a TMPRSS2 expression plasmid was cotransfected. The transfection medium was replaced at $8 \mathrm{~h}$ post-transfection with fresh culture medium and cells were harvested at $48 \mathrm{~h}$ post-transfection. The harvested cells were either treated with trypsin (Sigma, $25 \mu \mathrm{g} / \mathrm{ml}$ final concentration) or PBS for $10 \mathrm{~min}$ and then lysed in sodium dodecyl sulfate (SDS) loading buffer. For immunoblotting, the lysates were separated by SDS-gel electrophoresis and transferred onto nitrocellulose membranes (Hartenstein). MERS-S expression was detected using a monoclonal antibody directed against the V5 tag (Invitrogen) or a polyclonal antibody directed against the S2 subunit of the MERS-S protein (Sino Biological Inc.). For detection of MERS-S protein in infected cells, Caco2 and VeroB4 cells were infected with 
MERS-CoV (human betacoronavirus $2 \mathrm{c} \mathrm{EMC/2012)} \mathrm{at} \mathrm{an} \mathrm{MOI} \mathrm{of} 0.01$ and 5, respectively. At 24 $h$ post infection, the cells were harvested and treated with NuPAGE LDS sample buffer (Invitrogen), boiled for $20 \mathrm{~min}$ at $95^{\circ} \mathrm{C}$ and analyzed by Western blot as described above. As a loading control the membranes were incubated with anti- $\beta$-actin antibody (Sigma).

Analysis of MERS-S incorporation into virus-like particles. For the production of virus-like particles (VLPs), 293T cells were cotransfected with the HIV-1 Gag (p55)-encoding plasmid p96ZM651gag-opt and plasmids encoding MERS-S wt or MERS-S mutants. Cotransfection of empty plasmid served as negative control. The transfection medium (i.e. culture medium after addition of transfection reagents) was replaced by fresh culture medium at $8 \mathrm{~h}$ post transfection and supernatants containing VLPs were harvested at $48 \mathrm{~h}$ post transfection. The supernatants were sterile-filtered using $0.45 \mu \mathrm{m}$ pore-size filters (Sartorius) and concentrated by ultracentrifugation through a $20 \%$ sucrose cushion at $20,000 \mathrm{~g}$ for $2 \mathrm{~h}$ at $4^{\circ} \mathrm{C}$. Pellets were resuspended in TNE buffer ( $0.01 \mathrm{M}$ Tris- $\mathrm{HCl}, \mathrm{pH} 7.4 ; 0.15 \mathrm{M} \mathrm{NaCl} ; 2 \mathrm{mM}$ EDTA), $2 \times$ SDS loading buffer was added and the samples analyzed by Western blot for expression of MERS-S, as described above, and for expression of p55 Gag employing supernatants of hybridoma 182H12-5C (AIDS Reagent Program, Division of AIDS, NIAID, NIH), which produces an antibody directed against the p24-capsid protein.

Cell-cell fusion assay. The cell-cell fusion assay was carried out as described before (24). In brief, $293 \mathrm{~T}$ effector cells were seeded in six-well plates and calcium phosphate transfected with either empty plasmid as negative control or plasmids encoding MERS-S wt and MERS-S mutants in combination with plasmid pGAL4-VP16, which encodes the herpes simplex virus VP16 transactivator fused to the DNA binding domain of the yeast transcription factor GAL4. In 
parallel, 293T target cells were seeded in 48-well plates and cotransfected with either empty plasmid or expression plasmids coding for DPP4 and/or TMPRSS2 together with plasmid pGAL5-luc, which encodes the luciferase reporter gene under the control of a promoter containing five GAL 4 binding sites. At $8 \mathrm{~h}$ post transfection the transfection medium was replaced by fresh culture medium. At $24 \mathrm{~h}$ post transfection, effector cells were detached, diluted in fresh medium and added to the target cells. At $8 \mathrm{~h}$ after cell-mixing, medium supplemented with trypsin (Sigma) was added to the cultures at a final concentration of $100 \mathrm{ng} / \mu \mathrm{l}$. At $48 \mathrm{~h}$ after cocultivation, cell-cell fusion was quantified by determination of luciferase activities in cell lysates, using a commercially available kit (PJK).

MERS-S-driven transduction. A lentiviral vector was pseudotyped with MERS-S as described before (17). Briefly, 293T cells were calcium phosphate transfected with the HIV-1 derived vector pNL4-3-Luc-RE' (36) and expression plasmid encoding MERS-S wt or mutants, LASVGPC, EBOV-GP or VSV-G. Pseudotypes bearing no glycoprotein served a negative control. The transfection medium was replaced by fresh culture medium at $8 \mathrm{~h}$ post transfection and culture supernatants were harvested at $48 \mathrm{~h}$ post transfection. The supernatants were passed through 0.45 $\mu \mathrm{m}$ pore-size filters, aliquotted and stored at $-80^{\circ} \mathrm{C}$. For transduction, $293 \mathrm{~T}$ cells transfected with DPP4 expression plasmid or Caco-2 cells were seeded in 96-well plates and incubated with equal volumes of vector containing supernatants. Normalization of supernatants for equal viral p24capsid protein content was performed using a commercially available HIV-1 p24-ELISA (Advanced BioScience Laboratories). At $8 \mathrm{~h}$ post transduction, transduction medium (culture medium containing vector) was removed and replaced by fresh culture medium. At $72 \mathrm{~h}$ after addition of supernatants to target cells, luciferase activities in cell lysates were determined with a commercially available kit (Promega) according to the manufacturer's instructions. 
Cathepsin bypass. 293T cells were transfected with expression plasmids for DPP4 or/and TMPRSS2 and seeded into 96-well plates. Prior to transduction, cells were pretreated with DMSO or the cathepsin $\mathrm{B} / \mathrm{L}$ inhibitor MDL28170 (Calbiochem) for $60 \mathrm{~min}$ at $37^{\circ} \mathrm{C}$. Thereafter, the cells were transduced with equal volumes of pseudotypes in the presence of inhibitor at a final concentration of $10 \mu \mathrm{M}$. At $8 \mathrm{~h}$ post transduction the medium was replaced by fresh culture medium without inhibitor and transduction efficiency was measured after $72 \mathrm{~h}$ by determining luciferase activities in cell lysates.

Inhibition of proprotein convertases. In order to assess the role of proprotein convertase activity in MERS-S processing in transfected $293 \mathrm{~T}$ cells, the cells were transfected with plasmids encoding MERS-S, EBOV-GP and LASV-GPC or empty plasmid. The medium was changed at 6 $h$ post transfection and proprotein convertase inhibitor (Merck) was added to the fresh medium at the indicated concentrations. Medium was replaced again at $32 \mathrm{~h}$ post transfection and inhibitor was replenished. Cells were lysed at $48 \mathrm{~h}$ post transfection and cleavage of viral glycoproteins was detected by Western blot, employing a monoclonal antibody recognizing the V5 tag. As a loading control, an anti- $\beta$-actin antibody was used.

To assess whether proprotein convertase activity is required for MERS-S-driven cell-cell fusion, 293T target cells, expressing MERS-S or no glycoprotein as well as effector cells transfected to express DPP4 and/or TMPRSS2 were incubated with $1 \mu \mathrm{M}$ proprotein convertase inhibitor. One day after transfection, the cells were mixed to allow cell-cell fusion and medium was supplemented with proprotein convertase inhibitor at $1 \mu \mathrm{M}$ final concentration. Cell-cell fusion was quantified by determination of luciferase activity in cell lysates at $48 \mathrm{~h}$ after cocultivation, using a commercially available kit (PJK). 
For analysis of the importance of proprotein convertase activity for MERS-S-driven viruscell fusion, vectors bearing MERS-S, LASV-GPC, EBOV-GP or VSV-G or no glycoprotein were generated in the presence or absence of $1 \mu \mathrm{M}$ proprotein convertase inhibitor. As target cells, 293T cells, transfected with DPP4 encoding plasmid or empty plasmid, were seeded into 96 well plates and pretreated with $0.5 \mu \mathrm{M}$ proprotein convertase inhibitor for $60 \mathrm{~min}$ at $37^{\circ} \mathrm{C}$. The cells were then incubated with pseudotypes for $8 \mathrm{~h}$, followed by replacement of infection medium with culture medium containing inhibitor. Transduction efficiency was measured after $72 \mathrm{~h}$ by determining luciferase activities in cell lysates.

To determine the role of proprotein convertase activity in infection with authentic MERSCoV, Caco-2 cells seeded in 24-well plates were incubated with DMSO or rising concentrations of proprotein convertase inhibitor for $1 \mathrm{~h}$ at $37^{\circ} \mathrm{C}$ and were then inoculated with MERS-CoV (MOI of 0.01 and 0.001 in quadruplicates) in the presence of inhibitor. After an incubation of 30 $\min$ at $4^{\circ} \mathrm{C}$, the cells were washed and again incubated in culture medium with the inhibitor. At $24 \mathrm{~h}$ post infection, the cells were washed, harvested and the pellet was lysed with RIPA lysis buffer, supplemented with $4 \times \mathrm{NuPAGE}$ (Invitrogen) and boiled for $20 \mathrm{~min}$ at $95^{\circ} \mathrm{C} . \mathrm{S}$ protein expression in lysates was detected by Western blot, employing a polyclonal antibody directed against the S2 subunit of MERS-S (Sino Biological Inc.). In parallel, for quantification of viral RNA, $50 \mu$ l of the cell supernatant was dissolved in RAV1 buffer (Macherey-Nagel) for RNA extraction followed by qRT-PCR analysis using the upE assay as previously described (39). Quantification of infectious particles was done by plaque assay using Vero B4 cells as published (7). Briefly, 10-fold dilutions of supernatants were tested in duplicates using cell monolayers of Vero B4 cells. After $1 \mathrm{~h}$ of virus adsorption cells were washed and overlayed with a $1.2 \%$ avicel resin. After 3 days the plates were fixed with $7 \%$ paraformaldehyde and stained with crystal violet solution. To investigate the influence of $\mathrm{PCI}$ on the formation of MERS-CoV induced 
cytopathogenic effects Vero B4 cells were infected at an MOI of 0.1 and fixed with $7 \%$ paraformaldehyde after $42 \mathrm{~h}$ post infection. MERS-CoV antigen detection was performed by incubation with a MERS patient serum as described (40). Bound antibodies were detected with a cyanine 2-labeled goat-anti human immunoglobulin G secondary antibody (Dianova). Nuclei were stained by mounting the slides with DAPI containing ProLong Gold antifade mounting medium (Life technologies). 


\section{RESULTS}

MERS-S is proteolytically processed in transfected and infected cells. In order to investigate MERS-S cleavage in virus producing cells, we determined whether the $\mathrm{S}$ protein is cleaved in transfected and infected cells. Western blot analysis of S protein transfected 293T cells and MERS-CoV infected Vero B4 cells with an antibody specific to the S2 subunit of MERS-S revealed two prominent $\mathrm{S}$ protein bands with molecular weights of $170 \mathrm{kDa}$ and $90 \mathrm{kDa}$ (Fig. 1), in keeping with our previous results (17). The $170 \mathrm{kDa}$ band corresponds to uncleaved MERS-S while the presence of the $90 \mathrm{kDa}$ indicates efficient processing of MERS-S into an N-terminal S1 subunit (not detected) and a C-terminal S2 subunit (Fig. 1).

Several RXXR motifs located at the border of the $\$ 1$ and $\$ 2$ subunits are required for processing of MERS-S. Inspection of the sequences located at the border of the S1 and S2 subunits of MERS-S revealed the presence of four RXXR sequences (Fig. 2A), which might represent recognition sites for proprotein convertases (33). In order to determine the importance of these motifs for MERS-S cleavage and activation, we changed the arginine residues in 626RXXR-629, 691-RXXR-694, 748-RXXR-751 and 884-RXXR-887 to alanine residues, creating the potential cleavage site mutants PCMI, PCM2, PCM3 and PCM4 (Fig. 2A). All S protein mutants were expressed with the same efficiency as wt MERS-S in transfected cells (Fig. 2B). The only exception was PCM2, for which consistently no expression was detected (not shown). Importantly, mutation of potential cleavage sites 3 and 4 alone impacted $S$ protein processing: The presence of the $90 \mathrm{kDa}$ band was reduced in cells expressing PCM3 and a band with a molecular weight slightly higher than $90 \mathrm{kDa}$ was observed upon expression of PCM4 (Fig. 2B). Processing of PCM1 was comparable to that seen for MERS-S wt. However, combined mutation of potential cleavage sites 1 and 3 ( $\mathrm{PCM} 1+\mathrm{PCM}$ ) abrogated S protein processing ( $\mathrm{Fig} .2 \mathrm{~B}$ ), 
suggesting that also potential cleavage site 1 contributes to $S$ protein cleavage in this experimental setting. Similar effects were seen when potential cleavage sites 3 and 4 were simultaneously altered (PCM3 + PCM4) or when all three potential cleavage sites were mutated in parallel (PCM1 + PCM3 + PCM4). Collectively, these results indicate that MERS-S is cleaved in transfected cells and that cleavage is reduced or altered upon mutation of potential cleavage sites 1,3 and 4.

Mutation of 748-RXXR-751 (PCM3) and 884-RXXR-887 (PCM4) reduces MERS-S-driven cell-cell and virus-cell fusion. Next, we investigated whether the integrity of potential cleavage sites 1,3 and 4 is required for $S$ protein-driven cell-cell and virus-cell fusion. For analysis of cellcell fusion, we employed a previously described assay (24), which is based on directed expression of S protein and receptor in effector and target $293 \mathrm{~T}$ cells, respectively. Expression of MERS-S in effector cells allowed inefficient fusion with control transfected 293T target cells, which are known to express low amounts of endogenous DPP4 (41), and the efficiency of cellcell fusion was markedly increased when target cells were transfected with DPP4 encoding plasmid (Fig. 3A). In contrast, cell-cell fusion driven by PCMI, PCM3 and PCM4 was inefficient (PCM1) or absent (PCM3, PCM4), irrespective of expression of DPP4 (Fig. 3A). Similar results were obtained when virus-cell fusion was analyzed employing a previously described lentiviral vector (17) and DPP4-transfected 293T cells as targets, although the most severe defects were observed for PCM1 and PCM4 while PCM3 retained substantial activity (Fig. 3B). Finally, S protein mutants in which more than one potential cleavage site was altered showed a phenotype comparable to that observed for PCMI and PCM4, suggesting that potential cleavage sites 1, 3 and 4 are all required for full $\mathrm{S}$ protein activity in cell-cell and virus-cell fusion reactions, although the relative contribution of single sites varies. 
In order to define the nature of the defects associated with mutation of potential cleavage sites, we selected PCM3 and PCM4 for detailed analysis, since both mutants showed altered S protein cleavage (Fig. 2B) but differed in their capacity to drive virus-cells fusion: PCM3 exhibited substantial activity while PCM4 was largely inactive (Fig. 3B). We first examined whether the reduced activities of PCM3 and PCM4 in the virus-cell fusion assay were due to reduced incorporation of the respective $\mathrm{S}$ proteins in lentiviral particles. Western blot analysis of particles concentrated through a sucrose cushion revealed that particle incorporation of both mutants was comparable to that detected for MERS-S wt (Fig. 3C). Of note, the processing defects observed for cell-associated S proteins (Fig. 2B) were even more pronounced for virionassociated S proteins: PCM3 was mainly uncleaved and the cleavage product of PCM4, although prominent, had a slightly higher molecular weight than the cleavage product obtained for MERS. S wt (Fig. 3C). Transduction of the colon carcinoma cell line Caco-2, which expresses endogenous DPP4 (42), showed that PCM3 is able to drive virus-cell fusion while PCM4 is largely defective (Fig. 3D). These results confirm the observations made with 293T target cells and demonstrate that defects of PCM3 and PCM4 in virus-cell fusion are not due to reduced particle incorporation of these $\mathrm{S}$ protein mutants.

\section{Mutation of 748-RXXR-751 (PCM3) and 884-RXXR-887 (PCM4) is compatible with}

MERS-S processing by trypsin and TMPRSS2. In order to assess whether mutation of potential cleavage sites 3 and 4 interferes with S protein activation pathways operative once mature $\mathrm{S}$ protein is presented on the surface of cells or virions, we assessed $\mathrm{S}$ protein activation by trypsin and TMPRSS2. Proteolysis of MERS-S wt upon addition of trypsin or coexpression of TMPRSS2 was readily detectable (Fig. 4A), as expected (17). In keeping with this finding, cellcell fusion driven by MERS-S wt was promoted by directed expression of DPP4 or TMPRSS2 on target cells and by trypsin treatment (Fig. 4B). Thus, receptor and protease expression can both 
limit MERS-S-driven cell-cell fusion, as previously reported for SARS-S (43). Finally, the cathepsin B/L inhibitor MDL28170 reduced MERS-S-driven fusion of virions with control transfected cells and this effect was rescued by expression of TMPRSS2, as expected from previous work (17). PCM3 was efficiently cleaved (Fig. 4A) and activated by trypsin and TMPRSS2 for cell-cell fusion (Fig. 4B). Moreover, fusion of virions with control transfected cells was blocked by the cathepsin $B / L$ inhibitor and this effect was not seen when TMPRSS2 expressing target cells were examined (Fig. 4C), indicating that the potential cleavage site 3 is dispensable for $\mathrm{S}$ protein activation by trypsin, TMPRSS 2 and cathepsin B/L. In contrast, PCM4 failed to drive cell-cell and virus-cell fusion under all conditions tested (Fig. 4B and not shown), despite efficient processing by both trypsin and TMPRSS2 (Fig. 4A) - although it should be noted that one cleavage fragment observed upon TMPRSS2-mediated proteolysis of MERS-S wt was either weak or not detected upon cleavage of PCM4. In sum, these results demonstrate that the reduced capacity of PCM3 and PCM4 to drive cell-cell and virus-cell fusion is not due to limited cleavability by trypsin and, in case of PCM3, the trypsin-like protease TMPRSS2. MERS-S is processed by proprotein convertases. We next sought to identify the proteases responsible for MERS-S cleavage in virus producing cells. For this, we investigated whether $\mathrm{S}$ protein cleavage can be blocked by a cell-permeable tripeptide derivative containing an $\mathrm{Arg}-\mathrm{X}$ Arg motive, which is known to inhibit several proprotein convertases, including furin (44). Treatment with this proprotein convertase inhibitor $(\mathrm{PCI})$ reduced the production of the $90 \mathrm{kDa}$ band in cells transfected to express MERS-S (Fig. 5). Moreover, the presence of PCI diminished processing of the Zaire ebolavirus glycoprotein (EBOV-GP) into GP1 and GP2 (Fig. 5), which depends on the activity of the proprotein convertase furin (45). In contrast, processing of the glycoprotein of Lassa virus (LASV-GPC), which is mediated by the proprotein convertase SKI1/S1P (46), was not suppressed (Fig, 5). This finding is in keeping with the known differences in 
substrate specificity (and thus inhibitor sensitivity) of SKI-I/SIP compared to proprotein convertases with specificity for basic amino acids, like furin (47). Collectively, these results show that the activity of proprotein convertases is essential for MERS-S processing in transfected cells. Proprotein convertase activity is not essential for efficient MERS-S-driven cell-cell and virus-cell fusion. The results obtained so far were compatible with the concept that cleavage of MERS-S by proprotein convertases depends on the integrity of PCS1, 3 and 4 and is required for S protein activity in cell-cell and virus-cell fusion reactions. Unexpectedly, however, the continuous presence of $\mathrm{PCI}$ in target and effector cell cultures, prior, during and after mixing had no appreciable effect on MERS-S-mediated cell-cell fusion (Fig. 6A). Next, we asked whether MERS-S processing by proprotein convertases is required for MERS-S-mediated virus-cell fusion. Addition of PCI to cells producing MERS-S harboring lentiviral particles reduced transduction of $293 \mathrm{~T}$ target cells roughly 100-fold (Fig. 6B). In contrast, infectivity of particles bearing LASV-GPC or EBOV-GP was not affected (Fig. 6B), in keeping with the findings that processing of LASV-GPC is not inhibited by PCI (Fig. 5) and that processing of EBOV-GP by proprotein convertases is dispensable for GP-driven virus-cell fusion $(48,49)$. Notably, no inhibitory effect was detected when $293 \mathrm{~T}$ cells transfected to express DPP4 were chosen as targets (Fig. $6 \mathrm{~B}$ ), indicating that $\mathrm{S}$ protein processing in virus producing cells might be dispensable for infectivity when target cells express robust amounts of DPP4. In sum, these results suggest that proprotein convertase activity is largely dispensable for MERS-S-driven cellcell and virus-cell fusion, at least when target cells produce high levels of DPP4.

Proprotein convertase activity is not required for MERS-CoV infectivity. The lack of a prominent inhibitory effect of PCI on MERS-S-driven cell-cell and virus-cell fusion might be due to high levels of directed MERS-S and DPP4 expression in these experimental systems. Therefore, we assessed whether PCI inhibits MERS-CoV spread in target cells expressing 
endogenous DPP4. PCI treatment of Caco-2 cells infected with MERS-CoV did not inhibit total MERS-S expression but reduced S protein cleavage efficiently and in a concentration dependent manner (Fig. 7A), confirming that MERS-S is a substrate of proprotein convertases in infected cells. However, $\mathrm{PCI}$ treatment did not reduce MERS-CoV propagation, as determined by the amount of viral RNA (Fig. 7B, left panel) or infectious units (Fig. 7B, right panel) present in culture supernatants. Similarly, treatment of MERS- $\mathrm{CoV}$ infected cultures had little if any effect on the formation of cytopathic effects (CPE) as demonstrated by comparable destruction of the cell monolayer (Fig. 7C). Thus, processing of MERS-S by proprotein convertases is dispensable for MERS-CoV infectivity in cell cultures. 


\section{DISCUSSION}

The processing of the glycoproteins of HIV (30) and highly pathogenic avian influenza viruses (31) by proprotein convertases is essential for viral infectivity. As a consequence, antiviral strategies aiming at the inhibition of these enzymes are being developed (44). Our results add MERS-S to the list of proprotein convertase substrates and show that several RXXR motifs within MERS-S are required for efficient S protein processing. However, activity of proprotein convertases was dispensable for infectivity of MERS-CoV, indicating that in the context of MERS-CoV infection proprotein convertases do not constitute targets for antiviral intervention. Finally, we observed that mutation of RXXR motifs within MERS-S not only compromises proteolytic processing but also reduces $\mathrm{S}$ protein-driven cell-cell and virus-cell fusion. Why intact RXXR motifs were required for the latter processes remains to be clarified.

The recent finding that TMPRSS2 expression primes influenza virus HA in cell culture (50-52) and is required for spread and pathogenesis of $\mathrm{HINI}$ influenza virus in mice (28) showed that influenza viruses might depend on the activity of a single protease for amplification in the infected host. These findings, jointly with the observations that TMPRSS 2 also activates MERS$\operatorname{CoV}(17,21,22)$ and other coronaviruses $(23,25,53)$ and that knock-out of TMPRSS2 has no phenotype in the absence of infection (54), defined TMPRSS2 as a prime target for therapeutic intervention. However, TMPRSS2 might not be the only cellular protease which constitutes a potential therapeutic target in the context of coronavirus infection. Thus, it is at present unclear whether cleavage of MERS-S during biogenesis in infected cells is required for subsequent cleavage and activation of the $\mathrm{S}$ protein by TMPRSS2 during viral uptake into target cells. Such a scenario would not be unprecedented given that entry mediated by the glycoproteins of certain bunyaviruses depends on glycoprotein processing during synthesis in the constitutive secretory pathway and, as suggested by a recent report, during viral uptake into target cells (55). 
Alternatively, it is conceivable that processing of MERS-S in infected cells is dispensable for virus-cell but required for cell-cell fusion, which results in formation of syncytia, a feature of MERS-CoV pathogenesis (6).

We found that MERS-S is efficiently cleaved in S protein transfected $293 \mathrm{~T}$ cells and MERS-CoV infected Vero B4 and Caco-2 cells and inhibition experiments showed that proprotein convertase activity is essential for MERS-S cleavage. The finding that MERS-S is efficiently cleaved in transfected or MERS-CoV infected cells is in keeping with several studies examining MERS-S expression for other purposes $(21,56,57)$. One report showed that MERS-S is not cleaved in transfected cells (22) but a MERS-S variant with a truncated cytoplasmic tail was examined and it is conceivable that this deletion interfered with $\mathrm{S}$ protein exposure to or recognition by proprotein convertases. Alternatively, the cells used for $\mathrm{S}$ protein expression might have produced only low amounts of proprotein convertases. Robust $\mathrm{S}$ protein processing by proprotein convertases has also been reported for mouse hepatitis virus strain A59 $(58,59)$ and IBV $(29,60)$ while cleavage of SARS-S by these proteases is inefficient $(43,61,62)$. Thus, MERS-S belongs to the subgroup of coronavirus $\mathrm{S}$ proteins, which are substrates of proprotein convertases, and MERS-S processing in different cellular systems, including the lung cell line Calu-3, is robust.

Most proprotein convertases cleave the following motif: $(\mathrm{R} / \mathrm{K})-2 \mathrm{nX}-\mathrm{R} \downarrow$, with $\mathrm{n}$ standing for 0-3 amino acids (47). The finding that RXXR motifs located at the predicted border between S1 and S2 subunit are important for MERS-S processing by proprotein convertases might therefore not be unexpected. Nevertheless, it is noteworthy that at least two RXXR motifs had to be mutated in parallel to markedly reduce $\mathrm{S}$ protein processing. This suggests that the processing enzyme(s) can recognize more than one cleavage site. Indeed, the S2 fragment produced upon cleavage of PCM4 showed a slightly increased molecular weight relative to the fragment 
generated from MERS-S wt, which would be in keeping with usage of an upstream cleavage site, most likely potential cleavage site 3 . Alternatively, the integrity of the RXXR motifs located at the border of the $\mathrm{S} 1$ and $\mathrm{S} 2$ subunit might be required to present a single cleavage site in a protease sensitive configuration.

Processing by proprotein convertases is required for full activity of certain MHV and IBV $\mathrm{S}$ proteins in cell-cell and virus-cell fusion reactions, although inactivation of the respective cleavage sites does not abrogate viral infectivity $(29,58-60)$. Similarly, mutation of furin cleavage sites in the glycoproteins of ebolaviruses is compatible with robust viral spread in vitro and in vivo $(48,49)$. In contrast, mutation of the furin cleavage site in the HIV envelope protein renders virions non-infectious and it has been suggested that processing of SARS-S by proprotein convertases, although being inefficient, is still required for full viral spread and for the establishment of cytopathic effects in infected cultures (61). The present study provides evidence that efficient blockade of MERS-S processing by $\mathrm{PCI}$ has no appreciable effects on $\mathrm{S}$ protein activity in cell-cell fusion assay and does not modulate MERS-CoV spread in susceptible cells. In contrast, inhibition of MERS-S processing markedly reduced MERS-S-driven fusion of virions with $293 \mathrm{~T}$ cells expressing low amounts of endogenous DPP4. It is therefore conceivable that processing of MERS-S by proprotein convertases is required for optimal spread of MERS-CoV in target cells expressing low levels of DPP4. Such a scenario would be in keeping with the observation that inefficient SARS-S-driven cell-cell fusion due to limited receptor expression can be rescued by directed expression of S protein activating proteases and vice versa (43).

The mutation of the RXXR motifs at the border between the S1 and S2 subunit markedly reduced $\mathrm{S}$ protein processing by proprotein convertases and $\mathrm{S}$ protein activity in cell-cell and virus-cell fusion assays. However, inhibition studies with PCI revealed that these phenotypes were not linked, raising the question why the RXXR motifs are essential for S protein function. 
We suspected that these motifs might be necessary for efficient receptor binding, due to a potential impact on S protein folding, but studies conducted with soluble DPP4 fused to the Fc portion of human immunoglobulin did not support this hypothesis (not shown). Alternatively, the integrity of the RXXR sequences might be required for $\mathrm{S}$ protein activation. The finding that both PCM3 and PCM4 are cleaved efficiently by trypsin and TMPRSS2 seems to argue against this possibility. However, it is conceivable that fusion of MERS-S-expressing cells with 293T target cells might depend on the activity of an endogenously expressed protease, which cleaves MERSS at RXXR motifs. Similarly, the markedly reduced capacity of PCMI and PCM4 to drive fusion of virions with $293 \mathrm{~T}$ cells might be the consequence of inefficient activation by cathepsin $\mathrm{L}$, the protease which facilitates MERS-S-dependent transduction and MERS-CoV infection of 293T cells $(17,21)$. In this regard, it is noteworthy that PCM1 and PCM3 showed differential activity in cell-cell and virus-cell fusion assays, which would be in keeping with a differential proteasedependence of these processes. Collectively, the role of RXXR motifs in MERS-S activity requires further investigation and one focus should be on proteolytic activation.

In sum, our results identify MERS-S as a substrate of proprotein convertases but indicate that the activity of these enzymes is dispensable for MERS-CoV spread in target cell lines and potentially also in the infected human host. Furthermore, our findings suggest that the mode of $\mathrm{S}$ protein activation might depend on the level of receptor expression, a scenario that warrants further analyses. 


\section{ACKNOWLEDGEMENTS}

We thank Stephan Kallies for excellent technical assistance. This work was supported by FP7-

EMPERIE (contract No 223498 to C.D.), the German Ministry for Research and Education

(01KIO701 to C.D. and 01KI1005C to S.P.), SFB 900 (to S.P.) and the Leibniz Foundation. 


\section{REFERENCES}

1. Graham, R. L., E. F. Donaldson, and R. S. Baric. 2013, A decade after SARS: strategies for controlling emerging coronaviruses. Nat. Rev. Microbiol, 11:836-848.

2. Hilgenfeld, R. and M. Peiris. 2013. From SARS to MERS: 10 years of research on highly pathogenic human coronaviruses. Antiviral Res. 100:286-295.

3. Drexler, J. F., V. M. Corman, and C. Drosten. 2014. Ecology, evolution and classification of bat coronaviruses in the aftermath of SARS. Antiviral Res. 101:45-56.

4. Ge, X. Y., J. L. Li, X. L. Yang, A. A. Chmura, G. Zhu, J. H. Epstein, J. K. Mazet, B. Hu, W. Zhang, C. Peng, Y. J. Zhang, C. M. Luo, B. Tan, N. Wang, Y. Zhu, G. Crameri, S. Y. Zhang, L. F. Wang, P. Daszak, and Z. L. Shi. 2013. Isolation and characterization of a bat SARS-like coronavirus that uses the ACE2 receptor. Nature 503:535-538.

5. de Groot, R. J., S. C. Baker, R. S. Baric, C. S. Brown, C. Drosten, L. Enjuanes, R. A. Fouchier, M. Galiano, A. E. Gorbalenya, Z. A. Memish, S. Perlman, L. L. Poon, E. J. Snijder, G. M. Stephens, P. C. Woo, A. M. Zaki, M. Zambon, and J. Ziebuhr. 2013. Middle East respiratory syndrome coronavirus (MERS-CoV): announcement of the Coronavirus Study Group. J. Virol. 87:7790-7792.

6. Zaki, A. M., B. S. van, T. M. Bestebroer, A. D. Osterhaus, and R. A. Fouchier 2012. Isolation of a novel coronavirus from a man with pneumonia in Saudi Arabia. N. Engl. J. Med. 367:1814-1820.

7. Drosten, C., M. Seilmaier, V. M. Corman, W. Hartmann, G. Scheible, S. Sack, W. Guggemos, R. Kallies, D. Muth, S. Junglen, M. A. Muller, W. Haas, H. Guberina, T. Rohnisch, M. Schmid-Wendtner, S. Aldabbagh, U. Dittmer, H. Gold, P. Graf, F. Bonin, A. Rambaut, and C. M. Wendtner. 2013. Clinical features and virological analysis of a case of Middle East respiratory syndrome coronavirus infection. Lancet Infect. Dis. 13:745-751.

8. Guery, B., J. Poissy, M. L. el, C. Sejourne, N. Ettahar, X. Lemaire, F. Vuotto, A. Goffard, S. Behilli, V. Enouf, V. Caro, A. Mailles, D. Che, J. C. Manuguerra, D. Mathieu, A. Fontanet, and S. van der Werf. 2013. Clinical features and viral diagnosis of two cases of infection with Middle East Respiratory Syndrome coronavirus: a report of nosocomial transmission. Lancet 381:2265-2272.

9. Mailles, A., K. Blanckaert, P. Chaud, S. van der Werf, B. Lina, V. Caro, C. Campese, B. Guery, H. Prouvost, X. Lemaire, M. C. Paty, S. Haeghebaert, D. Antoine, N. Ettahar, H. Noel, S. Behillil, S. Hendricx, J. C. Manuguerra, V. Enouf, R. G. La, C. Semaille, B. Coignard, D. Levy-Bruhl, F. Weber, C. Saura, and D. Che, 2013. First cases of Middle East Respiratory Syndrome Coronavirus (MERS-CoV) infections in France, investigations and implications for the prevention of human-tohuman transmission, France, May 2013, Euro. Surveill 18. 
10. Puzelli, S., A. Azzi, M. G. Santini, M. A. Di, M. Facchini, M. R. Castrucci, M. Meola, R. Arvia, F. Corcioli, F. Pierucci, S. Baretti, A. Bartoloni, D. Bartolozzi, M. M. de, L. Galli, M. G. Pompa, G. Rezza, E. Balocchini, and I. Donatelli. 2013. Investigation of an imported case of Middle East Respiratory Syndrome Coronavirus (MERS-CoV) infection in Florence, Italy, May to June 2013. Euro. Surveill 18

11. WHO. Middle East respiratory syndrome coronavirus (MERS-CoV) - update. March, 12, 2014. http://www.who.int/csr/don/2014_03_12/en/

12. Cauchemez, S., M. D. Van Kerkhove, S. Riley, C. A. Donnelly, C. Fraser, and N. M. Ferguson. 2013. Transmission scenarios for Middle East Respiratory Syndrome Coronavirus (MERS-CoV) and how to tell them apart. Euro. Surveill 18.

13. Belouzard, S., J. K. Millet, B. N. Licitra, and G. R. Whittaker. 2012. Mechanisms of coronavirus cell entry mediated by the viral spike protein. Viruses. 4:1011-1033.

14. Heald-Sargent, T. and T. Gallagher, 2012. Ready, set, fuse! The coronavirus spike protein and acquisition of fusion competence. Viruses, 4:557-580.

15. Lu, G., Y. Hu, Q. Wang, J. Qi, F. Gao, Y. Li, Y. Zhang, W. Zhang, Y. Yuan, J. Bao, B. Zhang, Y. Shi, J. Yan, and G. F. Gao. 2013. Molecular basis of binding between novel human coronavirus MERS-CoV and its receptor CD26. Nature 500:227-231.

16. Raj, V. S., H. Mou, S. L. Smits, D. H. Dekkers, M. A. Muller, R. Dijkman, D. Muth, J. A. Demmers, A. Zaki, R. A. Fouchier, V. Thiel, C. Drosten, P. J. Rottier, A. D. Osterhaus, B. J. Bosch, and B. L. Haagmans. 2013. Dipeptidyl peptidase 4 is a functional receptor for the emerging human coronavirus-EMC. Nature 495:251-254.

17. Gierer, S., S. Bertram, F. Kaup, F. Wrensch, A. Heurich, A. Kramer-Kuhl, K. Welsch, M. Winkler, B. Meyer, C. Drosten, U. Dittmer, H. T. von, G. Simmons, H. Hofmann, and S. Pöhlmann. 2013. The spike protein of the emerging betacoronavirus EMC uses a novel coronavirus receptor for entry, can be activated by TMPRSS2, and is targeted by neutralizing antibodies. J. Virol. 87:5502-5511.

18. Simmons, G., P. Zmora, S. Gierer, A. Heurich, and S. Pohlmann. 2013. Proteolytic activation of the SARS-coronavirus spike protein: Cutting enzymes at the cutting edge of antiviral research. Antiviral Res. 100;605-614.

19. White, J. M., S. E. Delos, M. Brecher, and K. Schornberg. 2008. Structures and mechanisms of viral membrane fusion proteins: multiple variations on a common theme. Crit Rev. Biochem. Mol. Biol. 43:189-219.

20. Bertram, S., I. Glowacka, I. Steffen, A. Kuhl, and S. Pohlmann. 2010. Novel insights into proteolytic cleavage of influenza virus hemagglutinin. Rev. Med. Virol. 20:298-310.

21. Shirato, K., M. Kawase, and S. Matsuyama. 2013. Middle East respiratory syndrome coronavirus infection mediated by the transmembrane serine protease TMPRSS2. J. Virol. 87:12552-12561. 
22. Qian, Z., S. R. Dominguez, and K. V. Holmes. 2013. Role of the spike glycoprotein of human Middle East respiratory syndrome coronavirus (MERS-CoV) in virus entry and syncytia formation. PLoS. One. 8:e76469.

23. Bertram, S., R. Dijkman, M. Habjan, A. Heurich, S. Gierer, I. Glowacka, K. Welsch, M. Winkler, H. Schneider, H. Hofmann-Winkler, V. Thiel, and S. Pohlmann. 2013. TMPRSS2 activates the human coronavirus 229E for cathepsin-independent host cell entry and is expressed in viral target cells in the respiratory epithelium. J. Virol. 87:61506160 .

24. Glowacka, I., S. Bertram, M. A. Muller, P. Allen, E. Soilleux, S. Pfefferle, I. Steffen, T. S. Tsegaye, Y. He, K. Gnirss, D. Niemeyer, H. Schneider, C. Drosten, and S. Pohlmann. 2011. Evidence that TMPRSS2 activates the severe acute respiratory syndrome coronavirus spike protein for membrane fusion and reduces viral control by the humoral immune response. J. Virol. 85:4122-4134.

25. Kawase, M., K. Shirato, L. van der Hoek, F. Taguchi, and S. Matsuyama. 2012. Simultaneous treatment of human bronchial epithelial cells with serine and cysteine protease inhibitors prevents severe acute respiratory syndrome coronavirus entry. J. Virol. 86:6537-6545.

26. Matsuyama, S., N. Nagata, K. Shirato, M. Kawase, M. Takeda, and F. Taguchi. 2010. Efficient activation of the severe acute respiratory syndrome coronavirus spike protein by the transmembrane protease TMPRSS2. J. Virol. 84:12658-12664.

27. Shulla, A., T. Heald-Sargent, G. Subramanya, J. Zhao, S. Perlman, and T. Gallagher: 2011. A transmembrane serine protease is linked to the severe acute respiratory syndrome coronavirus receptor and activates virus entry. J. Virol. 85:873-882.

28. Hatesuer, B., S. Bertram, N. Mehnert, M. M. Bahgat, P. S. Nelson, S. Pohlman, and K. Schughart. 2013. Tmprss2 Is Essential for Influenza HIN1 Virus Pathogenesis in Mice. PLoS. Pathog. 9:el003774.

29. Yamada, Y. and D. X. Liu. 2009. Proteolytic activation of the spike protein at a novel RRRR/S motif is implicated in furin-dependent entry, syncytium formation, and infectivity of coronavirus infectious bronchitis virus in cultured cells. J. Virol. 83:87448758 .

30. Hallenberger, S., V. Bosch, H. Angliker, E. Shaw, H. D. Klenk, and W. Garten. 1992 Inhibition of furin-mediated cleavage activation of HIV-1 glycoprotein gp160. Nature 360:358-361.

31. Stieneke-Grober, A., M. Vey, H. Angliker, E. Shaw, G. Thomas, C. Roberts, H. D. Klenk, and W. Garten. 1992. Influenza virus hemagglutinin with multibasic cleavage site is activated by furin, a subtilisin-like endoprotease. EMBO J. 11:2407-2414.

32. Thomas, G. 2002. Furin at the cutting edge: from protein traffic to embryogenesis and disease. Nat. Rev. Mol. Cell Biol. 3:753-766. 
33. Pasquato, A., P. J. Ramos da, C. Galan, N. G. Seidah, and S. Kunz. 2013. Viral envelope glycoprotein processing by proprotein convertases. Antiviral Res. 99:49-60.

34. Simmons, G., J. D. Reeves, C. C. Grogan, L. H. Vandenberghe, F. Baribaud, J. C. Whitbeck, E. Burke, M. J. Buchmeier, E. J. Soilleux, J. L. Riley, R. W. Doms, P. Bates, and S. Pohlmann. 2003. DC-SIGN and DC-SIGNR bind ebola glycoproteins and enhance infection of macrophages and endothelial cells. Virology 305:115-123.

35. Hofmann, H., G. Simmons, A. J. Rennekamp, C. Chaipan, T. Gramberg, E. Heck, M. Geier, A. Wegele, A. Marzi, P. Bates, and S. Pohlmann. 2006. Highly conserved regions within the spike proteins of human coronaviruses $229 \mathrm{E}$ and NL63 determine recognition of their respective cellular receptors. J, Virol, 80:8639-8652.

36. Connor, R. I., B. K. Chen, S. Choe, and N. R. Landau. 1995. Vpr is required for efficient replication of human immunodeficiency virus type-1 in mononuclear phagocytes. Virology 206:935-944.

37. Gao, F., Y. Li, J. M. Decker, F. W. Peyerl, F. Bibollet-Ruche, C. M. Rodenburg, Y. Chen, D. R. Shaw, S. Allen, R. Musonda, G. M. Shaw, A. J. Zajac, N. Letvin, and B. H. Hahn. 2003. Codon usage optimization of HIV type 1 subtype $\mathrm{C}$ gag, pol, env, and nef genes: in vitro expression and immune responses in DNA-vaccinated mice. AIDS Res. Hum. Retroviruses 19:817-823.

38. Kühl, A., M. Hoffmann, M. A. Muller, V. J. Munster, K. Gnirss, M. Kiene, T. S. Tsegaye, G. Behrens, G. Herrler, H. Feldmann, C. Drosten, and S. Pöhlmann. 2011. Comparative analysis of Ebola virus glycoprotein interactions with human and bat cells. J. Infect. Dis. 204 Suppl 3:S840-S849.

39. Corman, V. M., R. Kallies, H. Philipps, G. Gopner, M. A. Muller, I. Eckerle, S. Brunink, C. Drosten, and J. F. Drexler. 2014. Characterization of a novel betacoronavirus related to middle East respiratory syndrome coronavirus in European hedgehogs. J. Virol. 88:717-724.

40. Corman, V. M., M. A. Muller, U. Costabel, J. Timm, T. Binger, B. Meyer, P. Kreher, E. Lattwein, M. Eschbach-Bludau, A. Nitsche, T. Bleicker, O. Landt, B. Schweiger, J. F. Drexler, A. D. Osterhaus, B. L. Haagmans, U. Dittmer, F. Bonin, T. Wolf, and C. Drosten. 2012, Assays for laboratory confirmation of novel human coronavirus (hCoV-EMC) infections. Euro. Surveill 17.

41. Wilson, C. H. and C. A. Abbott. 2012. Expression profiling of dipeptidyl peptidase 8 and 9 in breast and ovarian carcinoma cell lines. Int. J. Oncol. 41:919-932.

42. Darmoul, D., M. Lacasa, L. Baricault, D. Marguet, C. Sapin, P. Trotot, A. Barbat, and G. Trugnan. 1992. Dipeptidyl peptidase IV (CD 26) gene expression in enterocytelike colon cancer cell lines HT-29 and Caco-2. Cloning of the complete human coding sequence and changes of dipeptidyl peptidase IV mRNA levels during cell differentiation. J. Biol. Chem. 267:4824-4833. 
43. Simmons, G., S. Bertram, I. Glowacka, I. Steffen, C. Chaipan, J. Agudelo, K. Lu, A. J. Rennekamp, H. Hofmann, P. Bates, and S. Pohlmann. 2011. Different host cell proteases activate the SARS-coronavirus spike-protein for cell-cell and virus-cell fusion. Virology 413:265-274.

44. Becker, G. L., Y. Lu, K. Hardes, B. Strehlow, C. Levesque, I. Lindberg, K. Sandvig, U. Bakowsky, R. Day, W. Garten, and T. Steinmetzer. 2012. Highly potent inhibitors of proprotein convertase furin as potential drugs for treatment of infectious diseases. $\mathrm{J}$. Biol. Chem. 287:21992-22003.

45. Volchkov, V. E., H. Feldmann, V. A. Volchkova, and H. D. Klenk. 1998. Processing of the Ebola virus glycoprotein by the proprotein convertase furin. Proc. Natl. Acad. Sci. U. S. A 95:5762-5767.

46. Lenz, O., M. J. ter, H. D. Klenk, N. G. Seidah, and W. Garten. 2001. The Lassa virus glycoprotein precursor GP-C is proteolytically processed by subtilase SKI-1/S1P. Proc. Natl. Acad. Sci. U. S. A 98:12701-12705.

47. Seidah, N. G. and A. Prat. 2012. The biology and therapeutic targeting of the proprotein convertases. Nat. Rev. Drug Discov. 11:367-383.

48. Neumann, G., H. Feldmann, S. Watanabe, I. Lukashevich, and Y. Kawaoka. 2002. Reverse genetics demonstrates that proteolytic processing of the Ebola virus glycoprotein is not essential for replication in cell culture. J. Virol. 76:406-410.

49. Neumann, G., T. W. Geisbert, H. Ebihara, J. B. Geisbert, K. M. Daddario-DiCaprio, H. Feldmann, and Y. Kawaoka. 2007. Proteolytic processing of the Ebola virus glycoprotein is not critical for Ebola virus replication in nonhuman primates. J. Virol. 81:2995-2998.

50. Bertram, S., A. Heurich, H. Lavender, S. Gierer, S. Danisch, P. Perin, J. M. Lucas, P. S. Nelson, S. Pohlmann, and E. J. Soilleux. 2012. Influenza and SARS-coronavirus activating proteases TMPRSS2 and HAT are expressed at multiple sites in human respiratory and gastrointestinal tracts. PLoS. One. 7:e35876.

51. Bottcher-Friebertshauser, E., D. A. Stein, H. D. Klenk, and W. Garten. 2011. Inhibition of influenza virus infection in human airway cell cultures by an antisense peptide-conjugated morpholino oligomer targeting the hemagglutinin-activating protease TMPRSS2. J. Virol. 85:1554-1562.

52. Bottcher, E., T. Matrosovich, M. Beyerle, H. D. Klenk, W. Garten, and M. Matrosovich. 2006. Proteolytic activation of influenza viruses by serine proteases TMPRSS2 and HAT from human airway epithelium. J. Virol. 80:9896-9898.

53. Shirato, K., S. Matsuyama, M. Ujike, and F. Taguchi. 2011. Role of proteases in the release of porcine epidemic diarrhea virus from infected cells. J. Virol. 85:7872-7880.

54. Kim, T. S., C. Heinlein, R. C. Hackman, and P. S. Nelson. 2006. Phenotypic analysis of mice lacking the Tmprss2-encoded protease. Mol. Cell Biol. 26:965-975. 
55. Hofmann, H., X. Li, X. Zhang, W. Liu, A. Kuhl, F. Kaup, S. S. Soldan, F. GonzalezScarano, F. Weber, Y. He, and S. Pohlmann. 2013. Severe fever with thrombocytopenia virus glycoproteins are targeted by neutralizing antibodies and can use DC-SIGN as a receptor for pH-dependent entry into human and animal cell lines. J. Virol. 87:4384-4394.

56. Alagaili, A. N., T. Briese, N. Mishra, V. Kapoor, S. C. Samerof,, W. E. de, V. J. Munster, L. E. Hensley, I. S. Zalmout, A. Kapoor, J. H. Epstein, W. B. Karesh, P. Daszak, O. B. Mohammed, and W. I. Lipkin. 2014. Middle East respiratory syndrome coronavirus infection in dromedary camels in saudi arabia. MBio. $\mathbf{5}$.

57. Song, F., R. Fux, L. B. Provacia, A. Volz, M. Eickmann, S. Becker, A. D. Osterhaus, B. L. Haagmans, and G. Sutter. 2013. Middle East respiratory syndrome coronavirus spike protein delivered by modified vaccinia virus Ankara efficiently induces virusneutralizing antibodies. J. Virol. 87:11950-11954.

58. de Haan, C. A., K. Stadler, G. J. Godeke, B. J. Bosch, and P. J. Rottier. 2004. Cleavage inhibition of the murine coronavirus spike protein by a furin-like enzyme affects cell-cell but not virus-cell fusion. J. Virol. 78:6048-6054.

59. Frana, M. F., J. N. Behnke, L. S. Sturman, and K. V. Holmes. 1985. Proteolytic cleavage of the E2 glycoprotein of murine coronavirus: host-dependent differences in proteolytic cleavage and cell fusion. J. Virol. 56:912-920.

60. Cavanagh, D., P. J. Davis, D. J. Pappin, M. M. Binns, M. E. Boursnell, and T. D. Brown. 1986. Coronavirus IBV: partial amino terminal sequencing of spike polypeptide S2 identifies the sequence Arg-Arg-Phe-Arg-Arg at the cleavage site of the spike precursor propolypeptide of IBV strains Beaudette and M41. Virus Res. 4:133-143.

61. Bergeron, E., M. J. Vincent, L. Wickham, J. Hamelin, A. Basak, S. T. Nichol, M. Chretien, and N. G. Seidah. 2005. Implication of proprotein convertases in the processing and spread of severe acute respiratory syndrome coronavirus. Biochem. Biophys. Res. Commun. 326:554-563.

62. Follis, K. E., J. York, and J. H. Nunberg. 2006. Furin cleavage of the SARS coronavirus spike glycoprotein enhances cell-cell fusion but does not affect virion entry. Virology 350:358-369. 


\section{FIGURE LEGENDS}

FIG 1 MERS-S is cleaved in transfected and infected cells. 293T cells were transfected with a plasmid encoding the MERS-S protein or with empty plasmid (pcDNA). Vero B4 cells were either infected with MERS-CoV at an MOI of 5 or mock infected. Subsequently, the cells were lysed and analyzed by Western blot employing a polyclonal antibody directed against MERS-S. A $\beta$-actin antibody served as a loading control. Similar results were obtained in two separate experiments.

FIG 2 RXXR motifs located at the border between $\mathrm{S} 1$ and $\mathrm{S} 2$ are required for efficient MERS-S processing. A) The domain organization of the MERS-S protein is schematically depicted. The MERS-S sequence at the border between S1 and S2 subunit is shown. RXXR motifs, which constitute potential cleavage sites are highlighted and the start of the $\mathrm{S} 2$ subunit is underlined. The mutations introduced into the potential cleavage sites in MERS-S are shown. PCM, potential cleavage site mutant; $\mathrm{SP}$, signal peptide; RBD, receptor binding domain; TM, transmembrane domain; CT, cytoplasmic tail. B) 293T cells were transfected with expression plasmids coding for MERS-S wt and the indicated MERS-S mutants equipped with a C-terminal V5 tag. Transfection of empty plasmid ( $\mathrm{pcDNA}$ ) served as negative control. Expression of S proteins in cell lysates was determined by Western blot, using a V5 tag-specific monoclonal antibody. Expression of $\beta$ actin in cell lysates was assessed as a loading control. The results shown are representative for at least three independent experiments.

FIG 3 Mutation of 748-RXXR-751 (PCM3) and 884-RXXR-887 (PCM4) reduces MERS-Sdriven cell-cell and virus-cell fusion. A) $293 \mathrm{~T}$ effector cells were co-transfected with pGAL4- 
VP16 expression plasmid and plasmids encoding MERS-S wt or MERS-S mutants PCM1, PCM3 and PCM4. Cells transfected with empty plasmid (pcDNA) served as negative control. These effector cells were mixed with target cells, co-transfected with plasmid encoding the receptor DPP4 or empty plasmid, together with a plasmid encoding luciferase under the control of a promoter with five GAL4 binding sites. Cell-cell fusion was quantified by determination of luciferase activities in cell lysates. The results of a representative experiment performed with triplicate samples are shown. Error bars indicate standard deviation (SD). Similar results were obtained in two separate experiments. B) $293 \mathrm{~T}$ cells transfected with DPP4 expression plasmid were transduced with pseudotypes bearing either no glycoprotein (pcDNA), the glycoprotein of vesicular stomatitis virus (VSV-G), MERS-S wt or the indicated MERS-S mutants. Luciferase activities in cell lysates were measured at $72 \mathrm{~h}$ post transduction. The results of a representative experiment performed with triplicate samples are shown and were confirmed in two separate experiments. Error bars indicate SD. C) $293 \mathrm{~T}$ cells were cotransfected with an expression plasmid encoding HIV-1 p55 Gag and plasmids coding MERS-S wt or the indicated MERS-S mutants equipped with a C-terminal V5 tag. Transfection of empty plasmid (pcDNA) served as negative control. Subsequently, virus-like particles (VLPs) were harvested and concentrated by ultracentrifugation through a sucrose cushion. The presence of p55 Gag and MERS-S in concentrated VLPS was analyzed by Western blot employing anti-V 5 and anti-p55 Gag antibodies. Comparable results were obtained in two independent experiments. D) The experiment was carried out as described for panel B but Caco-2 cells were used as target cells. The results of representative experiments performed with triplicate samples are shown. Similar results were obtained in a separate experiment. 
FIG 4 Mutation of 748-RXXR-751 (PCM3) and 884-RXXR-887 (PCM4) is compatible with S protein processing by trypsin and TMPRSS2. A) Plasmids encoding MERS-S wt or the indicated MERS-S mutants were co-transfected into 293T cells with plasmid encoding TMPRSS2 or empty plasmid (pcDNA). Subsequently, the cells were treated with trypsin or PBS and S protein expression in cell lysates was analyzed by Western blot, using anti-V5 antibody. Detection of $\beta$ actin served as a loading control. MERS-S cleavage fragments generated by TMPRSS2 are pointed out by asterisks. Comparable observations were made in three independent experiments. B) The cell-cell fusion assay was carried out as described for figure $3 \mathrm{~A}$ but target cells transfected to express DPP4, TMPRSS2 or both DPP4 and TMPRSS2 were used. Cells transfected with empty plasmid (pcDNA) served as control. The effector/target cells mixtures were treated with trypsin or PBS and cell-cell fusion was quantified by determination of luciferase activities in cell lysates. The results of a representative experiment performed with triplicate samples are shown and were confirmed in two separate experiments. Error bars indicate standard deviation (SD). Tryp., trypsin. C) Target $293 \mathrm{~T}$ cells were transfected to express DPP4, TMPRSS2 or both DPP4 and TMPRSS2. Cells transfected with empty plasmid (pcDNA) served as negative control. The cells were incubated with the cathepsin B/L inhibitor MDL28170 for $1 \mathrm{~h}$ and then transduced with pseudotypes bearing MERS-S wt, PCM3 or VSV-G. Luciferase activities in cell lysates were measured at $72 \mathrm{~h}$ post transduction. The results of a representative experiment performed with triplicate samples are shown. Error bars indicate SD and comparable results were obtained in two independent experiments.

FIG 5 MERS-S is cleaved by proprotein convertases. $293 \mathrm{~T}$ cells were transfected with expression plasmids encoding MERS-S, Zaire ebolavirus glycoprotein (EBOV-GP) or Lassa virus glycoprotein (LASV-GPC), all equipped with a C-terminal V5 tag. Cells transfected with empty 
plasmid (pcDNA) served as negative control. Subsequently, cells were incubated with the indicated concentrations of the proprotein convertase inhibitor ( $\mathrm{PCI}$ ). At $48 \mathrm{~h}$ post transfection glycoprotein expression was analyzed by Western blot, using the V5 antibody. Detection of $\beta$-actin served as loading control. The results shown are representative of three independent experiments.

FIG 6 Proprotein convertases activity is dispensable for MERS-S-driven cell-cell and viruscell fusion. A) The cell-cell fusion assay was carried out as described for figure $3 \mathrm{~A}$ except that target cells transfected to express DPP4, TMPRSS2 or both DPP4 and TMPRSS2 were used. Both effector and target cells were incubated with $1 \mu \mathrm{M}$ of proprotein convertase inhibitor (PCI) as indicated and one day later mixed for co-cultivation. The effector/target cells mixtures were incubated with PBS or PCI and cell-cell fusion was quantified by determination of luciferase activities in cell lysates. The results of a representative experiment performed with triplicates samples are shown. Error bars indicate standard deviation (SD). Two separate experiments yielded similar results. B) Lentiviral pseudotypes carrying MERS-S, Lassa virus glycoprotein (LASV-GPC), Zaire ebolavirus glycoprotein (EBOV-GP) or the glycoprotein of vesicular stomatitis virus (VSV-G) as well as pseudotypes bearing no viral glycoprotein (pcDNA) were generated in the presence or absence of PCI $(1 \mu \mathrm{M})$. Subsequently, target 293T cells transfected with empty plasmid or DPP4 expression plasmid were pre-incubated with DMSO, PBS or $\mathrm{PCl}$ at a final concentration of $0.5 \mu \mathrm{M}$, for 30-60 min followed by transduction with the above specified pseudotypes. At $72 \mathrm{~h}$ post transduction, luciferase activities in cell lysates were measured. The average of five to seven independent experiments performed with triplicate samples is shown. Transduction with pseudotypes bearing VSV-G in the 
absence of inhibitor was set as $100 \%$. Error bars indicate standard error of the mean (SEM). At two tailed students t-test was applied to assess statistical significance.

FIG 7 Processing of MERS-S by proprotein convertases is dispensable for MERS-CoV infectivity. Caco-2 cells were incubated with the indicated concentrations of proprotein convertase inhibitor $(\mathrm{PCI})$ for $1 \mathrm{~h}$ and then inoculated with MERS-CoV at an MOI of 0.01 and 0.001 for $30 \mathrm{~min}$ at $4^{\circ} \mathrm{C}$. Thereafter, virus was removed, inhibitor replenished and cells were lysed at $24 \mathrm{~h}$ post infection for $\mathrm{S}$ protein detection by Western blot analysis ( $\mathrm{A}$, shown only MOI 0.01). In parallel, viral genomic RNA copies (B, left panel) or infectious MERS-CoV particles (B, right panel) in supernatants of MERS-CoV infected Caco-2 cells (with and without $\mathrm{PCI}$ treatment) were determined by qRT-PCR (upE assay) or plaque assay. The experiment was performed in quadruplicates and repeated twice with two different MOIs giving comparable results. Shown is one representative experiment (MOI 0.001). C) Cytopathogenic effects of MERS-CoV (MOI of 0.1 ) infected Vero $\mathrm{B} 4$ cells at $42 \mathrm{~h}$ post infection in the presence and absence of PCI. Viral antigen was detected with a MERS patient serum (1:100 diluted) followed by a cyanine 2-labeled goat-anti human immunoglobulin G. Nuclei were stained with DAPIcontaining mounting medium. Samples were analyzed by immunofluorescence microscopy (Zeiss) and pictures were taken at the same microscopic settings at a magnification of 200-fold. Similar results were obtained in two independent experiments performed with duplicate samples. 
Gierer et al.

Figure 1

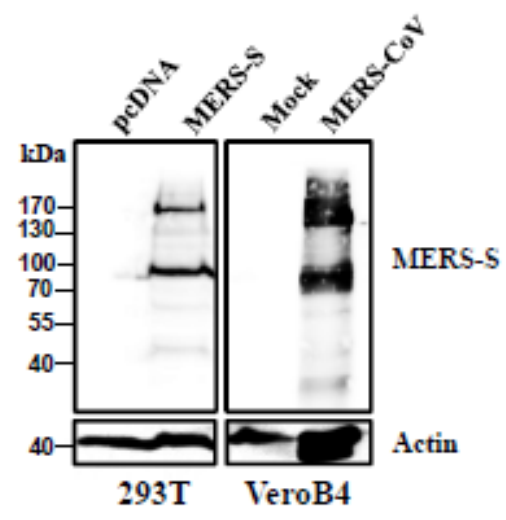


Gierer et al.

Figure 2

A)

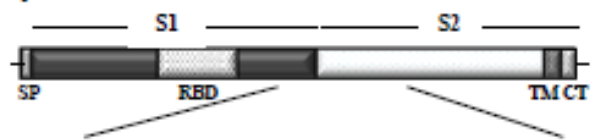

621 TAVGVRQQRP VYDAYQNLVG YYSDDGNYYC 651 LRACVSVPVS VIYDKBTKTH ATLPGSVACE

681 HISSTMSQYS RSTRSMLKRR DSTYGPLQTP

711 VGCVLGLVNS SLFVEDCKLP LGQSLCALPD

741 TPSTLTPRSV RSVPGEMRLA SIAFNHPIQV

771 DQLNSSYFKL SIPTNFSFGV TQBYIQTTIQ

801 KVTVDCKQYV CNGFQKCBQL LRBYGQFCSK

831 INQALHGANL RQDDSVRNLF ASVKSSQSSP

861 IIPGFGGDFN LTLLEPVSIS TGSRSARSAI

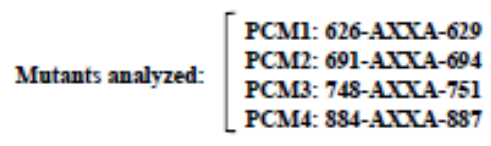

B)

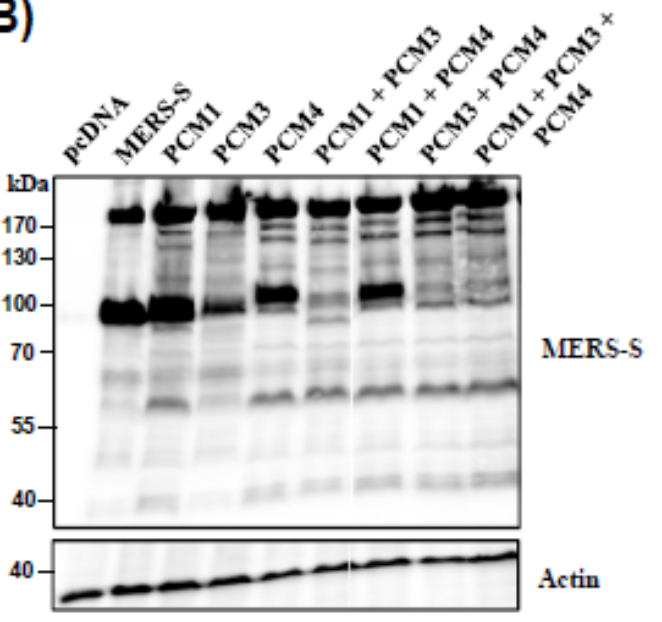


Gierer et al.

A)

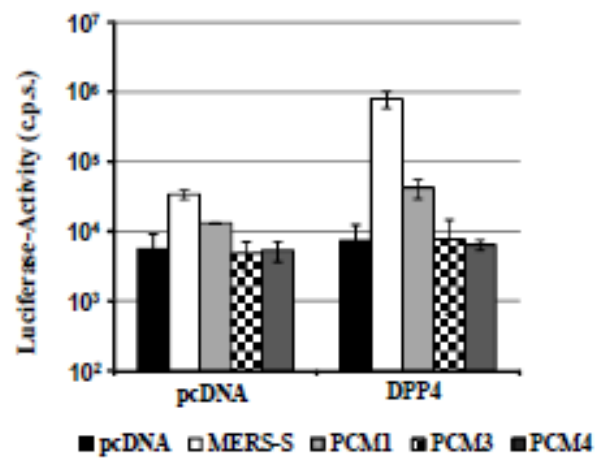

C)

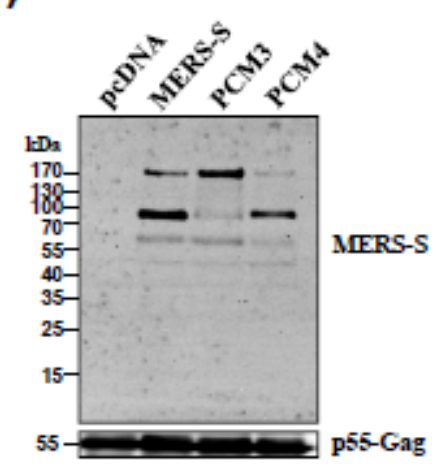

B)

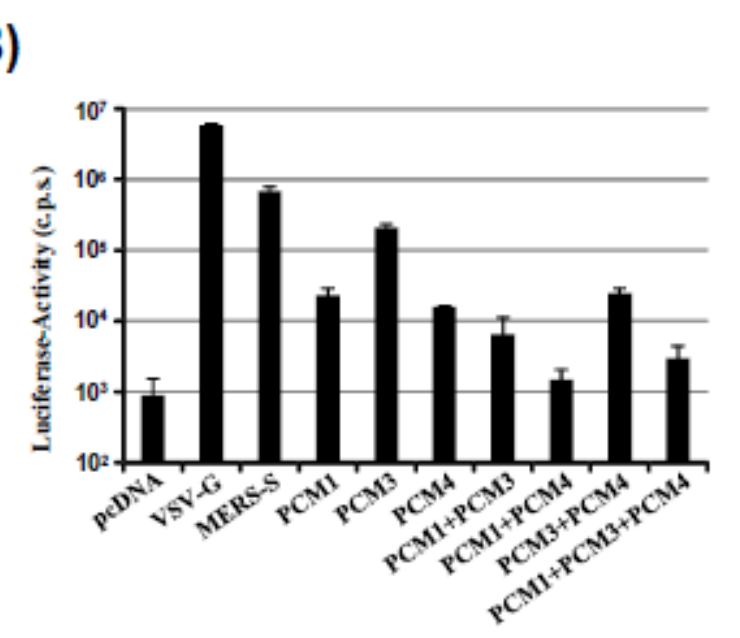

Figure 3

D)

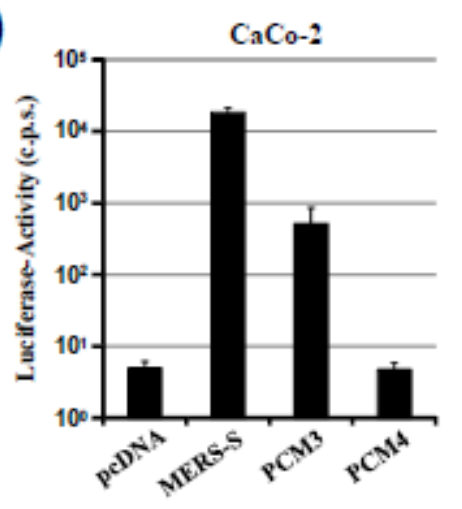


Gierer et al.

Figure 4

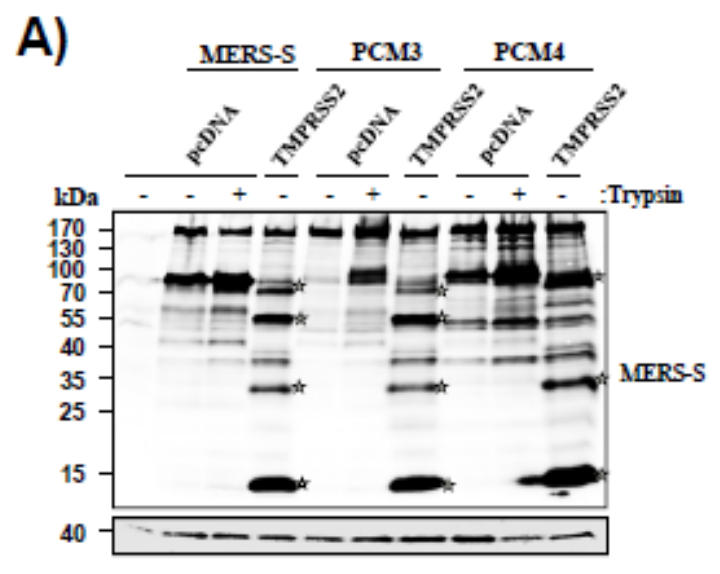

B)

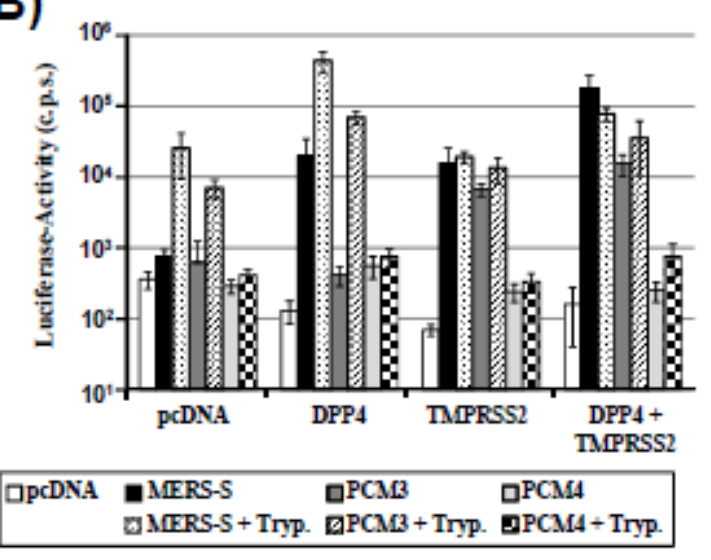

C)

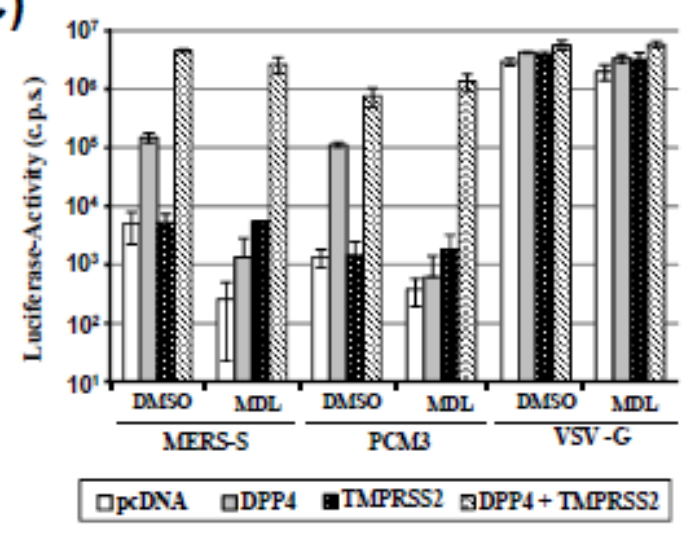


Gierer et al.

Figure 5
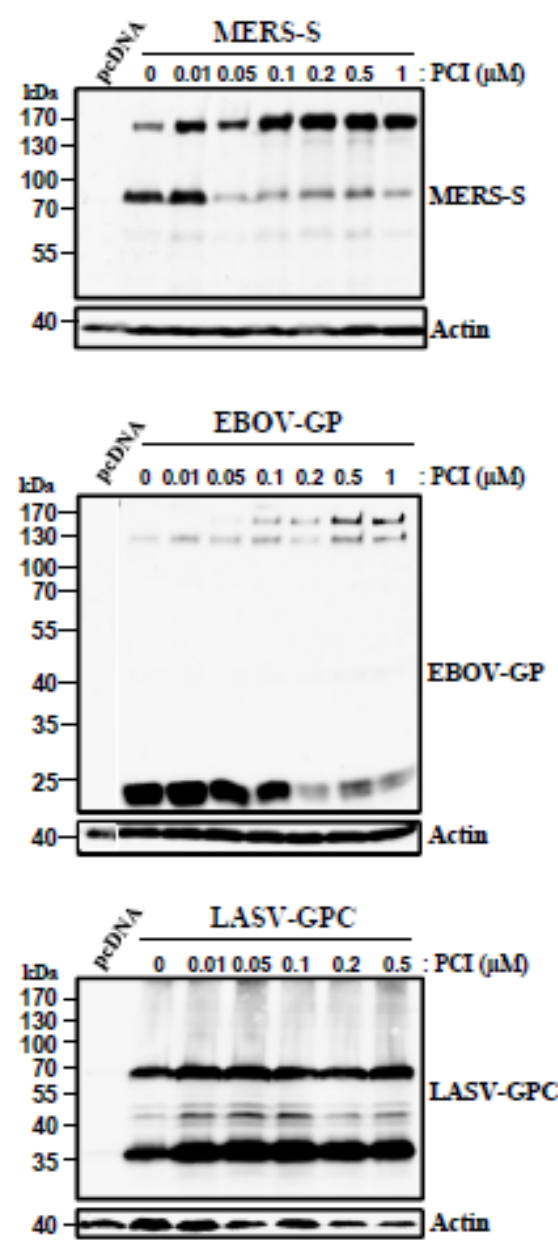
Gierer et al.

A)

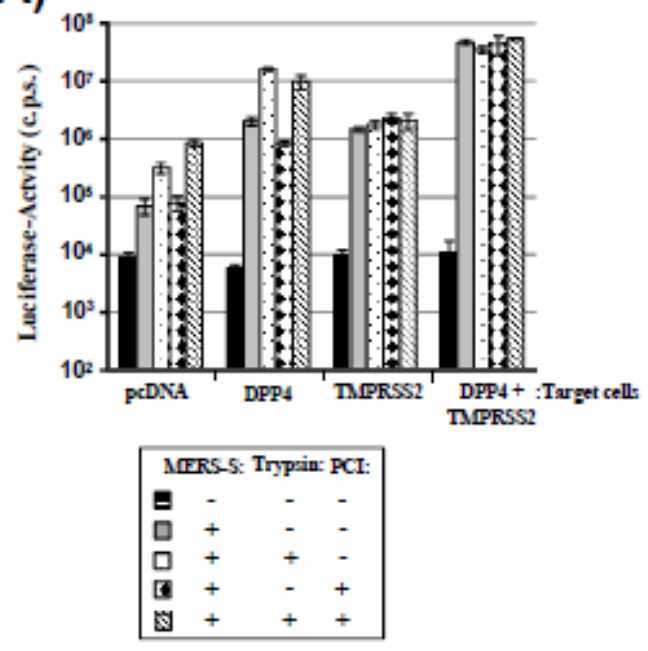

Figure 6

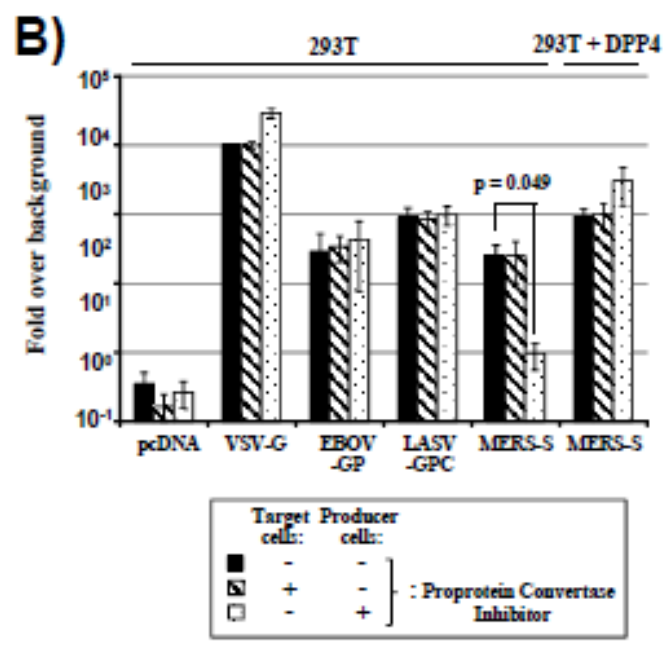


Gierer et al.

Figure 7

A)

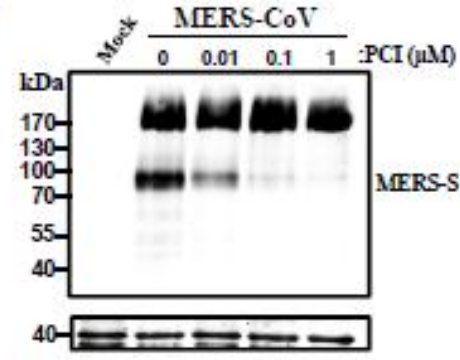

B)

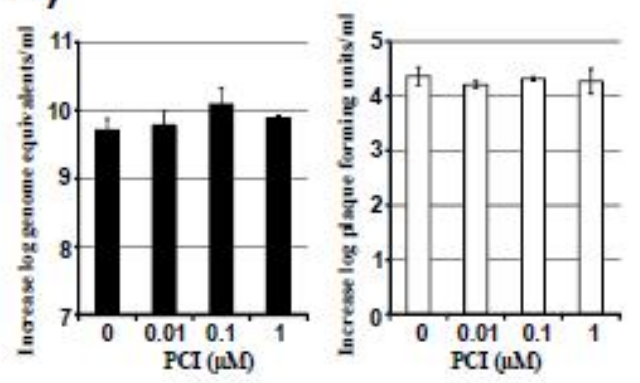

C)

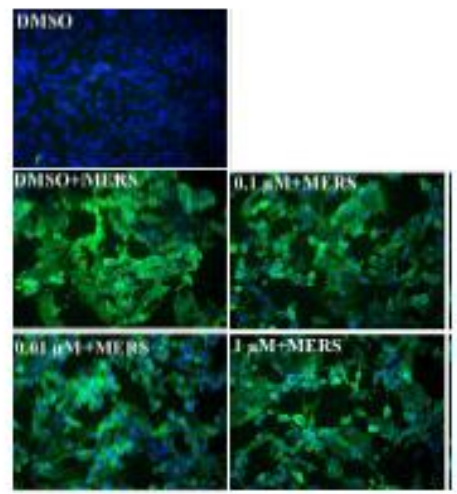


Third Manuscript 
Lack of MERS Coronavirus Neutralizing Antibodies in Humans, Eastern Province, Saudi Arabia

Stefanie Gierer,' Heike Hofmann-Winkler,' Waleed H. Albuali, Stephanie Bertram, Abdullah M. Al-Rubaish, Abdullah A. Yousef, Awatif N. Al-Nafaie, Amein K. Al-Ali, Obeid E. Obeid, Khaled R. Alkharsah, and Stefan Pöhlmann'

We used a lentiviral vector bearing the viral spike protein to detect neutralizing antibodies against Middle East respiratory syndrome coronavirus (MERS-CoV) in persons from the Eastern Province of Saudi Arabia. None of the 268 samples tested displayed neutralizing activity, which sug. gests that MERS.CoV infections in humans are infrequent in this province.

The emergence of the Middle East respiratory syndrome coronavirus (MERS-CoV, formerly termed EMC coronavirus [/]) could pose a serious threat to public health (2). As of September 2013, a total of 108 laboratory-confirmed infections (with 50 deaths) caused by MERS.CoV have been reported to the World Health Organization (WHO), most from Saudi Arabia (3), but data are limited on MERSCoV seroprevalence in humans $(f)$.

We recently developed a lentiviral vector system to study host cell entry mediated by the spike protein of MERS-CoV (MERS-S) (5). This system mimics key aspects of MERS-CoV cellular entry and enables sensitive and quantitative detection of neutralizing antibodies, which are known to be generated in infected patients (5) We used this system to determine the presence of MERS$\mathrm{CoV}$ neutralizing antibodies in serum and plasma samples obtained from patients at King Fahd Hospital of the

Author affilations: German Primate Center, Gottingen, Germany (S. Gierer, H. Hofmann-Wnker, S. Bertram, S. Pohlmann); and University of Dammam, Dammam, Saudi Arabia (W.H. Albuali, A.M. Al-Rubaish, A.A. Yousef, A.N. Al-Nafaie, A.K. AJ-Ali, O.E Obeid, KR. Alkharsah)

DOI: http//dx doi org/10.3201/oid1912.130701
University in Alkhobar, Saudi Arabia. The hospital is a referral hospital that serves the Eastern Provinee of Saudi Arabia, including the Dammam and Alhasa governorates, from which several MERS cases were reported, according to the Ministry of Health of Saudi Arabia and a recent study (6); no MERS patients were seen at King Fahd Hospital. Blood collection for this study was approved by the University of Dammam ethics committec, and informed, written consent for participation was received for all study participants.

\section{The Study}

Two collections of patient samples were analyzed. The first collection consisted of 158 serum samples taken from children hospitalized for lower respiratory tract infoetions during May 2010-May 2011. The samples came from 77 female and 81 male patients with a median age of 11.6 months (range 7.3 months to 9 years). The second sample collection consisted of 110 plasma samples from men with a median age of 28 years (range 19-52 years) who donated blood at the hospital during December 2012.

Analysis of MERS-S-driven transduction of target cells revealed that none of the samples investigated contained neutralizing antibodics against MERS-S (Figure 1). As a control, a subset of the samples was analyzed for inhibition of cellular entry mediated by the $\mathrm{G}$ protein of vesicular stomatitis virus (VSV-G), an animal virus that does not circulate in Saudi Arabia, and the spike protein of the human coronavirus NL63 (NL63-S), a globally circulating coronavirus. None of the samples robustly inhibited VSV-G-dependent entry, whereas most samples markedly reduced entry-driven by NL63-S (Figure 1), as expected (7). Experiments using serum samples of known neutralizing capacity confirmed that our neutralization experiments were sensitive and specific (Figure 2). Thus, serum samples obtained from a patient infoeted with MERS.CoV potently inhibited MERS-S but not VSV-G- or NL63-S-driven entry, whereas the reverse observation was made with serum samples reactive against NL63-S (Figure 2). In sum, none of the samples from children with respiratory infections and none of the samples from healthy adult men showed detectable amounts of MERS-S-neutralizing antibodies, but most neutralized NL63-S-driven host cell entry.

\section{Conclusions}

Our results suggest that the estimatod MERS-CoV seroprevalence in the area served by King Fahd Hospital was $<2.3 \%$ in children during $2010-2011$ and $<3.3 \%$ in male adults in 2012 (upper limits of the $95 \%$ Cls for $0 / 158$ and $0 / 110$, respectively, by Fisher exact test). Our analysis of samples from children might have underestimated seroprevalence

'These authors contributed equally to this article. 

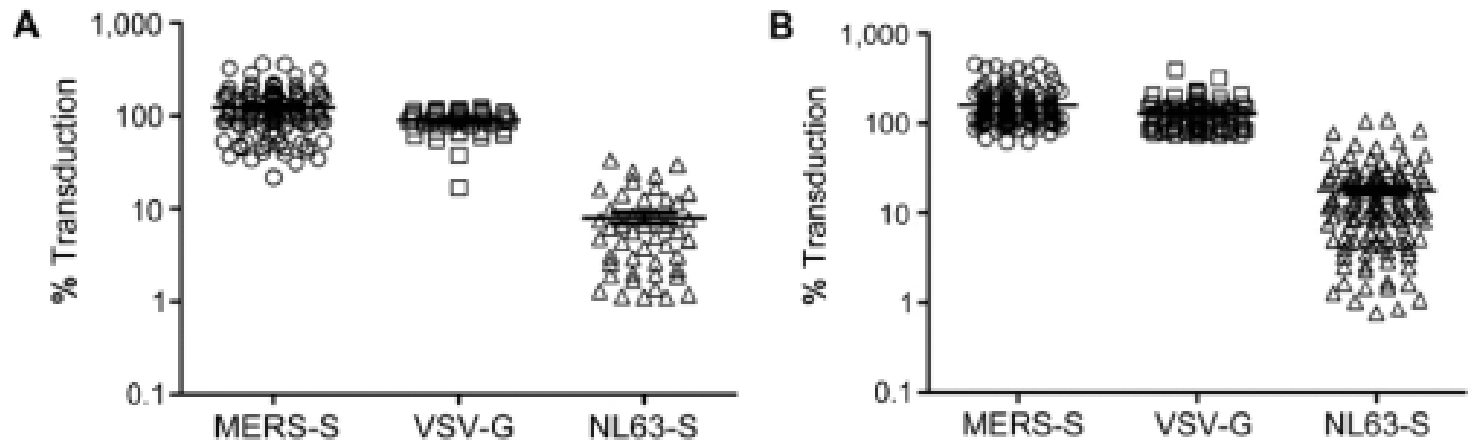

Figure 1. Neutralizing activity of serum and plasma samples obtained from patients at King Fahd Hospital of the University in Alkhobar, Saudi Arabia. A) Lentiviral vectors encoding luciferase and bearing the indicated viral glycoproteins were incubated with 1:20 dilutions of plasma from healthy adults, obtained during December 2012, and then added to target cells. Transduction efficiency was measured by quantification of luciferase activities in cell lysetes and is shown relative to transduction of cells in the absence of serum, which was set at $100 \%$. All 110 plasma samples available were tested for neutralization of Middle East respiratory syndrome coronavirus spike protein (MERS-S)-dependent transduction; subsets were also tested for neutralization of transduction driven by the $G$ protein of vesicular stomatis virus (VSV-G) (46/110) and the S protein of human coronavirus NL63 (NL63-S) (46/110). B) Analysis conducted as described for panel A using 158 serum samples from children with lower respiratory tract infections, obtained during May 2010-May 2011. All samples were analyzed for neutralization of MERS-S-mediated transduction; subsets were also tested for neutralization of transduction driven by VSV-G (76/158) and NL63-S (123/158). Horizontal lines indicate mean \pm SEM.

because if they were hospitalized for MERS-CoV infection, a vinus-specific antibody response might have developed after sample collection. Moreover, although infection of young children has been reported $(8)$, the average age of MERS patients is 50 years. Our findings using samples from adult men argue against the extensive spread of MERS-CoV within this group in the Eastern Province of Saudi Arabia during 2012, which is noteworthy given recent reports of asymptomatic MERS-CoV infections $(9,10)$.
We cannot rule out that other diagnostic methods that are not limited to detection of neutralizing antibodies might have identified positive samples in our collection. Future analyses are required to determine MERS-CoV seroprevalence in larger patient collectives and in animal species, such as dromedary camels, that could transmit the virus to humans $(4,1 /)$.

S.G. and S.P. were supported by BMBF (01KI1005C).
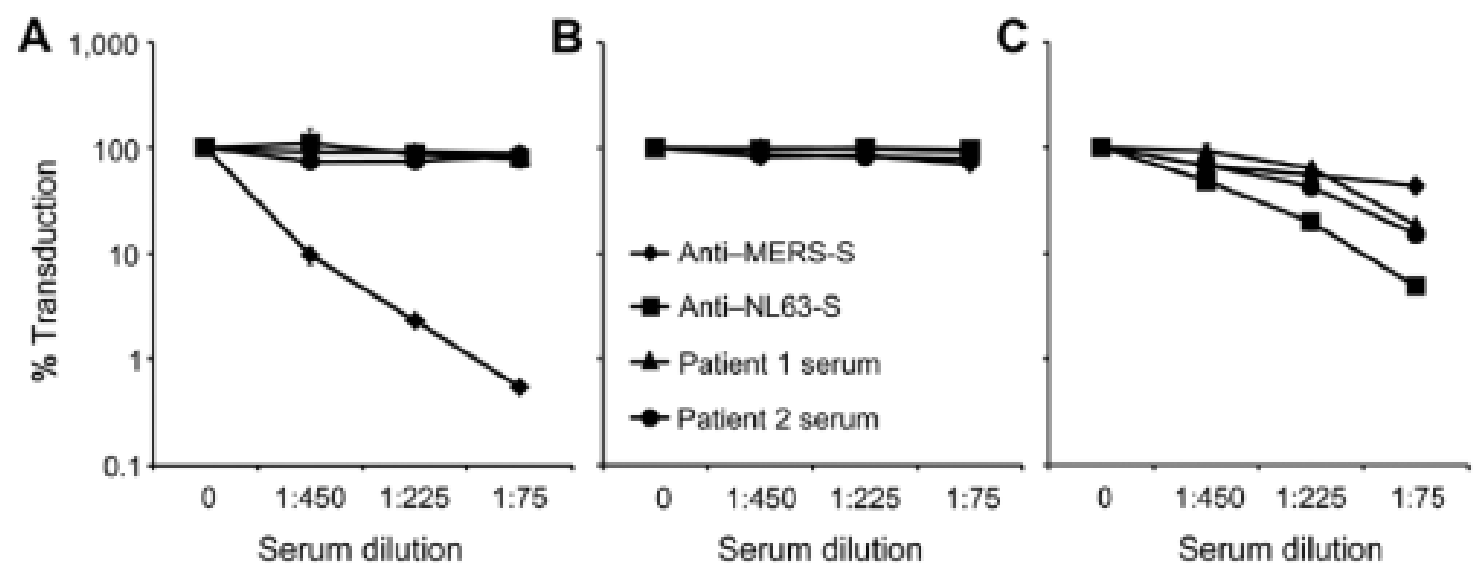

Figure 2 Analysis of serum samples with known neutralizing activity Neutralization of transduction driven by the Middle East respiratory syndrome coronavirus spike protein (MERS-S) (A), G protein of vesicular stomatitis virus (B), and S protein of human coronavirus NL63 (NLE3-S) (C) were determined as described for Figure 1, except that serum with known reactivity to MERS-S and NL63-S and serum from 2 patients at King Fahd Hospital of the University in Alkhobar, Saudi Arabia, that neutralized NL63-S-mediated transduction (Figure 1, panel A) were analyzed. Transduction of target cells in the absence of serum was set at $100 \%$. 


\section{DISPATCHES}

Ms Gierer is a third-year PhD candidate in the Georg-August University School of Science of the University of Gottingen, Gottingen, Germany. Her research is focused on coronavirus interactions with host cells, particularly at the stage of viral entry.

\section{References}

1. de Groot RJ, Baker SC, Baric RS, Brown CS, Drosten C, Enjuanes L. et al. Middle East respiratory syndrome coronavirus (MFRS-CoV): announcement of the Coronavirus Study Group J Virol. 2013:87:7790-2. httpe//dx.doi.org/10.1128 JVL 012.44-13

2. Zaki AM, van Bohecmen S, Bestebroer TM, Osterhaus AD, Fouchier RA. Isolation of a novel coronavinus trom a man with pecumonia in Saudi Arabia. N Engl J Med. 2012:367:1814-20 httpe/dx.doi.org/10.1056/NEJMoa1211721

3. World Health Organization. Middle East respiratory syndrome coronavirus (MERS-CoV) update. 2013 Aug 30 [cited 2013 Sep 10]. http://www, who int cso don $201308 \quad 30$ en index.html

4. Perera RA, Wang P. Gomse MR, El-Shesheny R, Kandal A Bogato $O$, et al. Seroepidemiology for MERS coronavirus using microneutralisation and pseudoparticle virus neutralisation assays reveal a high prevalence of antibody in dromodary camels in Fgype June 2013. Euro Suneill. 2013;18.20574

5. Gierer S, Bertram S, Kaup F, Wrenseh F, Heunch A, Kramer-Kohl A et al. The speke-protein of the emerging betscosonasirus EMC uses a novel cotonavirus recepor for entry, can be activated by TMPRSS2 and is targeted by neutral izing antibodies. J Virol. 2013:87:5502-11. hatpo/dx.doi.org 10.1128 JVL $00128-13$
6. Asini A MoGeer A. Perl TM. Price CS, Al Rabecah A. Cummings DA, ef al. Hospital outbreak of Middle East respiratory syndrome coronavirus. N Engl J Mod. 2013;369;407-16, http: dxdoi ory 10.1056/NEJMoal 306742

7. Hofmann H. Pyre K. van der Hock 1. Geier M. Berkbout B, Pohlmann S. Iluman coronavinus N1.63 employs the severe acute respiratory syndrome coronavinas reseptor for cellular entry. Proc Natl Acad Sci U S A. 2005,102:7988-93, http//Axdoi.ong/10.1073. peas 0409465102

8. World Health Orgarization. Novel corcenavirus infection - sammary and literature update. $2013 \mathrm{Aug} 13$ [cited $2013 \mathrm{Sep} 10$ ] httpr/ www uhoint

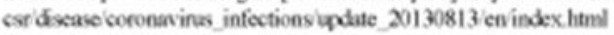

9. Omrani AS, Matin MA, Haddsd Q. Al-Nakhli D, Memish ZA. Alburrak AM. A family cluater of Middle East respiratory syndrome coronavirus infections related to a likely unrecognixed asymptom. atic or mild case. Int J Infect Dis. 2013:17:e668-72. http //dx dos. ore 10.1016 j ijid $2013,07.001$

10. Memish 2A. Zumla AL. Assiri A. Middle East respiratory syndrome coronswirus infections in health care workers. N Engl f Med. 2013:369:884 - 6. http//Ax doi.org/10.1056 NFJMc1308698

11. Reusken CB, Haagmans BI . Moller MA. Gutierrez C, Godeke G., Meyer B, ef al. Middle East respiratory syndrome coronavinus neutralising serum antibodies in dromedary camels a comparative serological study. Lancet Infect Dis. 2013, Epub ahesd of print. http: dx.doi.ong 10.1016 S1473-3099(13)70164-6

Address for corresposdenos: Stefan Pohlmann Infoction Biology Unit, German Primate Center, Kellnerueg 4, 370m Gottingen, Germany; email: spochlmannadpe cu 


\section{DISCUSSION}

\subsection{The spike protein of the emerging betacoronavirus EMC uses a novel coronavirus receptor for entry, can be activated by TMPRSS2, and is targeted by neutralizing antibodies.}

The novel Middle East Respiratory Syndrome Coronavirus (MERS-CoV), formerly known as hCoV-EMC, with its high mortality rate, displays a significant threat to public health. In order to develop antiviral agents, viral and host cell interdependency has to be elucidated. Coronavirus entry is mediated by the spike (S) protein, which is a major determinant of the viral cell tropism [Kuo et al., 2000]. The binding of the S protein to its receptor is the first step of viral invasion [Belouzard et al., 2012]. Receptors, that are engaged by other human coronaviruses are CD13 (hCoV-229E), ACE2 (SARS-CoV, hCoV-NL63) and sialic acid (hCoV-OC43) [Vlasak et al., 1988, Yeager et al., 1992, Li et al., 2003]. Which receptor is used by the MERS-CoV S protein (MERS-S) for entry was unknown. Coronavirus S proteins depend on proteolytic activation by host cell proteases to gain their fusiogenic potential [Harrison 2005]. The S proteins of hCoV-299E and SARS-CoV can be activated by the $\mathrm{pH}-$ dependent cysteine protease cathepsin L (CTSL) [Simmons et al., 2005, Kawase et al., 2009] and the type II transmembrane serine protease TMPRSS2 [Matsuyama et al., 2010]. The proteases which activate MERS-S were unknown.

Employing a lentiviral pseudotyping system, it could be demonstrated that the MERS-S protein does not engage known human coronavirus receptors, but facilitates entry into a broad spectrum of human cell lines, suggesting that the MERS-CoV receptor molecule is broadly expressed in human tissue. Furthermore, it could be shown that the $\mathrm{S}$ protein is activated by cathepsin L and TMPRSS2. Finally, a pseudotyping system was used to demonstrate the presence of neutralizing antibodies in a serum of a convalescent patient.

Previous studies have shown that the host cell entry of coronaviruses can be studied with the help of retroviral vectors, pseudotyped with coronaviral S proteins [Hofmann et al., 2004, Moore et al., 2004, Simmons et al., 2004]. Therefore, lentiviral pseudotypes were employed in the present study to analyze MERS-S-driven host cell entry. Efficient expression of the $S$ protein and incorporation into lentiviral pseudotypes was verified by Western blot analyses. Thereby, two prominent bands could be detected, one corresponding to the precursor $\mathrm{S}$ protein and one to a cleavage product, which is in concordance with the proteolytic processing 
of some coronavirus S protein during biogenesis [de Haan et al., 2004]. If this cleavage pattern is also detectable in MERS-CoV infected cells, and if the processing is relevant for viral infectivity was investigated in subsequent studies (see below). MERS-S-bearing vectors transduced a broad spectrum of human cell lines, including Caco-2 cells (colon), HOS (osteosarcoma), Huh-7 (liver), MRC5 (fetal lung fibroblasts) and 293T (kidney) as well as PMA-induced macrophages. Cells derived from the retina (RPE), glioblastoma (U373), endothelium (EA-hy) and from lung (A549, alveolar basal epithelial cells) were not susceptible. These findings suggest a broad expression of the receptor which is used by MERS-CoV for entry, and provides insights into the organ and tissue tropism of MERS-CoV. Moreover, these findings might explain MERS-CoV replication in multiple organ systems, which might in turn correlate with the high mortality rate that is connected with MERS-CoV infection. Independent studies confirmed the results discussed above and found that nonciliated epithelium cells and type II pneumocytes are the major targets for MERS-CoV [Chan et al., 2013, Kindler et al., 2013, Raj et al., 2013, Zielecki et al., 2013]. Of note, MERS-CoV was shown to replicate in cells of the lower respiratory tract, while those from the upper respiratory tract were not susceptible [Chan et al., 2013]. The observed MERS-CoV cell tropism of the respiratory tract correlates with the clinical picture, patients present, especially the severe pneumonia [Zaki et al., 2012, Drosten et al., 2013]. Renal failure as a frequent clinical symptom in MERS patients [Bermingham et al., 2012] is in agreement with the susceptibility of kidney cells to $\mathrm{S}$ protein-driven entry [Bermingham et al., 2012]. Interestingly, both SARS-CoV and MERS-CoV exhibit a similar organ tropism (lung, colon and kidney), which would suggest the use of a common cellular receptor for entry: The ACE2 molecule. However, the present study showed that lentiviral pseudotypes bearing MERS-S were not able to transduce cell lines expressing ACE2 or any of the other known coronavirus receptors, indicating that MERS-CoV utilizes a novel receptor, which is in concordance with other studies [Müller et al., 2012]. Subsequently, Raj and colleagues could identify the receptor of question as the exopeptidase dipeptidyl peptidase 4 (DPP4 or CD26) [Raj et al., 2013]. DPP4 expression correlates with the tissue tropism of MERS-CoV [Boonacker and Van Noorden 2003, Raj et al., 2013]. However, this correlation is not absolute, thus suggesting the possibility of an alternative receptor [Zhao et al., 2013].

For entry into target cells, the membrane of enveloped viruses has to fuse with the host cell membrane. To unfold its fusogenic potential, the viral glycoprotein needs to be triggered, either by receptor engagement, as for the murine leukemia virus envelope protein (MLV-Env) 
[McClure et al., 1988], low pH (vesicular stomatitis virus glycoprotein, VSV-G) [Superti et al., 1987], or both (SARS-S, influenza virus HA) [White et al., 2008]. Alternatively, cleavage by host cell proteases might suffice to trigger the membrane fusion reaction as has been suggested for coronavirus S proteins [Simmons et al., 2004]. It could be shown that the pHdependent endosomal cysteine proteases cathepsin B and L activate the Ebolavirus glycoprotein [Chandran et al., 2005] and that cathepsin L activates the SARS-S protein [Simmons et al., 2005]. These endosomal proteases depend on low $\mathrm{pH}$, which can be inhibited by lysosomotropic agents such as ammonium chloride. Direct inhibition of both endosomal proteases can be facilitated by MDL28170 [Simmons et al., 2005]. To identify host cell enzymes which are responsible for the activation of MERS-S, both inhibitors were employed and were shown to block MERS-S-mediated transduction. This indicates that the processing of MERS-S, like SARS-S, requires low $\mathrm{pH}$ and the activity of the endosomal cysteine proteases cathepsin B and L. Two studies confirmed these findings and discovered that cathepsin L is the major protease responsible for activation of MERS-S [Qian et al., 2013, Shirato et al., 2013].

The influenza virus hemagglutinin [Böttcher et al., 2006] and SARS-S can hijack TMPRSS2 for cellular entry. In the latter case, glycoprotein activation by TMPRSS2 allows for cathepsin-B/L-independent entry [Matsuyama et al., 2010, Glowacka et al., 2011, Shulla et al., 2011]. Since the entry strategies of MERS-CoV seem to be similar to that of SARS-CoV, it appeared to be likely that MERS-S could also be activated by TMPRSS2 and potentially other type II transmembrane serine proteases (TTSPs). Indeed, Western blot analyses showed that MERS-S is processed by trypsin, TMPRSS2 and HAT, while the TTSPs TMPRSS3, TMPRSS4 and TMPRSS6 failed to cleave the S protein. The same observation was made when S-bearing virus-like particles were generated in the presence of these proteases. Based on these findings, inhibitors were used to investigate if the TTSPs-mediated processing of MERS-S would result in S protein activation. MDL28170 was used to inhibit cathepsin B/L and camostat mesylate to inhibit TMPRSS2 [Kawase et al., 2012]. It could be shown that MDL28170 blocked entry into 293T cells and that this blockade was rescued by the expression of TMPRSS2, indicating that MERS-S can use TMPRSS2 for viral entry in a cathepsin B/L-independent manner. Moreover, infection experiments using Caco-2 cells, which endogenously express TMPRSS2 [Bertram et al., 2010], revealed that MERS-S activation by TMPRSS2 (as assed by camostat treatment) dominates over activation by 
cathepsin B/L. Similar results were obtained with other TMPRSS2-expressing cells (Vero cells, Calu-3 cells) [Shirato et al., 2013].

TMPRSS2 is expressed in the human respiratory epithelium together with the MERS-S receptor DPP4 [Boonacker and Van Noorden 2003, Raj et al., 2013] and the SARS-S receptor ACE2 [Bertram et al., 2012, Raj et al., 2013]. Notably, infection of TMPRSS2 expressing VeroB4 cells induced the formation of large syncytia [Qian et al., 2013, Shirato et al., 2013], illustrating the high membrane fusion potential of MERS-S. Thus, inhibitors targeting proteases required for viral entry exhibit therapeutic potential to suppress viral replication, which has already been suggested for infection with filoviruses and other coronaviruses [Simmons et al., 2005, Zhou and Simmons 2012]. However, the biological relevance of TMPRSS2-dependent MERS-CoV glycoprotein activation awaits further investigation and TMPRSS2-knockout mice [Hatesuer et al., 2013] might be suitable tools, since Adenoviral vector-hDPP4-transduced mice were recently shown to support MERS-CoV spread [Zhao et al., 2014].

The coronavirus $\mathrm{S}$ protein is the major target for neutralizing antibodies of the human immune response [Hofmann et al., 2004], which in turn might contribute to the control of coronavirus infection. Therefore, the pseudotyping system might be useful for diagnostic purposes. Employing the pseudotyping system, neutralizing antibodies were found to be generated in a covalescent patient. The same finding was obtained with authentic MERS-CoV [Corman et al., 2012, Buchholz et al., 2013, Chan et al., 2013, Aburizaiza et al., 2014]. Furthermore, the experiments of the present study show that there is no cross-reactivity of MERS-Sneutralizing antibodies against the glycoprotein of SARS-CoV. Interestingly, Chan and colleagues found significant titers of MERS-CoV reactive antibodies in sera from convalescent SARS patients [Chan et al., 2013], suggesting that antibodies directed against SARS-S might also neutralize MERS-S. A putative cross-reactive capability with the highly related HKU4 and HKU5 still has to be investigated.

In summary, the present study provided insights into the cell tropism of MERS-CoV and identified host cell proteases which can activate MERS-S. On the basis of these findings, therapeutic strategies targeting these proteases could be developed. Blockade of TMPRSS2 might be particularly attractive, since genetic knock-out of tmprss 2 in mice has no phenotype [Kim et al., 2006]. Finally, the findings demonstrated that the pseudotyping system is suitable to detect neutralizing antibodies against MERS-CoV and could be developed as a diagnostic tool. 


\subsection{Inhibition of proprotein convertases abrogates processing of the MERS- coronavirus spike protein in infected cells but does not reduce viral infectivity}

The coronavirus spike (S) glycoprotein, including the MERS-CoV spike protein (MERS-S), depends on proteolytically processing by host cell proteases to obtain its fusogenic potential [Gierer et al., 2013, Simmons et al., 2013]. Proteolytic activation can occur at different stages of the coronavirus infection cycle: During S protein biosynthesis in the secretory pathway of infected cells and during entry into target cells, either at the cell surface or within the acidic environment of the endosome [Heald-Sargent and Gallagher 2012]. It could be shown that MERS-S can be activated both at the host cell surface by the transmembrane serine protease TMPRSS2, and following internalization of virions into endosomes by the $\mathrm{pH}$-dependent cysteine protease cathepsin L [Gierer et al., 2013, Qian et al., 2013, Shirato et al., 2013]. Furthermore, it was demonstrated that MERS-S is cleaved in transfected cells [Gierer et al., 2013, Shirato et al., 2013], but whether this is also the case in infected cells remained to be determined. In addition, the biological relevance of this cleavage process was unknown and the responsible enzyme remained to be identified.

The present study shows that MERS-S is also cleaved in infected cells and that proprotein convertases are responsible for the cleavage, which requires the presence of several RXXR motifs located at the border between the S1 and S2 subunit. However, processing of MERS-S by proprotein convertases was not required for viral infectivity.

It was previously demonstrated that the S protein of MERS-CoV and other coronaviruses can be activated by TMPRSS2 and cathespin L [Simmons et al., 2005, Matsuyama et al., 2010, Glowacka et al., 2011, Shulla et al., 2011, Kawase et al., 2012, Bertram et al., 2013, Gierer et al., 2013, Qian et al., 2013, Shirato et al., 2013]. However, it is conceivable that MERS-S requires an initial cleavage process during biogenesis for subsequent activation by TMPRSS2 or cathepsin L for infectious viral entry into target cells. Evidence for a two-step cleavage process, the first in the secretory pathway, the second during viral uptake, has been presented for certain bunyavirus glycoproteins [Hofmann et al., 2013]. Alternatively, it is possible that cleavage during biogenesis in infected cells is necessary for cell-cell fusion but not for viruscell fusion, which would result in the formation of syncytia, a common feature of MERS-CoV pathogenesis [Zaki et al., 2012]. For instance, cleavage of the coronavirus MHV-A59 spike protein at a furin consensus sequence is required for cell-cell but not virus-cell fusion [Frana et al., 1985, Spaan et al., 1988, de Haan et al., 2004]. 
Western blot analysis revealed that MERS-S is cleaved in virus producing cells. Two prominent glycoprotein signals were detected in lysates from $\mathrm{S}$ protein transfected 293T cells and MERS-CoV infected Vero B4 and Caco-2 cells, indicating that MERS-S is efficiently cleaved in various cell types during biogenesis in the secretory pathway. This observation is in concordance with other studies [Gierer et al., 2013, Shirato et al., 2013, Song et al., 2013, Alagaili et al., 2014]. One group did not observe cleavage products upon MERS-S expression [Qian et al., 2013]. A possible explanation could be that they analyzed an S protein with a truncated cytoplasmatic tail and this deletion might alter $\mathrm{S}$ protein folding and proteolytic processing.

Shown in Western blot analyses, the employment of a proprotein convertase inhibitor (PCI) revealed that the protease responsible for MERS-S processing was found to be a member of the proprotein convertase family. This finding is not unprecedented, since proprotein convertases are also responsible for the processing of the spike protein of MHV-A59 [Frana et al., 1985, de Haan et al., 2004] and IBV [Cavanagh et al., 1986, Yamada and Liu 2009]. The SARS-CoV spike protein is inefficiently cleaved by proprotein convertases, but cleavage seems to be required for viral spread and for the formation of cytopathic effects [Bergeron et al., 2005, Follis et al., 2006, Simmons et al., 2011]. The spike protein of MHV type 2 is not cleaved by proprotein convertases and needs to be activated by cathepsin inside endosomal vesicles [Qiu et al., 2006].

The consensus motif of most proprotein convertases is (R/K)-2nX-R $\downarrow[$ Seidah and Prat 2012], and inspection of the MERS-S sequence revealed four minimal furin cleavage motifs (RXXR) at the border between the $\mathrm{S} 1$ and $\mathrm{S} 2$ subunit, that can possibly be engaged by proprotein convertases [Pasquato et al., 2013]. To investigate the role of these motifs in MERS-S processing, critical amino acids were exchanged from arginine to alanine residues (resulting in potential cleavage site mutants, PCM) and the corresponding MERS-S mutants were analyzed for cleavability. The majority of the mutant spike proteins were efficiently expressed and the mutation of two potential cleavage sites (3 and 4) had an impact on S protein processing. However, combined mutation of two potential cleavage sites was required to completely abrogate cleavage of transfected $S$ protein. This observation suggests that proprotein convertases might be able to engage more than one cleavage motif in the spike protein and that blockade of one motif results in the cleavage of another. An indication for that is the observation that the molecular weight of the resulting cleavage product S2 of PCM4 was slightly increased. In this case, the protease might use potential cleavage site 3, 
instead of the mutated potential cleavage site 4. However, it is also conceivable that all three RXXR motifs are needed to maintain the structure of the cleavage site.

Many different type I transmembrane glycoproteins depend on processing of their viral glycoproteins by cellular PCs in order to achieve the fusion-active state, for example the HA of the highly pathogenic avian influenza viruses (HPAI) [Bosch et al., 1981, Stieneke-Grober et al., 1992, Vey et al., 1992] or the HIV-1 envelope glycoprotein [Hallenberger et al., 1992]. For other glycoproteins, however, processing by proprotein convertases has diverse consequences. For example, the MHV-A59-S is also cleaved by PCs and cleavage was found to be required for cell- cell but not for virus- cell fusion [Frana et al., 1985, Spaan et al., 1988, de Haan et al., 2004], while MHV-2-S is not cleaved during biogenesis in the constitutive secretory pathway of infected cells [Qiu et al., 2006]. Moreover, the ability of the Ebolavirus glycoprotein to facilitate viral entry was not affected by the inactivation of the furin cleavage site [Neumann et al., 2002].

Functional analysis of MERS-S mutants revealed that that the inactivation of three RXXR motifs reduced MERS-CoV spike-driven cell-cell and virus-cell fusion, respectively, although the mutant proteins were efficiently expressed and incorporated into virus-like particles. In contrast, the mutants were still proteolytically processed by trypsin and TMPRSS2.

These observations revealed that the cleavage of MERS-S and the ability of MERS-S to drive cell-cell and virus-cell fusion depends on the integrity of all 3 predicted cleavage sites. It was therefore unexpected that the inhibition of proprotein convertase by a proprotein convertase inhibitor had no effect on MERS-driven cell-cell and virus-cell fusion when target cells expressing high amounts of DPP4 were used. However, reduced virus-cell fusion was observed when $293 \mathrm{~T}$ target cells with only a low endogenous expression of DPP4 were employed. Thus, a high amount of DPP4 on target cells might compensate for absence of MERS-S processing by proprotein convertases. Processing of MERS-S by proprotein convertases could therefore be necessary for optimal spread in cell lines which express only a low level of DPP4. This scenario is reminiscent of SARS-S-driven cell-cell fusion, which is ineffective when receptor expression is low but can be restored by expression of S proteinactivating proteases [Simmons et al., 2011]. This possibility should be further investigated. Alternatively, secondary effects on $\mathrm{S}$ protein processing or maturation due to inactivation of RXXR motifs could also be an explanation for the reduced MERS-S-driven cell-cell and virus-cell fusion. Finally, endogenously DPP4 expressing Caco-2 cells were treated with the proprotein convertase inhibitor and infected with authentic MERS-CoV. Confirming that 
MERS-S is indeed a substrate for proprotein convertases, inhibition of cleavage by PCI administration was observed. However, amplification of MERS-CoV in cell culture was not affected by the inhibitor, as the amount of viral RNA and the titer of released infectious particles was not reduced, and there was only an insignificant change in cytopathic effects. The activity of proprotein convertase is therefore dispensable for MERS-CoV infectivity in cell culture. Therefore, the massive syncytia formation, in MERS cytopathology might be rather due to activity of proteases other than proprotein convertases, e.g. that of TTSPs [Qian et al., 2013, Shirato et al., 2013].

It was shown that RXXR motifs are essential for proprotein convertase-mediated processing, and mutated RXXR motifs result in reduced cell-cell and virus-cell fusion, however, inhibition studies with PCI revealed that these phenotypes were not linked. The possibility that the RXXR motifs might be necessary for appropriate spike protein folding and efficient receptor binding was excluded by FACS-based analyses of S protein binding to soluble DPP4. The RXXR motif might not only serve as target sites for proprotein convertases but could also be recognized by other proteases, which activate the spike protein for membrane fusion, a possibility that would explain the reduction of MERS-S-dependent membrane fusion activity when the recognition motifs are mutated. A candidate protease recognizing RXXR motifs is cathepsin L, since virus-cell fusion of PCM1 and PCM4 was, compared to the wild type, reduced in $293 \mathrm{~T}$ cells. This hypothesis needs further investigation and the protease(s) in question have to be identified.

In summary, it could be shown that the MERS-CoV spike protein is a substrate for proprotein convertases, which cleaves MERS-S in the secretory pathway of infected cells. However, MERS-S cleavage by proprotein convertases was found to be dispensable for viral activation and spread in host cells. The development of therapeutic agents should therefore focus on inhibition of protease activating MERS-S during viral entry: TMPRSS2 and cathepsin L. 


\subsection{Lack of MERS coronavirus neutralizing antibodies in patients from Eastern Province, Saudi Arabia}

The emergence of the Middle East Respiratory Syndrome Coronavirus proved to be a threat to human health that should not be underestimated. As of May $9^{\text {th }}, 2014,536$ cases and 145 deaths have been reported (http://www.who.int/csr/disease/coronavirus_infections/MERS_ CoV_Update_09_May_2014.pdf?ua=1), with the majority of infections occurring in Saudi Arabia (World Health Organization; http://who.int/csr/don/2014_04_24_mers/en/). When this study was started, it was unclear whether the virus is circulating in an animal host and is subsequently introduced into the human population, or whether it circulates continuously in humans [Cauchemez et al., 2013].

Due to limited surveillance data it cannot be ruled out that a significant number of MERS cases has gone undetected because of mild progression or because of continuous, asymptomatic circulation in humans [Memish et al., 2013, Omrani et al., 2013, Penttinen et $a l ., 2013]$. The detection of neutralizing antibodies can be used to estimate the prevalence of MERS-CoV infection in high-risk areas. Moreover, evidence for zoonotic transmission might be obtained upon comparison of antibody prevalence in humans who were exposed or not exposed to animals.

To detect neutralizing antibodies in patient sera, a lentiviral pseudotyping system has proved useful. Lentiviral pseudotypes are env-defective, single-cycle virions, complemented with a viral envelope protein of choice, e.g. the coronavirus spike protein. Upon successful transduction, a reporter gene is expressed in the target cell, which enables quantification of glycoprotein-mediated entry. However, as the particles lack the genetic information for an envelope protein, infectious progeny virions will not be released from the transduced cell; thus no high biosafety level is required when operating with this diagnostic tool. This system has previously been used to detect neutralizing antibodies in sera obtained from SARS-CoV and hCoV-NL63 patients [Hofmann et al., 2004, Hofmann et al., 2005] and also proved suitable to verify a neutralizing antibody response after MERS-CoV infection in the present study.

To receive information about the MERS-CoV seroprevalence, samples were obtained from the geographic area where most MERS-CoV cases occurred or were linked to: Saudi Arabia. The patient samples were obtained from the King Fahd Hospital of the University in 
Alkhobar, Eastern Province, Saudi Arabia, in which no MERS patients had been attended to during the time of sample collection. The samples included 158 serum samples taken from children (age range: 7.3 months to 9 years), who presented with lower respiratory tract infection, between May 2010 and May 2011, as well as 110 plasma samples collected from healthy adult blood donors in December 2012.

Transduction analyses of target cells with MERS-S-bearing pseudotypes revealed that none of the patient samples tested contained neutralizing antibodies. As a negative control, a subset of the samples was investigated for inhibition of entry driven by the glycoprotein of the vesicular stomatitis virus (VSV-G), which is an animal virus that does not circulate in Saudi Arabia. As expected, none of the samples inhibited entry driven by VSV-G. As positive control, pseudotypes bearing the spike protein of the globally circulating human coronavirus NL63 were used and found to be frequently inhibited by the patient samples. Finally, in order to prove the sensitivity and specificity of the neutralization assay and to exclude cross-reactivity, a MERS-CoV-reactive serum of known neutralizing capacity was used and was found to robustly inhibit MERS-S-driven entry in a concentration-dependent manner. On the basis of the data obtained with controls, it can be concluded that the pseudotyping system was able to detect MERS-S-neutralizing antibodies with high specificity and sensitivity but failed to detect such antibodies in the patient samples tested.

From the 268 serum samples analysed, the estimated seroprevalence of MERS-CoV distribution in King Fahd Hospital patients using Fisher's exact test was <2.3\% among children (2010-2011) and 3.3\% among adults (2012) (upper limits of the 95\% confidence intervals for $0 / 158$ and $0 / 110$ ). The low seroprevalence in samples derived from children obtained between 2010 and 2011 could be explained by molecular clock analyses, which estimated that the most recent ancestor of MERS-CoV existed in the middle of 2011 [Cotten et al., 2013, Drosten et al., 2013, Cotten et al., 2014]. However, it should be noted that although infections of children with MERS-CoV have been reported [Hui et al., 2014, Memish et al., 2014, http://www.recombinomics.com/News/05161301/MERS_CoV_ Children_KSA.html], the average age of infected patients is $\sim 50$ years (http://www.who.int/csr/disease/ coronavirus_infections/update_20130920/en/). In parallel, the missing detection of neutralizing antibodies in the adult group argues against an asymptomatic spread of MERS-CoV infection in the Eastern Province, although there have been severe case reports from this geographic region [Memish et al., 2013, Omrani et al., 2013]. 
Other studies assessing the seroprevalence of residents of the Middle East obtained findings in accordance with our data: No neutralizing antibodies were detectable in healthy blood donors and individuals which were possibly exposed [Chan et al., 2013, Aburizaiza et al., 2014]. Also, antibodies directed against MERS-S could not be found in samples from pilgrims returning from the Hajj in 2012 and 2013 [Al-Tawfiq and Memish 2012, Gautret et al., 2014].

However, it has to be mentioned that other diagnostic tools besides neutralization assays should be employed to analyse the samples tested in the present study in order to exclude the possibility of false-negative results. These tools could include PCR-based approaches targeting specific fragments within the MERS-CoV genome, as well as immunoassays measuring the presence of MERS-CoV-specific antibodies irrespective of their capacity to neutralize [Corman et al., 2012, Reusken et al., 2013].

Some studies focused on the seroprevalence in dromedary camels, the animal that is believed to be the intermediate host [Albarrak et al., 2012, Drosten et al., 2013, Kupferschmidt 2013] and found a neutralizing antibody response against MERS-CoV or a closely related virus in sera from these animals [Hemida et al., 2013, Perera et al., 2013, Reusken et al., 2013, Woo et al., 2014]. High antibody titers were even detected in samples collected in the years 1992, 2003 and 2005 [Alagaili et al., 2014, Alexandersen et al., 2014, Meyer et al., 2014], indicating that dromedary camels have been frequently infected since decades and that a sporadic transmission from animals to humans might have been going on for years. The first virological confirmation of MERS-CoV infection in dromedaries that was linked to a human case was made by Haagmans and colleagues [Haagmans et al., 2014]. However, the route of transmission and the possibility of a third source of transmission has to be investigated, and transmission experiments in animal models could be useful to shed light onto those questions [Nishiura et al., 2014].

Taken together, the findings of the study and work done by others suggest that MERS-CoV might not have circulated before 2012 in the area from which MERS cases are now constantly reported. 


\section{List of references}

Aburizaiza, A. S., F. M. Mattes, E. I. Azhar, A. M. Hassan, Z. A. Memish, D. Muth, B. Meyer, E. Lattwein, M. A. Muller and C. Drosten (2014). "Investigation of anti-middle East respiratory syndrome antibodies in blood donors and slaughterhouse workers in Jeddah and Makkah, Saudi Arabia, fall 2012." J Infect Dis 209(2): 243-246.

Al-Daghri, N. M., O. S. Al-Attas, M. S. Alokail, K. M. Alkharfy, M. Yousef, S. L. Sabico and G. P. Chrousos (2011). "Diabetes mellitus type 2 and other chronic non-communicable diseases in the central region, Saudi Arabia (Riyadh cohort 2): a decade of an epidemic." BMC Med 9: 76.

Al-Tawfiq, J. A. and Z. A. Memish (2012). "The Hajj: updated health hazards and current recommendations for 2012." Euro Surveill 17(41): 20295.

Al-Tawfiq, J. A., H. Momattin, J. Dib and Z. A. Memish (2014). "Ribavirin and interferon therapy in patients infected with the Middle East respiratory syndrome coronavirus: an observational study." Int J Infect Dis 20: 42-46.

Alagaili, A. N., T. Briese, N. Mishra, V. Kapoor, S. C. Sameroff, P. D. Burbelo, E. de Wit, V. J. Munster, L. E. Hensley, I. S. Zalmout, A. Kapoor, J. H. Epstein, W. B. Karesh, P. Daszak, O. B. Mohammed and W. I. Lipkin (2014). "Middle East respiratory syndrome coronavirus infection in dromedary camels in saudi arabia." MBio 5(2).

Alagaili, A. N., T. Briese, N. Mishra, V. Kapoor, S. C. Sameroff, E. de Wit, V. J. Munster, L. E. Hensley, I. S. Zalmout, A. Kapoor, J. H. Epstein, W. B. Karesh, P. Daszak, O. B. Mohammed and W. I. Lipkin (2014). "Middle East respiratory syndrome coronavirus infection in dromedary camels in saudi arabia." $\underline{\text { MBio }} \mathbf{5}(2)$.

Albarrak, A. M., G. M. Stephens, R. Hewson and Z. A. Memish (2012). "Recovery from severe novel coronavirus infection." Saudi Med J 33(12): 1265-1269.

Alexandersen, S., G. P. Kobinger, G. Soule and U. Wernery (2014). "Middle East respiratory syndrome coronavirus antibody reactors among camels in Dubai, United Arab Emirates, in 2005." Transbound Emerg Dis 61(2): 105-108.

Annan, A., H. J. Baldwin, V. M. Corman, S. M. Klose, M. Owusu, E. E. Nkrumah, E. K. Badu, P. Anti, O. Agbenyega, B. Meyer, S. Oppong, Y. A. Sarkodie, E. K. Kalko, P. H. Lina, E. V. Godlevska, C. Reusken, A. Seebens, F. Gloza-Rausch, P. Vallo, M. Tschapka, C. Drosten and J. F. Drexler (2013). "Human betacoronavirus 2c EMC/2012-related viruses in bats, Ghana and Europe." Emerg Infect Dis 19(3): 456-459. 
Antalis, T. M., T. H. Bugge and Q. Wu (2011). "Membrane-anchored serine proteases in health and disease." Prog Mol Biol Transl Sci 99: 1-50.

Anthony, S. J., R. Ojeda-Flores, O. Rico-Chavez, I. Navarrete-Macias, C. M. ZambranaTorrelio, M. K. Rostal, J. H. Epstein, T. Tipps, E. Liang, M. Sanchez-Leon, J.

Sotomayor-Bonilla, A. A. Aguirre, R. Avila-Flores, R. A. Medellin, T. Goldstein, G.

Suzan, P. Daszak and W. I. Lipkin (2013). "Coronaviruses in bats from Mexico." J Gen Virol 94(Pt 5): 1028-1038.

Assiri, A., J. A. Al-Tawfiq, A. A. Al-Rabeeah, F. A. Al-Rabiah, S. Al-Hajjar, A. AlBarrak, H. Flemban, W. N. Al-Nassir, H. H. Balkhy, R. F. Al-Hakeem, H. Q.

Makhdoom, A. I. Zumla and Z. A. Memish (2013). "Epidemiological, demographic, and clinical characteristics of 47 cases of Middle East respiratory syndrome coronavirus disease from Saudi Arabia: a descriptive study." Lancet Infect Dis 13(9): 752-761.

Assiri, A., A. McGeer, T. M. Perl, C. S. Price, A. A. Al Rabeeah, D. A. Cummings, Z. N. Alabdullatif, M. Assad, A. Almulhim, H. Makhdoom, H. Madani, R. Alhakeem, J. A. AlTawfiq, M. Cotten, S. J. Watson, P. Kellam, A. I. Zumla, Z. A. Memish and K. M.-C. I. Team (2013). "Hospital outbreak of Middle East respiratory syndrome coronavirus." N Engl J Med 369(5): 407-416.

Augustyns, K., G. Bal, G. Thonus, A. Belyaev, X. M. Zhang, W. Bollaert, A. M. Lambeir, C. Durinx, F. Goossens and A. Haemers (1999). "The unique properties of dipeptidyl-peptidase IV (DPP IV / CD26) and the therapeutic potential of DPP IV inhibitors." Curr Med Chem 6(4): 311-327.

Baron, J., C. Tarnow, D. Mayoli-Nussle, E. Schilling, D. Meyer, M. Hammami, F. Schwalm, T. Steinmetzer, Y. Guan, W. Garten, H. D. Klenk and E. BottcherFriebertshauser (2013). "Matriptase, HAT, and TMPRSS2 activate the hemagglutinin of H9N2 influenza A viruses." J Virol 87(3): 1811-1820.

Basak, A., B. B. Toure, C. Lazure, M. Mbikay, M. Chretien and N. G. Seidah (1999). "Enzymic characterization in vitro of recombinant proprotein convertase PC4." Biochem J 343 Pt 1: 29-37.

Beaulieu, A., E. Gravel, A. Cloutier, I. Marois, E. Colombo, A. Desilets, C. Verreault, R. Leduc, E. Marsault and M. V. Richter (2013). "Matriptase proteolytically activates influenza virus and promotes multicycle replication in the human airway epithelium." J Virol 87(8): 4237-4251.

Belouzard, S., V. C. Chu and G. R. Whittaker (2009). "Activation of the SARS coronavirus spike protein via sequential proteolytic cleavage at two distinct sites." Proc Natl Acad Sci U S A 106(14): 5871-5876. 
Belouzard, S., J. K. Millet, B. N. Licitra and G. R. Whittaker (2012). "Mechanisms of coronavirus cell entry mediated by the viral spike protein." Viruses 4(6): 1011-1033.

Bergeron, E., M. J. Vincent, L. Wickham, J. Hamelin, A. Basak, S. T. Nichol, M. Chretien and N. G. Seidah (2005). "Implication of proprotein convertases in the processing and spread of severe acute respiratory syndrome coronavirus." Biochem Biophys Res Commun 326(3): 554-563.

Bermingham, A., M. A. Chand, C. S. Brown, E. Aarons, C. Tong, C. Langrish, K. Hoschler, K. Brown, M. Galiano, R. Myers, R. G. Pebody, H. K. Green, N. L. Boddington, R. Gopal, N. Price, W. Newsholme, C. Drosten, R. A. Fouchier and M. Zambon (2012). "Severe respiratory illness caused by a novel coronavirus, in a patient transferred to the United Kingdom from the Middle East, September 2012." Euro Surveill 17(40): 20290.

Bertram, S., R. Dijkman, M. Habjan, A. Heurich, S. Gierer, I. Glowacka, K. Welsch, M. Winkler, H. Schneider, H. Hofmann-Winkler, V. Thiel and S. Pohlmann (2013). "TMPRSS2 activates the human coronavirus 229E for cathepsin-independent host cell entry and is expressed in viral target cells in the respiratory epithelium." J Virol 87(11): 6150-6160.

Bertram, S., I. Glowacka, P. Blazejewska, E. Soilleux, P. Allen, S. Danisch, I. Steffen, S. Y. Choi, Y. Park, H. Schneider, K. Schughart and S. Pohlmann (2010). "TMPRSS2 and TMPRSS4 facilitate trypsin-independent spread of influenza virus in Caco-2 cells." J Virol 84(19): 10016-10025.

Bertram, S., I. Glowacka, M. A. Muller, H. Lavender, K. Gnirss, I. Nehlmeier, D. Niemeyer, Y. He, G. Simmons, C. Drosten, E. J. Soilleux, O. Jahn, I. Steffen and S. Pohlmann (2011). "Cleavage and activation of the severe acute respiratory syndrome coronavirus spike protein by human airway trypsin-like protease." J Virol 85(24): 1336313372.

Bertram, S., A. Heurich, H. Lavender, S. Gierer, S. Danisch, P. Perin, J. M. Lucas, P. S. Nelson, S. Pohlmann and E. J. Soilleux (2012). "Influenza and SARS-coronavirus activating proteases TMPRSS2 and HAT are expressed at multiple sites in human respiratory and gastrointestinal tracts." PLoS One 7(4): e35876.

Blanchard, E. G., C. Miao, T. E. Haupt, L. J. Anderson and L. M. Haynes (2011). "Development of a recombinant truncated nucleocapsid protein based immunoassay for detection of antibodies against human coronavirus OC43." J Virol Methods 177(1): 100-106.

Boonacker, E. and C. J. Van Noorden (2003). "The multifunctional or moonlighting protein CD26/DPPIV." Eur J Cell Biol 82(2): 53-73. 
Bosch, B. J., W. Bartelink and P. J. Rottier (2008). "Cathepsin L functionally cleaves the severe acute respiratory syndrome coronavirus class I fusion protein upstream of rather than adjacent to the fusion peptide." J Virol 82(17): 8887-8890.

Bosch, B. J., V. S. Raj and B. L. Haagmans (2013). "Spiking the MERS-coronavirus receptor." Cell Res 23(9): 1069-1070.

Bosch, B. J., R. van der Zee, C. A. de Haan and P. J. Rottier (2003). "The coronavirus spike protein is a class I virus fusion protein: structural and functional characterization of the fusion core complex." J Virol 77(16): 8801-8811.

Bosch, F. X., W. Garten, H. D. Klenk and R. Rott (1981). "Proteolytic cleavage of influenza virus hemagglutinins: primary structure of the connecting peptide between HA1 and HA2 determines proteolytic cleavability and pathogenicity of Avian influenza viruses." Virology 113(2): 725-735.

Böttcher, E., T. Matrosovich, M. Beyerle, H. D. Klenk, W. Garten and M. Matrosovich (2006). "Proteolytic activation of influenza viruses by serine proteases TMPRSS2 and HAT from human airway epithelium." J Virol 80(19): 9896-9898.

Boycott, R., H. D. Klenk and M. Ohuchi (1994). "Cell tropism of influenza virus mediated by hemagglutinin activation at the stage of virus entry." Virology 203(2): 313-319.

Breban, R., J. Riou and A. Fontanet (2013). "Interhuman transmissibility of Middle East respiratory syndrome coronavirus: estimation of pandemic risk." Lancet 382(9893): 694-699.

Buchholz, U., M. A. Muller, A. Nitsche, A. Sanewski, N. Wevering, T. Bauer-Balci, F. Bonin, C. Drosten, B. Schweiger, T. Wolff, D. Muth, B. Meyer, S. Buda, G. Krause, L. Schaade and W. Haas (2013). "Contact investigation of a case of human novel coronavirus infection treated in a German hospital, October-November 2012." Euro Surveill 18(8).

Bugge, T. H., T. M. Antalis and Q. Wu (2009). "Type II transmembrane serine proteases." J Biol Chem 284(35): 23177-23181.

Cauchemez, S., M. D. Van Kerkhove, S. Riley, C. A. Donnelly, C. Fraser and N. M. Ferguson (2013). "Transmission scenarios for Middle East Respiratory Syndrome Coronavirus (MERS-CoV) and how to tell them apart." Euro Surveill 18(24).

Cavanagh, D., D. A. Brian, M. A. Brinton, L. Enjuanes, K. V. Holmes, M. C. Horzinek, M. M. Lai, H. Laude, P. G. Plagemann, S. G. Siddell and et al. (1993). "The 
Coronaviridae now comprises two genera, coronavirus and torovirus: report of the Coronaviridae Study Group." Adv Exp Med Biol 342: 255-257.

Cavanagh, D., P. J. Davis, D. J. Pappin, M. M. Binns, M. E. Boursnell and T. D. Brown (1986). "Coronavirus IBV: partial amino terminal sequencing of spike polypeptide S2 identifies the sequence Arg-Arg-Phe-Arg-Arg at the cleavage site of the spike precursor propolypeptide of IBV strains Beaudette and M41." Virus Res 4(2): 133-143.

Chaipan, C., D. Kobasa, S. Bertram, I. Glowacka, I. Steffen, T. S. Tsegaye, M. Takeda, T. H. Bugge, S. Kim, Y. Park, A. Marzi and S. Pohlmann (2009). "Proteolytic activation of the 1918 influenza virus hemagglutinin." J Virol 83(7): 3200-3211.

Chan, J. F., K. H. Chan, G. K. Choi, K. K. To, H. Tse, J. P. Cai, M. L. Yeung, V. C. Cheng, H. Chen, X. Y. Che, S. K. Lau, P. C. Woo and K. Y. Yuen (2013). "Differential cell line susceptibility to the emerging novel human betacoronavirus 2c EMC/2012: implications for disease pathogenesis and clinical manifestation." J Infect Dis 207(11): 17431752.

Chan, K. H., J. F. Chan, H. Tse, H. Chen, C. C. Lau, J. P. Cai, A. K. Tsang, X. Xiao, K. K. To, S. K. Lau, P. C. Woo, B. J. Zheng, M. Wang and K. Y. Yuen (2013). "Crossreactive antibodies in convalescent SARS patients' sera against the emerging novel human coronavirus EMC (2012) by both immunofluorescent and neutralizing antibody tests." J Infect 67(2): 130-140.

Chan, R. W., M. C. Chan, S. Agnihothram, L. L. Chan, D. I. Kuok, J. H. Fong, Y. Guan, L. L. Poon, R. S. Baric, J. M. Nicholls and J. S. Peiris (2013). "Tropism of and innate immune responses to the novel human betacoronavirus lineage $\mathrm{C}$ virus in human ex vivo respiratory organ cultures." J Virol 87(12): 6604-6614.

Chandran, K., N. J. Sullivan, U. Felbor, S. P. Whelan and J. M. Cunningham (2005). "Endosomal proteolysis of the Ebola virus glycoprotein is necessary for infection." Science 308(5728): 1643-1645.

Chen, Y., K. R. Rajashankar, Y. Yang, S. S. Agnihothram, C. Liu, Y. L. Lin, R. S. Baric and F. Li (2013). "Crystal structure of the receptor-binding domain from newly emerged Middle East respiratory syndrome coronavirus." J Virol 87(19): 10777-10783.

Chen, Y. W., M. S. Lee, A. Lucht, F. P. Chou, W. Huang, T. C. Havighurst, K. Kim, J. K. Wang, T. M. Antalis, M. D. Johnson and C. Y. Lin (2010). "TMPRSS2, a serine protease expressed in the prostate on the apical surface of luminal epithelial cells and released into semen in prostasomes, is misregulated in prostate cancer cells." Am J Pathol 176(6): 2986-2996. 
Choi, S. Y., S. Bertram, I. Glowacka, Y. W. Park and S. Pohlmann (2009). "Type II transmembrane serine proteases in cancer and viral infections." Trends Mol Med 15(7): 303312.

Cinatl, J., B. Morgenstern, G. Bauer, P. Chandra, H. Rabenau and H. W. Doerr (2003). "Treatment of SARS with human interferons." Lancet 362(9380): 293-294.

Coleman, C. M., K. L. Matthews, L. Goicochea and M. B. Frieman (2014). "Wild-type and innate immune-deficient mice are not susceptible to the Middle East respiratory syndrome coronavirus." J Gen Virol 95(Pt 2): 408-412.

Corman, V. M., I. Eckerle, T. Bleicker, A. Zaki, O. Landt, M. Eschbach-Bludau, S. van Boheemen, R. Gopal, M. Ballhause, T. M. Bestebroer, D. Muth, M. A. Muller, J. F. Drexler, M. Zambon, A. D. Osterhaus, R. M. Fouchier and C. Drosten (2012). "Detection of a novel human coronavirus by real-time reverse-transcription polymerase chain reaction." Euro Surveill 17(39).

Corman, V. M., M. A. Muller, U. Costabel, J. Timm, T. Binger, B. Meyer, P. Kreher, E. Lattwein, M. Eschbach-Bludau, A. Nitsche, T. Bleicker, O. Landt, B. Schweiger, J. F. Drexler, A. D. Osterhaus, B. L. Haagmans, U. Dittmer, F. Bonin, T. Wolff and C. Drosten (2012). "Assays for laboratory confirmation of novel human coronavirus (hCoVEMC) infections." Euro Surveill 17(49).

Cotten, M., T. T. Lam, S. J. Watson, A. L. Palser, V. Petrova, P. Grant, O. G. Pybus, A. Rambaut, Y. Guan, D. Pillay, P. Kellam and E. Nastouli (2013). "Full-genome deep sequencing and phylogenetic analysis of novel human betacoronavirus." Emerg Infect Dis 19(5): 736-742B.

Cotten, M., S. J. Watson, A. I. Zumla, H. Q. Makhdoom, A. L. Palser, S. H. Ong, A. A. Al Rabeeah, R. F. Alhakeem, A. Assiri, J. A. Al-Tawfiq, A. Albarrak, M. Barry, A. Shibl, F. A. Alrabiah, S. Hajjar, H. H. Balkhy, H. Flemban, A. Rambaut, P. Kellam and Z. A. Memish (2014). "Spread, circulation, and evolution of the middle East respiratory syndrome coronavirus." MBio 5(1).

Danielsson, N., E. I. R. Team and M. Catchpole (2012). "Novel coronavirus associated with severe respiratory disease: case definition and public health measures." Euro Surveill 17(39).

Davies, H. A. and M. R. Macnaughton (1979). "Comparison of the morphology of three coronaviruses." Arch Virol 59(1-2): 25-33. 
de Groot, R. J., S. C. Baker, R. S. Baric, C. S. Brown, C. Drosten, L. Enjuanes, R. A. Fouchier, M. Galiano, A. E. Gorbalenya, Z. A. Memish, S. Perlman, L. L. Poon, E. J. Snijder, G. M. Stephens, P. C. Woo, A. M. Zaki, M. Zambon and J. Ziebuhr (2013). "Middle East respiratory syndrome coronavirus (MERS-CoV): announcement of the Coronavirus Study Group." J Virol 87(14): 7790-7792.

de Groot, R. J., W. Luytjes, M. C. Horzinek, B. A. van der Zeijst, W. J. Spaan and J. A. Lenstra (1987). "Evidence for a coiled-coil structure in the spike proteins of coronaviruses." $\underline{\mathbf{J}}$ Mol Biol 196(4): 963-966.

de Haan, C. A., K. Stadler, G. J. Godeke, B. J. Bosch and P. J. Rottier (2004). "Cleavage inhibition of the murine coronavirus spike protein by a furin-like enzyme affects cell-cell but not virus-cell fusion." J Virol 78(11): 6048-6054.

de Wilde, A. H., V. S. Raj, D. Oudshoorn, T. M. Bestebroer, S. van Nieuwkoop, R. W. Limpens, C. C. Posthuma, Y. van der Meer, M. Barcena, B. L. Haagmans, E. J. Snijder and B. G. van den Hoogen (2013). "MERS-coronavirus replication induces severe in vitro cytopathology and is strongly inhibited by cyclosporin A or interferon-alpha treatment." $\mathbf{J}$ Gen Virol 94(Pt 8): 1749-1760.

de Wit, E., J. Prescott, L. Baseler, T. Bushmaker, T. Thomas, M. G. Lackemeyer, C. Martellaro, S. Milne-Price, E. Haddock, B. L. Haagmans, H. Feldmann and V. J. Munster (2013). "The Middle East respiratory syndrome coronavirus (MERS-CoV) does not replicate in Syrian hamsters." PLoS One 8(7): e69127.

de Wit, E., A. L. Rasmussen, D. Falzarano, T. Bushmaker, F. Feldmann, D. L. Brining, E. R. Fischer, C. Martellaro, A. Okumura, J. Chang, D. Scott, A. G. Benecke, M. G. Katze, H. Feldmann and V. J. Munster (2013). "Middle East respiratory syndrome coronavirus (MERS-CoV) causes transient lower respiratory tract infection in rhesus macaques." Proc Natl Acad Sci U S A 110(41): 16598-16603.

Donaldson, S. H., A. Hirsh, D. C. Li, G. Holloway, J. Chao, R. C. Boucher and S. E. Gabriel (2002). "Regulation of the epithelial sodium channel by serine proteases in human airways." J Biol Chem 277(10): 8338-8345.

Drosten, C., S. Gunther, W. Preiser, S. van der Werf, H. R. Brodt, S. Becker, H. Rabenau, M. Panning, L. Kolesnikova, R. A. Fouchier, A. Berger, A. M. Burguiere, J. Cinatl, M. Eickmann, N. Escriou, K. Grywna, S. Kramme, J. C. Manuguerra, S. Muller, V. Rickerts, M. Sturmer, S. Vieth, H. D. Klenk, A. D. Osterhaus, H. Schmitz and H. W. Doerr (2003). "Identification of a novel coronavirus in patients with severe acute respiratory syndrome." N Engl J Med 348(20): 1967-1976. 
Drosten, C., M. Seilmaier, V. M. Corman, W. Hartmann, G. Scheible, S. Sack, W. Guggemos, R. Kallies, D. Muth, S. Junglen, M. A. Muller, W. Haas, H. Guberina, T. Rohnisch, M. Schmid-Wendtner, S. Aldabbagh, U. Dittmer, H. Gold, P. Graf, F. Bonin, A. Rambaut and C. M. Wendtner (2013). "Clinical features and virological analysis of a case of Middle East respiratory syndrome coronavirus infection." Lancet Infect Dis 13(9): 745-751.

Du, L., Z. Kou, C. Ma, X. Tao, L. Wang, G. Zhao, Y. Chen, F. Yu, C. T. Tseng, Y. Zhou and S. Jiang (2013). "A truncated receptor-binding domain of MERS-CoV spike protein potently inhibits MERS-CoV infection and induces strong neutralizing antibody responses: implication for developing therapeutics and vaccines." PLoS One 8(12): e81587.

Du, L., G. Zhao, Z. Kou, C. Ma, S. Sun, V. K. Poon, L. Lu, L. Wang, A. K. Debnath, B. J. Zheng, Y. Zhou and S. Jiang (2013). "Identification of a receptor-binding domain in the S protein of the novel human coronavirus Middle East respiratory syndrome coronavirus as an essential target for vaccine development." J Virol 87(17): 9939-9942.

Ebert, D. H., J. Deussing, C. Peters and T. S. Dermody (2002). "Cathepsin L and cathepsin B mediate reovirus disassembly in murine fibroblast cells." J Biol Chem 277(27): 2460924617.

Falzarano, D., E. de Wit, C. Martellaro, J. Callison, V. J. Munster and H. Feldmann (2013). "Inhibition of novel beta coronavirus replication by a combination of interferonalpha2b and ribavirin." Sci Rep 3: 1686.

Falzarano, D., E. de Wit, A. L. Rasmussen, F. Feldmann, A. Okumura, D. P. Scott, D. Brining, T. Bushmaker, C. Martellaro, L. Baseler, A. G. Benecke, M. G. Katze, V. J. Munster and H. Feldmann (2013). "Treatment with interferon-alpha2b and ribavirin improves outcome in MERS-CoV-infected rhesus macaques." Nat Med 19(10): 1313-1317.

Follis, K. E., J. York and J. H. Nunberg (2006). "Furin cleavage of the SARS coronavirus spike glycoprotein enhances cell-cell fusion but does not affect virion entry." Virology 350(2): 358-369.

Frana, M. F., J. N. Behnke, L. S. Sturman and K. V. Holmes (1985). "Proteolytic cleavage of the E2 glycoprotein of murine coronavirus: host-dependent differences in proteolytic cleavage and cell fusion." J Virol 56(3): 912-920.

Gallagher, T. M. and M. J. Buchmeier (2001). "Coronavirus spike proteins in viral entry and pathogenesis." Virology 279(2): 371-374. 
Gautret, P., R. Charrel, S. Benkouiten, K. Belhouchat, A. Nougairede, T. Drali, N. Salez, Z. A. Memish, M. Al Masri, J. C. Lagier, M. Million, D. Raoult, P. Brouqui and P. Parola (2014). "Lack of MERS Coronavirus but Prevalence of Influenza Virus in French Pilgrims after 2013 Hajj." Emerg Infect Dis 20(3): 726-728.

Ge, X. Y., J. L. Li, X. L. Yang, A. A. Chmura, G. Zhu, J. H. Epstein, J. K. Mazet, B. Hu, W. Zhang, C. Peng, Y. J. Zhang, C. M. Luo, B. Tan, N. Wang, Y. Zhu, G. Crameri, S. Y. Zhang, L. F. Wang, P. Daszak and Z. L. Shi (2013). "Isolation and characterization of a bat SARS-like coronavirus that uses the ACE2 receptor." Nature 503(7477): 535-538.

Gierer, S., S. Bertram, F. Kaup, F. Wrensch, A. Heurich, A. Kramer-Kuhl, K. Welsch, M. Winkler, B. Meyer, C. Drosten, U. Dittmer, T. von Hahn, G. Simmons, H. Hofmann and S. Pohlmann (2013). "The spike protein of the emerging betacoronavirus EMC uses a novel coronavirus receptor for entry, can be activated by TMPRSS2, and is targeted by neutralizing antibodies." J Virol 87(10): 5502-5511.

Glowacka, I., S. Bertram, M. A. Muller, P. Allen, E. Soilleux, S. Pfefferle, I. Steffen, T. S. Tsegaye, Y. He, K. Gnirss, D. Niemeyer, H. Schneider, C. Drosten and S. Pohlmann (2011). "Evidence that TMPRSS2 activates the severe acute respiratory syndrome coronavirus spike protein for membrane fusion and reduces viral control by the humoral immune response." J Virol 85(9): 4122-4134.

Graham, R. L., E. F. Donaldson and R. S. Baric (2013). "A decade after SARS: strategies for controlling emerging coronaviruses." Nat Rev Microbiol 11(12): 836-848.

Guan, Y., B. J. Zheng, Y. Q. He, X. L. Liu, Z. X. Zhuang, C. L. Cheung, S. W. Luo, P. H. Li, L. J. Zhang, Y. J. Guan, K. M. Butt, K. L. Wong, K. W. Chan, W. Lim, K. F. Shortridge, K. Y. Yuen, J. S. Peiris and L. L. Poon (2003). "Isolation and characterization of viruses related to the SARS coronavirus from animals in southern China." Science 302(5643): 276-278.

Guberina, H., O. Witzke, J. Timm, U. Dittmer, M. A. Muller, C. Drosten and F. Bonin (2014). "A patient with severe respiratory failure caused by novel human coronavirus." Infection 42(1): 203-206.

Guery, B., J. Poissy, L. el Mansouf, C. Sejourne, N. Ettahar, X. Lemaire, F. Vuotto, A. Goffard, S. Behillil, V. Enouf, V. Caro, A. Mailles, D. Che, J. C. Manuguerra, D. Mathieu, A. Fontanet, S. van der Werf and M. E.-C. s. group (2013). "Clinical features and viral diagnosis of two cases of infection with Middle East Respiratory Syndrome coronavirus: a report of nosocomial transmission." Lancet 381(9885): 2265-2272.

Gulland, A. (2013). "Novel coronavirus spreads to Tunisia." BMJ 346: f3372. 
Gulland, A. (2013). "Two cases of novel coronavirus are confirmed in France." BMJ 346: f3114.

Guy, J. S., J. J. Breslin, B. Breuhaus, S. Vivrette and L. G. Smith (2000).

"Characterization of a coronavirus isolated from a diarrheic foal." J Clin Microbiol 38(12): 4523-4526.

Haagmans, B. L., S. H. Al Dhahiry, C. B. Reusken, V. S. Raj, M. Galiano, R. Myers, G. J. Godeke, M. Jonges, E. Farag, A. Diab, H. Ghobashy, F. Alhajri, M. Al-Thani, S. A. Al-Marri, H. E. Al Romaihi, A. Al Khal, A. Bermingham, A. D. Osterhaus, M. M. AlHajri and M. P. Koopmans (2014). "Middle East respiratory syndrome coronavirus in dromedary camels: an outbreak investigation." Lancet Infect Dis 14(2): 140-145.

Hallenberger, S., V. Bosch, H. Angliker, E. Shaw, H. D. Klenk and W. Garten (1992). "Inhibition of furin-mediated cleavage activation of HIV-1 glycoprotein gp160." Nature 360(6402): 358-361.

Hamers-Casterman, C., T. Atarhouch, S. Muyldermans, G. Robinson, C. Hamers, E. B. Songa, N. Bendahman and R. Hamers (1993). "Naturally occurring antibodies devoid of light chains." Nature 363(6428): 446-448.

Hamilton, B. S., D. W. Gludish and G. R. Whittaker (2012). "Cleavage activation of the human-adapted influenza virus subtypes by matriptase reveals both subtype and strain specificities." J Virol 86(19): 10579-10586.

Harrison, S. C. (2005). "Mechanism of membrane fusion by viral envelope proteins." $\underline{\text { Adv }}$ Virus Res 64: 231-261.

Hatesuer, B., S. Bertram, N. Mehnert, M. M. Bahgat, P. S. Nelson, S. Pohlman and K. Schughart (2013). "Tmprss2 is essential for influenza H1N1 virus pathogenesis in mice." PLoS Pathog 9(12): e1003774.

He, Y., J. Li, W. Li, S. Lustigman, M. Farzan and S. Jiang (2006). "Cross-neutralization of human and palm civet severe acute respiratory syndrome coronaviruses by antibodies targeting the receptor-binding domain of spike protein." J Immunol 176(10): 6085-6092.

Heald-Sargent, T. and T. Gallagher (2012). "Ready, set, fuse! The coronavirus spike protein and acquisition of fusion competence." Viruses 4(4): 557-580.

Hemida, M. G., R. A. Perera, P. Wang, M. A. Alhammadi, L. Y. Siu, M. Li, L. L. Poon, L. Saif, A. Alnaeem and M. Peiris (2013). "Middle East Respiratory Syndrome (MERS) 
coronavirus seroprevalence in domestic livestock in Saudi Arabia, 2010 to 2013." Euro Surveill 18(50): 20659.

Hendley, J. O., H. B. Fishburne and J. M. Gwaltney, Jr. (1972). "Coronavirus infections in working adults. Eight-year study with 229 E and OC 43." Am Rev Respir Dis 105(5): 805811.

Herrewegh, A. A., M. Mahler, H. J. Hedrich, B. L. Haagmans, H. F. Egberink, M. C. Horzinek, P. J. Rottier and R. J. de Groot (1997). "Persistence and evolution of feline coronavirus in a closed cat-breeding colony." Virology 234(2): 349-363.

Heurich, A., H. Hofmann-Winkler, S. Gierer, T. Liepold, O. Jahn and S. Pohlmann (2014). "TMPRSS2 and ADAM17 cleave ACE2 differentially and only proteolysis by TMPRSS2 augments entry driven by the severe acute respiratory syndrome coronavirus spike protein." J Virol 88(2): 1293-1307.

Hijawi, B., M. Abdallat, A. Sayaydeh, S. Alqasrawi, A. Haddadin, N. Jaarour, S. Alsheikh and T. Alsanouri (2013). "Novel coronavirus infections in Jordan, April 2012: epidemiological findings from a retrospective investigation." East Mediterr Health J 19 Suppl 1: S12-18.

Hofmann, H., K. Hattermann, A. Marzi, T. Gramberg, M. Geier, M. Krumbiegel, S. Kuate, K. Uberla, M. Niedrig and S. Pohlmann (2004). "S protein of severe acute respiratory syndrome-associated coronavirus mediates entry into hepatoma cell lines and is targeted by neutralizing antibodies in infected patients." J Virol 78(12): 6134-6142.

Hofmann, H., X. Li, X. Zhang, W. Liu, A. Kuhl, F. Kaup, S. S. Soldan, F. GonzalezScarano, F. Weber, Y. He and S. Pohlmann (2013). "Severe fever with thrombocytopenia virus glycoproteins are targeted by neutralizing antibodies and can use DC-SIGN as a receptor for pH-dependent entry into human and animal cell lines." J Virol 87(8): 4384-4394.

Hofmann, H. and S. Pohlmann (2004). "Cellular entry of the SARS coronavirus." Trends Microbiol 12(10): 466-472.

Hofmann, H., K. Pyrc, L. van der Hoek, M. Geier, B. Berkhout and S. Pohlmann (2005). "Human coronavirus NL63 employs the severe acute respiratory syndrome coronavirus receptor for cellular entry." Proc Natl Acad Sci U S A 102(22): 7988-7993.

Hofmann, H., G. Simmons, A. J. Rennekamp, C. Chaipan, T. Gramberg, E. Heck, M. Geier, A. Wegele, A. Marzi, P. Bates and S. Pohlmann (2006). "Highly conserved regions within the spike proteins of human coronaviruses 229E and NL63 determine recognition of their respective cellular receptors." J Virol 80(17): 8639-8652. 
Holmes, K. V. (2003). "SARS coronavirus: a new challenge for prevention and therapy." $\underline{J}$ Clin Invest 111(11): 1605-1609.

Hooper, J. D., J. A. Clements, J. P. Quigley and T. M. Antalis (2001). "Type II transmembrane serine proteases. Insights into an emerging class of cell surface proteolytic enzymes." J Biol Chem 276(2): 857-860.

Huang, I. C., B. J. Bosch, F. Li, W. Li, K. H. Lee, S. Ghiran, N. Vasilieva, T. S. Dermody, S. C. Harrison, P. R. Dormitzer, M. Farzan, P. J. Rottier and H. Choe (2006). "SARS coronavirus, but not human coronavirus NL63, utilizes cathepsin L to infect ACE2expressing cells." J Biol Chem 281(6): 3198-3203.

Hudson, C. B. and F. R. Beaudette (1932). "Infection of the Cloaca with the Virus of Infectious Bronchitis." Science 76(1958): 34.

Hui, D. S., Z. A. Memish and A. Zumla (2014). "Severe acute respiratory syndrome vs. the Middle East respiratory syndrome." Curr Opin Pulm Med 20(3): 233-241.

Ishidoh, K. and E. Kominami (1995). "Procathepsin L degrades extracellular matrix proteins in the presence of glycosaminoglycans in vitro." Biochem Biophys Res Commun 217(2): 624-631.

Jacquinet, E., N. V. Rao, G. V. Rao and J. R. Hoidal (2000). "Cloning, genomic organization, chromosomal assignment and expression of a novel mosaic serine proteinase: epitheliasin." FEBS Lett 468(1): 93-100.

Jiang, S., L. Lu, L. Du and A. K. Debnath (2013). "A predicted receptor-binding and critical neutralizing domain in $\mathrm{S}$ protein of the novel human coronavirus HCoV-EMC." $\mathrm{J}$ Infect 66(5): 464-466.

Kam, Y. W., Y. Okumura, H. Kido, L. F. Ng, R. Bruzzone and R. Altmeyer (2009). "Cleavage of the SARS coronavirus spike glycoprotein by airway proteases enhances virus entry into human bronchial epithelial cells in vitro." PLoS One 4(11): e7870.

Kane, S. E. and M. M. Gottesman (1990). "The role of cathepsin L in malignant transformation." Semin Cancer Biol 1(2): 127-136.

Kawase, M., K. Shirato, S. Matsuyama and F. Taguchi (2009). "Protease-mediated entry via the endosome of human coronavirus 229E." J Virol 83(2): 712-721. 
Kawase, M., K. Shirato, L. van der Hoek, F. Taguchi and S. Matsuyama (2012).

"Simultaneous treatment of human bronchial epithelial cells with serine and cysteine protease inhibitors prevents severe acute respiratory syndrome coronavirus entry." J Virol 86(12):

$6537-6545$

Kim, T. S., C. Heinlein, R. C. Hackman and P. S. Nelson (2006). "Phenotypic analysis of mice lacking the Tmprss2-encoded protease." Mol Cell Biol 26(3): 965-975.

Kindler, E., H. R. Jonsdottir, D. Muth, O. J. Hamming, R. Hartmann, R. Rodriguez, R. Geffers, R. A. Fouchier, C. Drosten, M. A. Muller, R. Dijkman and V. Thiel (2013). "Efficient replication of the novel human betacoronavirus EMC on primary human epithelium highlights its zoonotic potential." MBio 4(1): e00611-00612.

Kirschke, H., J. Langner, S. Riemann, B. Wiederanders, S. Ansorge and P. Bohley (1979). "Lysosomal cysteine proteinases." Ciba Found Symp(75): 15-35.

Klenk, H. D. and W. Garten (1994). "Host cell proteases controlling virus pathogenicity." Trends Microbiol 2(2): 39-43.

Kominami, E., T. Tsukahara, K. Hara and N. Katunuma (1988). "Biosyntheses and processing of lysosomal cysteine proteinases in rat macrophages." FEBS Lett 231(1): 225228.

Ksiazek, T. G., D. Erdman, C. S. Goldsmith, S. R. Zaki, T. Peret, S. Emery, S. Tong, C. Urbani, J. A. Comer, W. Lim, P. E. Rollin, S. F. Dowell, A. E. Ling, C. D. Humphrey, W. J. Shieh, J. Guarner, C. D. Paddock, P. Rota, B. Fields, J. DeRisi, J. Y. Yang, N. Cox, J. M. Hughes, J. W. LeDuc, W. J. Bellini, L. J. Anderson and S. W. Group (2003). "A novel coronavirus associated with severe acute respiratory syndrome." N Engl J Med 348(20): 1953-1966.

Kuo, L., G. J. Godeke, M. J. Raamsman, P. S. Masters and P. J. Rottier (2000). "Retargeting of coronavirus by substitution of the spike glycoprotein ectodomain: crossing the host cell species barrier." J Virol 74(3): 1393-1406.

Kupferschmidt, K. (2013). "Emerging diseases. Researchers scramble to understand camel connection to MERS." Science 341(6147): 702.

Lambeir, A. M., C. Durinx, S. Scharpe and I. De Meester (2003). "Dipeptidyl-peptidase IV from bench to bedside: an update on structural properties, functions, and clinical aspects of the enzyme DPP IV." Crit Rev Clin Lab Sci 40(3): 209-294. 
Lau, S. K., K. S. Li, A. K. Tsang, C. S. Lam, S. Ahmed, H. Chen, K. H. Chan, P. C. Woo and K. Y. Yuen (2013). "Genetic characterization of Betacoronavirus lineage $C$ viruses in bats reveals marked sequence divergence in the spike protein of pipistrellus bat coronavirus HKU5 in Japanese pipistrelle: implications for the origin of the novel Middle East respiratory syndrome coronavirus." J Virol 87(15): 8638-8650.

Lau, S. K., P. C. Woo, K. S. Li, Y. Huang, H. W. Tsoi, B. H. Wong, S. S. Wong, S. Y. Leung, K. H. Chan and K. Y. Yuen (2005). "Severe acute respiratory syndrome coronavirus-like virus in Chinese horseshoe bats." Proc Natl Acad Sci U S A 102(39): 1404014045.

Lau, S. K., P. C. Woo, C. C. Yip, H. Tse, H. W. Tsoi, V. C. Cheng, P. Lee, B. S. Tang, C. H. Cheung, R. A. Lee, L. Y. So, Y. L. Lau, K. H. Chan and K. Y. Yuen (2006).

"Coronavirus HKU1 and other coronavirus infections in Hong Kong." J Clin Microbiol 44(6): 2063-2071.

Lazarowitz, S. G. and P. W. Choppin (1975). "Enhancement of the infectivity of influenza A and B viruses by proteolytic cleavage of the hemagglutinin polypeptide." Virology 68(2): $440-454$.

Lee, N., D. Hui, A. Wu, P. Chan, P. Cameron, G. M. Joynt, A. Ahuja, M. Y. Yung, C. B. Leung, K. F. To, S. F. Lui, C. C. Szeto, S. Chung and J. J. Sung (2003). "A major outbreak of severe acute respiratory syndrome in Hong Kong." N Engl J Med 348(20): 1986-1994.

Li, W., M. J. Moore, N. Vasilieva, J. Sui, S. K. Wong, M. A. Berne, M. Somasundaran, J. L. Sullivan, K. Luzuriaga, T. C. Greenough, H. Choe and M. Farzan (2003).

"Angiotensin-converting enzyme 2 is a functional receptor for the SARS coronavirus." Nature 426(6965): 450-454.

Li, W., Z. Shi, M. Yu, W. Ren, C. Smith, J. H. Epstein, H. Wang, G. Crameri, Z. Hu, H. Zhang, J. Zhang, J. McEachern, H. Field, P. Daszak, B. T. Eaton, S. Zhang and L. F. Wang (2005). "Bats are natural reservoirs of SARS-like coronaviruses." Science 310(5748): 676-679.

Liang, G., Q. Chen, J. Xu, Y. Liu, W. Lim, J. S. Peiris, L. J. Anderson, L. Ruan, H. Li, B. Kan, B. Di, P. Cheng, K. H. Chan, D. D. Erdman, S. Gu, X. Yan, W. Liang, D. Zhou, L. Haynes, S. Duan, X. Zhang, H. Zheng, Y. Gao, S. Tong, D. Li, L. Fang, P. Qin, W. Xu and S. D. W. Group (2004). "Laboratory diagnosis of four recent sporadic cases of community-acquired SARS, Guangdong Province, China." Emerg Infect Dis 10(10): 17741781 . 
Lin, B., C. Ferguson, J. T. White, S. Wang, R. Vessella, L. D. True, L. Hood and P. S. Nelson (1999). "Prostate-localized and androgen-regulated expression of the membranebound serine protease TMPRSS2." Cancer Res 59(17): 4180-4184.

Loon, S. C., S. C. Teoh, L. L. Oon, S. Y. Se-Thoe, A. E. Ling, Y. S. Leo and H. N. Leong (2004). "The severe acute respiratory syndrome coronavirus in tears." Br J Ophthalmol 88(7): 861-863.

Lu, G., Y. Hu, Q. Wang, J. Qi, F. Gao, Y. Li, Y. Zhang, W. Zhang, Y. Yuan, J. Bao, B. Zhang, Y. Shi, J. Yan and G. F. Gao (2013). "Molecular basis of binding between novel human coronavirus MERS-CoV and its receptor CD26." Nature 500(7461): 227-231.

Lucas, J. M., L. True, S. Hawley, M. Matsumura, C. Morrissey, R. Vessella and P. S. Nelson (2008). "The androgen-regulated type II serine protease TMPRSS2 is differentially expressed and mislocalized in prostate adenocarcinoma." J Pathol 215(2): 118-125.

Mailles, A., K. Blanckaert, P. Chaud, S. van der Werf, B. Lina, V. Caro, C. Campese, B. Guery, H. Prouvost, X. Lemaire, M. C. Paty, S. Haeghebaert, D. Antoine, N. Ettahar, H. Noel, S. Behillil, S. Hendricx, J. C. Manuguerra, V. Enouf, G. La Ruche, C. Semaille, B. Coignard, D. Levy-Bruhl, F. Weber, C. Saura, D. Che and t. investigation (2013). "First cases of Middle East Respiratory Syndrome Coronavirus (MERS-CoV) infections in France, investigations and implications for the prevention of human-to-human transmission, France, May 2013." Euro Surveill 18(24).

Marra, M. A., S. J. Jones, C. R. Astell, R. A. Holt, A. Brooks-Wilson, Y. S. Butterfield, J. Khattra, J. K. Asano, S. A. Barber, S. Y. Chan, A. Cloutier, S. M. Coughlin, D. Freeman, N. Girn, O. L. Griffith, S. R. Leach, M. Mayo, H. McDonald, S. B. Montgomery, P. K. Pandoh, A. S. Petrescu, A. G. Robertson, J. E. Schein, A. Siddiqui, D. E. Smailus, J. M. Stott, G. S. Yang, F. Plummer, A. Andonov, H. Artsob, N. Bastien, K. Bernard, T. F. Booth, D. Bowness, M. Czub, M. Drebot, L. Fernando, R. Flick, M. Garbutt, M. Gray, A. Grolla, S. Jones, H. Feldmann, A. Meyers, A. Kabani, Y. Li, S. Normand, U. Stroher, G. A. Tipples, S. Tyler, R. Vogrig, D. Ward, B. Watson, R. C. Brunham, M. Krajden, M. Petric, D. M. Skowronski, C. Upton and R. L. Roper (2003). "The Genome sequence of the SARS-associated coronavirus." Science 300(5624): 1399-1404.

Matsuyama, S., N. Nagata, K. Shirato, M. Kawase, M. Takeda and F. Taguchi (2010). "Efficient activation of the severe acute respiratory syndrome coronavirus spike protein by the transmembrane protease TMPRSS2." J Virol 84(24): 12658-12664.

Matsuyama, S., M. Ujike, S. Morikawa, M. Tashiro and F. Taguchi (2005). "Proteasemediated enhancement of severe acute respiratory syndrome coronavirus infection." Proc Natl Acad Sci U S A 102(35): 12543-12547. 
McClure, M. O., M. Marsh and R. A. Weiss (1988). "Human immunodeficiency virus infection of CD4-bearing cells occurs by a pH-independent mechanism." EMBO J 7(2): 513 518.

McIntosh, K., R. K. Chao, H. E. Krause, R. Wasil, H. E. Mocega and M. A. Mufson (1974). "Coronavirus infection in acute lower respiratory tract disease of infants." J Infect Dis 130(5): 502-507.

Memish, Z. A., J. A. Al-Tawfiq, H. Q. Makhdoom, A. A. Al-Rabeeah, A. Assiri, R. F. Alhakeem, F. A. Alrabiah, S. Al Hajjar, A. Albarrak, H. Flemban, H. Balkhy, M. Barry, S. Alhassan, S. Alsubaie and A. Zumla (2014). "Screening for Middle East respiratory syndrome coronavirus infection in hospital patients and their healthcare worker and family contacts: a prospective descriptive study." Clin Microbiol Infect.

Memish, Z. A., N. Mishra, K. J. Olival, S. F. Fagbo, V. Kapoor, J. H. Epstein, R. Alhakeem, A. Durosinloun, M. Al Asmari, A. Islam, A. Kapoor, T. Briese, P. Daszak, A. A. Al Rabeeah and W. I. Lipkin (2013). "Middle East respiratory syndrome coronavirus in bats, Saudi Arabia." Emerg Infect Dis 19(11): 1819-1823.

Memish, Z. A., A. I. Zumla, R. F. Al-Hakeem, A. A. Al-Rabeeah and G. M. Stephens (2013). "Family cluster of Middle East respiratory syndrome coronavirus infections." N Engl J Med 368(26): 2487-2494.

Memish, Z. A., A. I. Zumla and A. Assiri (2013). "Middle East respiratory syndrome coronavirus infections in health care workers." N Engl J Med 369(9): 884-886.

Meyer, B., M. A. Muller, V. M. Corman, C. B. Reusken, D. Ritz, G. J. Godeke, E. Lattwein, S. Kallies, A. Siemens, J. van Beek, J. F. Drexler, D. Muth, B. J. Bosch, U. Wernery, M. P. Koopmans, R. Wernery and C. Drosten (2014). "Antibodies against MERS Coronavirus in Dromedary Camels, United Arab Emirates, 2003 and 2013." Emerg Infect Dis 20(4): 552-559.

Milne-Price, S., K. L. Miazgowicz and V. J. Munster (2014). "The emergence of the Middle East Respiratory Syndrome coronavirus." Pathog Dis.

Moore, M. J., T. Dorfman, W. Li, S. K. Wong, Y. Li, J. H. Kuhn, J. Coderre, N. Vasilieva, Z. Han, T. C. Greenough, M. Farzan and H. Choe (2004). "Retroviruses pseudotyped with the severe acute respiratory syndrome coronavirus spike protein efficiently infect cells expressing angiotensin-converting enzyme 2." J Virol 78(19): 10628-10635.

Mou, H., V. S. Raj, F. J. van Kuppeveld, P. J. Rottier, B. L. Haagmans and B. J. Bosch (2013). "The receptor binding domain of the new Middle East respiratory syndrome 
coronavirus maps to a 231-residue region in the spike protein that efficiently elicits neutralizing antibodies." J Virol 87(16): 9379-9383.

Müller, M. A., V. S. Raj, D. Muth, B. Meyer, S. Kallies, S. L. Smits, R. Wollny, T. M. Bestebroer, S. Specht, T. Suliman, K. Zimmermann, T. Binger, I. Eckerle, M. Tschapka, A. M. Zaki, A. D. Osterhaus, R. A. Fouchier, B. L. Haagmans and C. Drosten (2012). "Human coronavirus EMC does not require the SARS-coronavirus receptor and maintains

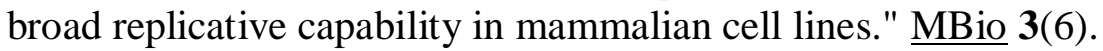

Munster, V. J., E. de Wit and H. Feldmann (2013). "Pneumonia from human coronavirus in a macaque model." N Engl J Med 368(16): 1560-1562.

Neumann, G., H. Feldmann, S. Watanabe, I. Lukashevich and Y. Kawaoka (2002).

"Reverse genetics demonstrates that proteolytic processing of the Ebola virus glycoprotein is not essential for replication in cell culture." J Virol 76(1): 406-410.

Neumann, G., T. W. Geisbert, H. Ebihara, J. B. Geisbert, K. M. Daddario-DiCaprio, H. Feldmann and Y. Kawaoka (2007). "Proteolytic processing of the Ebola virus glycoprotein is not critical for Ebola virus replication in nonhuman primates." J Virol 81(6): 2995-2998.

Nishiura, H., K. Ejima and K. Mizumoto (2014). "Missing information in animal surveillance of MERS-CoV." Lancet Infect Dis 14(2): 100.

Okumura, Y., E. Takahashi, M. Yano, M. Ohuchi, T. Daidoji, T. Nakaya, E. Bottcher, W. Garten, H. D. Klenk and H. Kido (2010). "Novel type II transmembrane serine proteases, MSPL and TMPRSS13, Proteolytically activate membrane fusion activity of the hemagglutinin of highly pathogenic avian influenza viruses and induce their multicycle replication." J Virol 84(10): 5089-5096.

Omrani, A. S., M. A. Matin, Q. Haddad, D. Al-Nakhli, Z. A. Memish and A. M. Albarrak (2013). "A family cluster of Middle East Respiratory Syndrome Coronavirus infections related to a likely unrecognized asymptomatic or mild case." Int J Infect Dis 17(9): e668-672.

Paoloni-Giacobino, A., H. Chen, M. C. Peitsch, C. Rossier and S. E. Antonarakis (1997). "Cloning of the TMPRSS2 gene, which encodes a novel serine protease with transmembrane, LDLRA, and SRCR domains and maps to 21q22.3." Genomics 44(3): 309-320.

Pasquato, A., J. Ramos da Palma, C. Galan, N. G. Seidah and S. Kunz (2013). "Viral envelope glycoprotein processing by proprotein convertases." Antiviral Res 99(1): 49-60. 
Peiris, J. S., S. T. Lai, L. L. Poon, Y. Guan, L. Y. Yam, W. Lim, J. Nicholls, W. K. Yee, W. W. Yan, M. T. Cheung, V. C. Cheng, K. H. Chan, D. N. Tsang, R. W. Yung, T. K. Ng, K. Y. Yuen and S. S. group (2003). "Coronavirus as a possible cause of severe acute respiratory syndrome." Lancet 361(9366): 1319-1325.

Pene, F., A. Merlat, A. Vabret, F. Rozenberg, A. Buzyn, F. Dreyfus, A. Cariou, F. Freymuth and P. Lebon (2003). "Coronavirus 229E-related pneumonia in immunocompromised patients." Clin Infect Dis 37(7): 929-932.

Peng, G. W., J. F. He, J. Y. Lin, D. H. Zhou, D. W. Yu, W. J. Liang, L. H. Li, R. N. Guo, H. M. Luo and R. H. Xu (2003). "[Epidemiological study on severe acute respiratory syndrome in Guangdong province]." Zhonghua Liu Xing Bing Xue Za Zhi 24(5): 350-352.

Penttinen, P. M., K. Kaasik-Aaslav, A. Friaux, A. Donachie, B. Sudre, A. J. AmatoGauci, Z. A. Memish and D. Coulombier (2013). "Taking stock of the first 133 MERS coronavirus cases globally--Is the epidemic changing?" Euro Surveill 18(39).

Perera, R. A., P. Wang, M. R. Gomaa, R. El-Shesheny, A. Kandeil, O. Bagato, L. Y. Siu, M. M. Shehata, A. S. Kayed, Y. Moatasim, M. Li, L. L. Poon, Y. Guan, R. J. Webby, M. A. Ali, J. S. Peiris and G. Kayali (2013). "Seroepidemiology for MERS coronavirus using microneutralisation and pseudoparticle virus neutralisation assays reveal a high prevalence of antibody in dromedary camels in Egypt, June 2013." Euro Surveill 18(36): pii=20574.

Perlman, S. and J. Netland (2009). "Coronaviruses post-SARS: update on replication and pathogenesis." Nat Rev Microbiol 7(6): 439-450.

Poon, L. L., D. K. Chu, K. H. Chan, O. K. Wong, T. M. Ellis, Y. H. Leung, S. K. Lau, P. C. Woo, K. Y. Suen, K. Y. Yuen, Y. Guan and J. S. Peiris (2005). "Identification of a novel coronavirus in bats." J Virol 79(4): 2001-2009.

Poon, L. L., O. K. Wong, K. H. Chan, W. Luk, K. Y. Yuen, J. S. Peiris and Y. Guan (2003). "Rapid diagnosis of a coronavirus associated with severe acute respiratory syndrome (SARS)." Clin Chem 49(6 Pt 1): 953-955.

Poutanen, S. M., D. E. Low, B. Henry, S. Finkelstein, D. Rose, K. Green, R. Tellier, R. Draker, D. Adachi, M. Ayers, A. K. Chan, D. M. Skowronski, I. Salit, A. E. Simor, A. S. Slutsky, P. W. Doyle, M. Krajden, M. Petric, R. C. Brunham, A. J. McGeer, C. National Microbiology Laboratory and T. Canadian Severe Acute Respiratory Syndrome Study (2003). "Identification of severe acute respiratory syndrome in Canada." N Engl J Med 348(20): 1995-2005. 
Puzelli, S., A. Azzi, M. G. Santini, A. Di Martino, M. Facchini, M. R. Castrucci, M. Meola, R. Arvia, F. Corcioli, F. Pierucci, S. Baretti, A. Bartoloni, D. Bartolozzi, M. de Martino, L. Galli, M. G. Pompa, G. Rezza, E. Balocchini and I. Donatelli (2013). "Investigation of an imported case of Middle East Respiratory Syndrome Coronavirus (MERS-CoV) infection in Florence, Italy, May to June 2013." Euro Surveill 18(34).

Qian, Z., S. R. Dominguez and K. V. Holmes (2013). "Role of the spike glycoprotein of human Middle East respiratory syndrome coronavirus (MERS-CoV) in virus entry and syncytia formation." PLoS One 8(10): e76469.

Qiu, Z., S. T. Hingley, G. Simmons, C. Yu, J. Das Sarma, P. Bates and S. R. Weiss (2006). "Endosomal proteolysis by cathepsins is necessary for murine coronavirus mouse hepatitis virus type 2 spike-mediated entry." J Virol 80(12): 5768-5776.

Rabenau, H. F., J. Cinatl, B. Morgenstern, G. Bauer, W. Preiser and H. W. Doerr (2005). "Stability and inactivation of SARS coronavirus." Med Microbiol Immunol 194(1-2): $1-6$.

Raj, V. S., H. Mou, S. L. Smits, D. H. Dekkers, M. A. Muller, R. Dijkman, D. Muth, J. A. Demmers, A. Zaki, R. A. Fouchier, V. Thiel, C. Drosten, P. J. Rottier, A. D. Osterhaus, B. J. Bosch and B. L. Haagmans (2013). "Dipeptidyl peptidase 4 is a functional receptor for the emerging human coronavirus-EMC." Nature 495(7440): 251-254.

Raj, V. S., S. L. Smits, L. B. Provacia, J. M. van den Brand, L. Wiersma, W. J. Ouwendijk, T. M. Bestebroer, M. I. Spronken, G. van Amerongen, P. J. Rottier, R. A. Fouchier, B. J. Bosch, A. D. Osterhaus and B. L. Haagmans (2014). "Adenosine deaminase acts as a natural antagonist for dipeptidyl peptidase 4-mediated entry of the Middle East respiratory syndrome coronavirus." J Virol 88(3): 1834-1838.

Reusken, C., H. Mou, G. J. Godeke, L. van der Hoek, B. Meyer, M. A. Muller, B. Haagmans, R. de Sousa, N. Schuurman, U. Dittmer, P. Rottier, A. Osterhaus, C. Drosten, B. J. Bosch and M. Koopmans (2013). "Specific serology for emerging human coronaviruses by protein microarray." Euro Surveill 18(14): 20441.

Reusken, C. B., M. Ababneh, V. S. Raj, B. Meyer, A. Eljarah, S. Abutarbush, G. J. Godeke, T. M. Bestebroer, I. Zutt, M. A. Muller, B. J. Bosch, P. J. Rottier, A. D. Osterhaus, C. Drosten, B. L. Haagmans and M. P. Koopmans (2013). "Middle East Respiratory Syndrome coronavirus (MERS-CoV) serology in major livestock species in an affected region in Jordan, June to September 2013." Euro Surveill 18(50): 20662.

Reusken, C. B., B. L. Haagmans, M. A. Muller, C. Gutierrez, G. J. Godeke, B. Meyer, D. Muth, V. S. Raj, L. Smits-De Vries, V. M. Corman, J. F. Drexler, S. L. Smits, Y. E. El Tahir, R. De Sousa, J. van Beek, N. Nowotny, K. van Maanen, E. Hidalgo-Hermoso, B. 
J. Bosch, P. Rottier, A. Osterhaus, C. Gortazar-Schmidt, C. Drosten and M. P. Koopmans (2013). "Middle East respiratory syndrome coronavirus neutralising serum antibodies in dromedary camels: a comparative serological study." Lancet Infect Dis 13(10): 859-866.

Reuss, A., A. Litterst, C. Drosten, M. Seilmaier, M. Bohmer, P. Graf, H. Gold, C. M. Wendtner, A. Zanuzdana, L. Schaade, W. Haas and U. Buchholz (2014). "Contact investigation for imported case of middle East respiratory syndrome, Germany." Emerg Infect Dis 20(4): 620-625.

Rota, P. A., M. S. Oberste, S. S. Monroe, W. A. Nix, R. Campagnoli, J. P. Icenogle, S. Penaranda, B. Bankamp, K. Maher, M. H. Chen, S. Tong, A. Tamin, L. Lowe, M. Frace, J. L. DeRisi, Q. Chen, D. Wang, D. D. Erdman, T. C. Peret, C. Burns, T. G. Ksiazek, P. E. Rollin, A. Sanchez, S. Liffick, B. Holloway, J. Limor, K. McCaustland, M. OlsenRasmussen, R. Fouchier, S. Gunther, A. D. Osterhaus, C. Drosten, M. A. Pallansch, L. J. Anderson and W. J. Bellini (2003). "Characterization of a novel coronavirus associated with severe acute respiratory syndrome." Science 300(5624): 1394-1399.

Rousselet, E., S. Benjannet, J. Hamelin, M. Canuel and N. G. Seidah (2011). "The proprotein convertase PC7: unique zymogen activation and trafficking pathways." J Biol Chem 286(4): 2728-2738.

Sainz, B., Jr., J. M. Rausch, W. R. Gallaher, R. F. Garry and W. C. Wimley (2005). "Identification and characterization of the putative fusion peptide of the severe acute respiratory syndrome-associated coronavirus spike protein." J Virol 79(11): 7195-7206.

Seidah, N. G. and A. Prat (2012). "The biology and therapeutic targeting of the proprotein convertases." Nat Rev Drug Discov 11(5): 367-383.

Shirato, K., M. Kawase and S. Matsuyama (2013). "Middle East respiratory syndrome coronavirus infection mediated by the transmembrane serine protease TMPRSS2." J Virol 87(23): 12552-12561.

Shirogane, Y., M. Takeda, M. Iwasaki, N. Ishiguro, H. Takeuchi, Y. Nakatsu, M. Tahara, H. Kikuta and Y. Yanagi (2008). "Efficient multiplication of human metapneumovirus in Vero cells expressing the transmembrane serine protease TMPRSS2." $\underline{\mathbf{J}}$ Virol 82(17): 8942-8946.

Shulla, A., T. Heald-Sargent, G. Subramanya, J. Zhao, S. Perlman and T. Gallagher (2011). "A transmembrane serine protease is linked to the severe acute respiratory syndrome coronavirus receptor and activates virus entry." J Virol 85(2): 873-882. 
Siddell, S., H. Wege and V. Ter Meulen (1983). "The biology of coronaviruses." J Gen Virol 64 (Pt 4): 761-776.

Simmons, G., S. Bertram, I. Glowacka, I. Steffen, C. Chaipan, J. Agudelo, K. Lu, A. J. Rennekamp, H. Hofmann, P. Bates and S. Pohlmann (2011). "Different host cell proteases activate the SARS-coronavirus spike-protein for cell-cell and virus-cell fusion." Virology 413(2): 265-274.

Simmons, G., D. N. Gosalia, A. J. Rennekamp, J. D. Reeves, S. L. Diamond and P. Bates (2005). "Inhibitors of cathepsin L prevent severe acute respiratory syndrome coronavirus entry." Proc Natl Acad Sci U S A 102(33): 11876-11881.

Simmons, G., J. D. Reeves, A. J. Rennekamp, S. M. Amberg, A. J. Piefer and P. Bates (2004). "Characterization of severe acute respiratory syndrome-associated coronavirus (SARS-CoV) spike glycoprotein-mediated viral entry." Proc Natl Acad Sci U S A 101(12): 4240-4245.

Simmons, G., P. Zmora, S. Gierer, A. Heurich and S. Pohlmann (2013). "Proteolytic activation of the SARS-coronavirus spike protein: cutting enzymes at the cutting edge of antiviral research." Antiviral Res 100(3): 605-614.

Song, F., R. Fux, L. B. Provacia, A. Volz, M. Eickmann, S. Becker, A. D. Osterhaus, B. L. Haagmans and G. Sutter (2013). "Middle East respiratory syndrome coronavirus spike protein delivered by modified vaccinia virus Ankara efficiently induces virus-neutralizing antibodies." J Virol 87(21): 11950-11954.

Spaan, W., D. Cavanagh and M. C. Horzinek (1988). "Coronaviruses: structure and genome expression." J Gen Virol 69 ( Pt 12): 2939-2952.

Stadler, K., V. Masignani, M. Eickmann, S. Becker, S. Abrignani, H. D. Klenk and R. Rappuoli (2003). "SARS--beginning to understand a new virus." Nat Rev Microbiol 1(3): 209-218.

Stieneke-Grober, A., M. Vey, H. Angliker, E. Shaw, G. Thomas, C. Roberts, H. D. Klenk and W. Garten (1992). "Influenza virus hemagglutinin with multibasic cleavage site is activated by furin, a subtilisin-like endoprotease." EMBO J 11(7): 2407-2414.

Stoka, V., B. Turk and V. Turk (2005). "Lysosomal cysteine proteases: structural features and their role in apoptosis." IUBMB Life 57(4-5): 347-353. 
Superti, F., L. Seganti, F. M. Ruggeri, A. Tinari, G. Donelli and N. Orsi (1987). "Entry pathway of vesicular stomatitis virus into different host cells." J Gen Virol 68 ( Pt 2): 387399.

Szabo, R. and T. H. Bugge (2008). "Type II transmembrane serine proteases in development and disease." Int J Biochem Cell Biol 40(6-7): 1297-1316.

Taguchi, F. and S. Matsuyama (2009). "[Cell entry mechanisms of coronaviruses]." Uirusu 59(2): 215-222.

The Who Mers-Cov Research, G. (2013). "State of Knowledge and Data Gaps of Middle East Respiratory Syndrome Coronavirus (MERS-CoV) in Humans." PLoS Curr 5.

Thomas, G. (2002). "Furin at the cutting edge: from protein traffic to embryogenesis and disease." Nat Rev Mol Cell Biol 3(10): 753-766.

Toure, B. B., J. S. Munzer, A. Basak, S. Benjannet, J. Rochemont, C. Lazure, M. Chretien and N. G. Seidah (2000). "Biosynthesis and enzymatic characterization of human SKI-1/S1P and the processing of its inhibitory prosegment." J Biol Chem 275(4): 2349-2358.

Tu, C., G. Crameri, X. Kong, J. Chen, Y. Sun, M. Yu, H. Xiang, X. Xia, S. Liu, T. Ren, Y. Yu, B. T. Eaton, H. Xuan and L. F. Wang (2004). "Antibodies to SARS coronavirus in civets." Emerg Infect Dis 10(12): 2244-2248.

Turk, B., D. Turk and V. Turk (2000). "Lysosomal cysteine proteases: more than scavengers." Biochim Biophys Acta 1477(1-2): 98-111.

Turk, V., B. Turk and D. Turk (2001). "Lysosomal cysteine proteases: facts and opportunities." EMBO J 20(17): 4629-4633.

Tyrrell, D. A., J. D. Almeida, C. H. Cunningham, W. R. Dowdle, M. S. Hofstad, K. McIntosh, M. Tajima, L. Y. Zakstelskaya, B. C. Easterday, A. Kapikian and R. W. Bingham (1975). "Coronaviridae." Intervirology 5(1-2): 76-82.

Tyrrell, D. A. and M. L. Bynoe (1965). "Cultivation of a Novel Type of Common-Cold Virus in Organ Cultures." Br Med J 1(5448): 1467-1470.

van Boheemen, S., M. de Graaf, C. Lauber, T. M. Bestebroer, V. S. Raj, A. M. Zaki, A. D. Osterhaus, B. L. Haagmans, A. E. Gorbalenya, E. J. Snijder and R. A. Fouchier 
(2012). "Genomic characterization of a newly discovered coronavirus associated with acute respiratory distress syndrome in humans." MBio 3(6).

van der Hoek, L., K. Pyrc, M. F. Jebbink, W. Vermeulen-Oost, R. J. Berkhout, K. C. Wolthers, P. M. Wertheim-van Dillen, J. Kaandorp, J. Spaargaren and B. Berkhout (2004). "Identification of a new human coronavirus." Nat Med 10(4): 368-373.

van der Hoek, L., K. Sure, G. Ihorst, A. Stang, K. Pyrc, M. F. Jebbink, G. Petersen, J. Forster, B. Berkhout and K. Uberla (2005). "Croup is associated with the novel coronavirus NL63." PLoS Med 2(8): e240.

Varia, M., S. Wilson, S. Sarwal, A. McGeer, E. Gournis, E. Galanis, B. Henry and T. Hospital Outbreak Investigation (2003). "Investigation of a nosocomial outbreak of severe acute respiratory syndrome (SARS) in Toronto, Canada." CMAJ 169(4): 285-292.

Vey, M., M. Orlich, S. Adler, H. D. Klenk, R. Rott and W. Garten (1992). "Hemagglutinin activation of pathogenic avian influenza viruses of serotype $\mathrm{H} 7$ requires the protease recognition motif R-X-K/R-R." Virology 188(1): 408-413.

Vijgen, L., E. Moes, E. Keyaerts, S. Li and M. Van Ranst (2008). "A pancoronavirus RTPCR assay for detection of all known coronaviruses." Methods Mol Biol 454: 3-12.

Vlasak, R., W. Luytjes, W. Spaan and P. Palese (1988). "Human and bovine coronaviruses recognize sialic acid-containing receptors similar to those of influenza $\mathrm{C}$ viruses." Proc Natl Acad Sci U S A 85(12): 4526-4529.

Volchkov, V. E., H. Feldmann, V. A. Volchkova and H. D. Klenk (1998). "Processing of the Ebola virus glycoprotein by the proprotein convertase furin." Proc Natl Acad Sci U S A 95(10): 5762-5767.

Wang, N., X. Shi, L. Jiang, S. Zhang, D. Wang, P. Tong, D. Guo, L. Fu, Y. Cui, X. Liu, K. C. Arledge, Y. H. Chen, L. Zhang and X. Wang (2013). "Structure of MERS-CoV spike receptor-binding domain complexed with human receptor DPP4." Cell Res 23(8): 986-993.

Watanabe, R., S. Matsuyama, K. Shirato, M. Maejima, S. Fukushi, S. Morikawa and F. Taguchi (2008). "Entry from the cell surface of severe acute respiratory syndrome coronavirus with cleaved $S$ protein as revealed by pseudotype virus bearing cleaved $S$ protein." J Virol 82(23): 11985-11991.

Weissenhorn, W., A. Hinz and Y. Gaudin (2007). "Virus membrane fusion." FEBS Lett 581(11): 2150-2155. 
White, J., K. Matlin and A. Helenius (1981). "Cell fusion by Semliki Forest, influenza, and vesicular stomatitis viruses." J Cell Biol 89(3): 674-679.

White, J. M., S. E. Delos, M. Brecher and K. Schornberg (2008). "Structures and mechanisms of viral membrane fusion proteins: multiple variations on a common theme." $\underline{\text { Crit }}$ Rev Biochem Mol Biol 43(3): 189-219.

Wise, R. J., P. J. Barr, P. A. Wong, M. C. Kiefer, A. J. Brake and R. J. Kaufman (1990). "Expression of a human proprotein processing enzyme: correct cleavage of the von Willebrand factor precursor at a paired basic amino acid site." Proc Natl Acad Sci U S A 87(23): 9378-9382.

Woo, P. C., S. K. Lau, C. M. Chu, K. H. Chan, H. W. Tsoi, Y. Huang, B. H. Wong, R. W. Poon, J. J. Cai, W. K. Luk, L. L. Poon, S. S. Wong, Y. Guan, J. S. Peiris and K. Y. Yuen (2005). "Characterization and complete genome sequence of a novel coronavirus, coronavirus HKU1, from patients with pneumonia." J Virol 79(2): 884-895.

Woo, P. C., S. K. Lau, C. S. Lam, C. C. Lau, A. K. Tsang, J. H. Lau, R. Bai, J. L. Teng, C. C. Tsang, M. Wang, B. J. Zheng, K. H. Chan and K. Y. Yuen (2012). "Discovery of seven novel Mammalian and avian coronaviruses in the genus deltacoronavirus supports bat coronaviruses as the gene source of alphacoronavirus and betacoronavirus and avian coronaviruses as the gene source of gammacoronavirus and deltacoronavirus." J Virol 86(7): 3995-4008.

Woo, P. C., S. K. Lau, U. Wernery, E. Y. Wong, A. K. Tsang, B. Johnson, C. C. Yip, C. C. Lau, S. Sivakumar, J. P. Cai, R. Y. Fan, K. H. Chan, R. Mareena and K. Y. Yuen (2014). "Novel betacoronavirus in dromedaries of the middle East, 2013." Emerg Infect Dis 20(4): 560-572.

Wu, X. D., B. Shang, R. F. Yang, H. Yu, Z. H. Ma, X. Shen, Y. Y. Ji, Y. Lin, Y. D. Wu, G. M. Lin, L. Tian, X. Q. Gan, S. Yang, W. H. Jiang, E. H. Dai, X. Y. Wang, H. L. Jiang, Y. H. Xie, X. L. Zhu, G. Pei, L. Li, J. R. Wu and B. Sun (2004). "The spike protein of severe acute respiratory syndrome (SARS) is cleaved in virus infected Vero-E6 cells." Cell Res 14(5): 400-406.

Wünschmann, A., R. Frank, K. Pomeroy and S. Kapil (2002). "Enteric coronavirus infection in a juvenile dromedary (Camelus dromedarius)." J Vet Diagn Invest 14(5): 441444.

Xu, R. H., J. F. He, M. R. Evans, G. W. Peng, H. E. Field, D. W. Yu, C. K. Lee, H. M. Luo, W. S. Lin, P. Lin, L. H. Li, W. J. Liang, J. Y. Lin and A. Schnur (2004).

"Epidemiologic clues to SARS origin in China." Emerg Infect Dis 10(6): 1030-1037. 
Xu, Y., Z. Lou, Y. Liu, H. Pang, P. Tien, G. F. Gao and Z. Rao (2004). "Crystal structure of severe acute respiratory syndrome coronavirus spike protein fusion core." J Biol Chem 279(47): 49414-49419.

Yamada, Y. and D. X. Liu (2009). "Proteolytic activation of the spike protein at a novel RRRR/S motif is implicated in furin-dependent entry, syncytium formation, and infectivity of coronavirus infectious bronchitis virus in cultured cells." J Virol 83(17): 8744-8758.

Yang, Z. Y., Y. Huang, L. Ganesh, K. Leung, W. P. Kong, O. Schwartz, K. Subbarao and G. J. Nabel (2004). "pH-dependent entry of severe acute respiratory syndrome coronavirus is mediated by the spike glycoprotein and enhanced by dendritic cell transfer through DC-SIGN." J Virol 78(11): 5642-5650.

Yao, Y., L. Bao, W. Deng, L. Xu, F. Li, Q. Lv, P. Yu, T. Chen, Y. Xu, H. Zhu, J. Yuan, S. Gu, Q. Wei, H. Chen, K. Y. Yuen and C. Qin (2014). "An animal model of MERS produced by infection of rhesus macaques with MERS coronavirus." J Infect Dis 209(2): 236242.

Yeager, C. L., R. A. Ashmun, R. K. Williams, C. B. Cardellichio, L. H. Shapiro, A. T. Look and K. V. Holmes (1992). "Human aminopeptidase N is a receptor for human coronavirus 229E." Nature 357(6377): 420-422.

Zaki, A. M., S. van Boheemen, T. M. Bestebroer, A. D. Osterhaus and R. A. Fouchier (2012). "Isolation of a novel coronavirus from a man with pneumonia in Saudi Arabia." $\underline{N}$ Engl J Med 367(19): 1814-1820.

Zhao, G., L. Du, C. Ma, Y. Li, L. Li, V. K. Poon, L. Wang, F. Yu, B. J. Zheng, S. Jiang and Y. Zhou (2013). "A safe and convenient pseudovirus-based inhibition assay to detect neutralizing antibodies and screen for viral entry inhibitors against the novel human coronavirus MERS-CoV." Virol J 10: 266.

Zhao, J., K. Li, C. Wohlford-Lenane, S. S. Agnihothram, C. Fett, J. Zhao, M. J. Gale, Jr., R. S. Baric, L. Enjuanes, T. Gallagher, P. B. McCray, Jr. and S. Perlman (2014). "Rapid generation of a mouse model for Middle East respiratory syndrome." Proc Natl Acad $\underline{\text { Sci U S A. }}$

Zhong, N. S., B. J. Zheng, Y. M. Li, Poon, Z. H. Xie, K. H. Chan, P. H. Li, S. Y. Tan, Q. Chang, J. P. Xie, X. Q. Liu, J. Xu, D. X. Li, K. Y. Yuen, Peiris and Y. Guan (2003). "Epidemiology and cause of severe acute respiratory syndrome (SARS) in Guangdong, People's Republic of China, in February, 2003." Lancet 362(9393): 1353-1358. 
Zhou, N., Y. Zhang, J. C. Zhang, L. Feng and J. K. Bao (2014). "The receptor binding domain of MERS-CoV: The dawn of vaccine and treatment development." J Formos Med Assoc 113(3): 143-147.

Zhou, Y. and G. Simmons (2012). "Development of novel entry inhibitors targeting emerging viruses." Expert Rev Anti Infect Ther 10(10): 1129-1138.

Zielecki, F., M. Weber, M. Eickmann, L. Spiegelberg, A. M. Zaki, M. Matrosovich, S. Becker and F. Weber (2013). "Human cell tropism and innate immune system interactions of human respiratory coronavirus EMC compared to those of severe acute respiratory syndrome coronavirus." J Virol 87(9): 5300-5304. 


\section{Appendix}

\section{List of abbreviations}

$\%$

A

ACE2

APN

ARDS

Bat-CoV

CDC

$\mathrm{CoV}$

CPE

CTSL

DPP4

E

EIA

ELISA

ER

ERGIC

et al.

FP

GC

GP

HA

HAT
Percentage

Alanin

Angiotensin-converting enzyme 2

Aminopeptidase $\mathrm{N}$

Acute respiratory distress syndrome

Bat coronavirus

Centers for Disease Control and Prevention

Coronavirus

Cytopathic effect

Cathepsin L

Dipeptidyl peptidase 4

Envelope

Enzymatic immunoassays

Enzyme-linked-immunosorbent assay

Endoplasmic reticulum

Endoplasmatic reticulum-Golgi apparatus intermediate

compartment

lat.: et alteri

Fusion peptide

Guanine-cytosine

Glycoprotein

Hemagglutinin

Human airway trypsin-like protease 
HB

HCoV-EMC

HIV

HPAI

HR

IFA

IFN

$\mathrm{IgG}$

K

$\mathrm{Kb}$

LDLRA

LPAI

M

MERS-CoV

MHV

MLV

mRNA

MSPL

$\mathrm{N}$

$\mathrm{NH}_{4} \mathrm{Cl}$

nsps

$\mathrm{nm}$

ORF

PC

PCR

$\mathrm{pH}$
Helix bundle

Human coronavirus Erasmus Medical Center

Human immunodeficiency virus

High pathogenic avian influenza

Heptad repeats

Immunofluorescent antibody

Interferon

Immunoglobulin $\mathrm{G}$

Lysin

Kilo bases

Low-density lipoprotein receptor domain class A

Low pathogenic avian influenza

Membrane

Middle East Respiratory Syndrome-Coronavirus

Mouse hepatitis coronavirus

Murine leukemia virus

Messenger ribonucleic acid

Mosaic serine protease large form

Nucleocapsid

Ammonium chloride

Nonstructural proteins

Nanomolar

Open reading frame

Proprotein convertase

Polymerase-chain-reaction

Potentia Hygrogenii 
pp

$\mathrm{R}$

RBD

RBM

$\mathrm{RdRp}$

RFS

RNA

RT-PCR

S

SARS-CoV

SRCR

TM

TRS

TTSP

upE

UTR

VSG-G

WHO
Polyproteins

Arginine

Receptor binding domain

Receptor binding motif

RNA-dependant RNA polymerase

Ribosomal frameshift site

Ribonucleic acid

Reverse-transcriptase-polymerase-chain-reaction

Spike

Severe Acute Respiratory Syndrome-Coronavirus

Scavenger receptor cysteine- rich domain

Transmembrane domain

Transcription- regulatory sequences

Type II transmembrane serine protease

Upstream of the envelope gene

Untranslated region

Vesicular stomatitis virus glycoprotein

World Health Organization 


\section{Acknowledgements}

First of all I want to express my gratitude to Prof. Dr. Stefan Pöhlmann for giving me this excellent opportunity to work on this fascinating project. I am thankfull for his valuable and constructive suggestions during the planning and development of this research work.

I would also like to thank Dr. Heike Hofmann-Winkler for her supervision, patience, helpfulness and the power of endurance to read my thesis over and over.

I would like to thank Prof. Dr. med. Martin Oppermann to consent to be my referee and for his helpful advises during my thesis.

Many thanks go to all the members of the laboratory for creating a warm atmosphere and beeing supportive in good times and in bad times, which we all have. I am thankfull for all the funny moments in the lab, at conferences and in the free time. This goes especially to Adeline Heurich, the "other half of the one person", because she always understood the matter and that helped a lot!

I want to thank all my friends, particularly Franzi Greifzu, for helping me a lot to deal with the million thesis questions that came along and Norman for bringing the sunshine in my life.

Last but not least my special thanks goes to my family. I am gratefull for their constant support and confidence in all the decisions I made in my life to unfold my own personality, and to make my education possible. 


\section{Curriculum Vitae}

\section{Personal data}

Name:

Birth date:

Place of birth:

Nationality

Academical education

Since 05/2011

11/2009-10/2010

03/2009-04/2009

10/2003-10/2010

04/2003-09/2003
Stefanie Gierer

March $18^{\text {th }}, 1984$

Suhl, Germany

German
$\mathrm{PhD}$ thesis, German Primate Center (DPZ), Infection Biology Unit, Prof. Dr. Stefan Pöhlmann: "The proteolytic processing of the MERS-coronavirus spike protein and its impact for viral entry"

Diploma thesis, Friedrich-Schiller-University of Jena, Institute of Microbiology and Microbial Phytopathology, Prof Dr. Erika Kothe: "Identification of heavy metal resistant genes in Streptomyces mirabilis P16B-1"

Internship, Universitätsklinikum Jena, Institute for Virology and Antiviral Therapy, Prof. Dr. Andreas Henke

Friedrich-Schiller University of Jena, degree: biology diploma Major subject: microbiology, minor subjects: immunology, medical microbiology,

Graduation: diploma (final grade: excellent)

Technical University of Dresden, degree: sociology diploma 
$10 / 11-12 / 2012$

03/14-17/2012

03/06-09/2013

09/19-20/2013
National Symposium on Zoonoses Research 2012 (Berlin, Germany)

Poster "Identification of amino acids in the SARScoronavirus spike protein important for activation by type II transmembrane serine proteases"

22nd anuual Meeting of the Society for Virology (Essen, Germany)

Poster "TMPRSS2 and HAT activate the spike protein of human coronavirus $229 \mathrm{E}$ for cathepsin- independent host cell entry"

23rd Annual Meeting of the Society for Virology (Kiel, Germany)

Poster "The spike-protein of the emerging betacoronavirus EMC uses a novel coronavirus receptor for entry, can be activated by TMPRSS2 and is targeted by neutralizing antibodies"

National Symposium on Zoonoses Research 2013 (Berlin, Germany)

Oral presentation "Analysis of the proteolytic activation of the MERS-coronavirus spike-protein" 


\section{List of Publications}

\section{First author}

Gierer, S., S. Bertram, F. Kaup, F. Wrensch, A. Heurich, A. Kramer-Kuhl, K. Welsch, M. Winkler, B. Meyer, C. Drosten, U. Dittmer, T. von Hahn, G. Simmons, H. Hofmann and S. Pohlmann (2013). "The spike protein of the emerging betacoronavirus EMC uses a novel coronavirus receptor for entry, can be activated by TMPRSS2, and is targeted by neutralizing antibodies." J Virol 87(10): 5502-5511.

Gierer, S., H. Hofmann-Winkler, W. H. Albuali, S. Bertram, A. M. Al-Rubaish, A. A. Yousef, A. N. Al-Nafaie, A. K. Al-Ali, O. E. Obeid, K. R. Alkharsah and S. Pohlmann (2013). "Lack of MERS coronavirus neutralizing antibodies in humans, eastern province, Saudi Arabia." Emerg Infect Dis 19(12): 2034-2036.

Gierer,S., M. A. Müller, A. Heurich, D. Ritz, B. Springstein, C. B. Karsten, A. Schendzielorz, K. Gnirß, C. Drosten, and Stefan Pöhlmann (2014). "Inhibition of proprotein convertases abrogates processing of the MERS-coronavirus spike protein in infected cells but does not reduce viral infectivity" J Infect Dis. 2014 Jul 23. pii: jiu407. [Epub ahead of print]

\section{Co-author}

Bertram, S., A. Heurich, H. Lavender, S. Gierer, S. Danisch, P. Perin, J. M. Lucas, P. S. Nelson, S. Pohlmann and E. J. Soilleux (2012). "Influenza and SARS-coronavirus activating proteases TMPRSS2 and HAT are expressed at multiple sites in human respiratory and gastrointestinal tracts." PLoS One 7(4): e35876.

Bertram, S., R. Dijkman, M. Habjan, A. Heurich, S. Gierer, I. Glowacka, K. Welsch, M. Winkler, H. Schneider, H. Hofmann-Winkler, V. Thiel and S. Pohlmann (2013). "TMPRSS2 activates the human coronavirus $229 \mathrm{E}$ for cathepsin-independent host cell entry and is expressed in viral target cells in the respiratory epithelium." J Virol 87(11): 6150-6160.

Heurich, A., H. Hofmann-Winkler, S. Gierer, T. Liepold, O. Jahn and S. Pohlmann (2014). "TMPRSS2 and ADAM17 cleave ACE2 differentially and only proteolysis by TMPRSS2 augments entry driven by the severe acute respiratory syndrome coronavirus spike protein." J Virol 88(2): 1293-1307. 


\section{Reviews}

Simmons, G., P. Zmora, S. Gierer, A. Heurich and S. Pohlmann (2013). "Proteolytic activation of the SARS-coronavirus spike protein: cutting enzymes at the cutting edge of antiviral research." Antiviral Res 100(3): 605-614. 